University of Nebraska - Lincoln

DigitalCommons@University of Nebraska - Lincoln

2008

Impact of Electron-Electron Spin Interaction on Electron Spin Relaxation of Nitroxide Diradicals and Tetraradical in Glassy Solvents Between 10 and $300 \mathrm{~K}$

Hideo Sato

University of Denver

Velavan Kathirvelu

University of Denver

Gaëlle Spagnol

University of Nebraska-Lincoln

Suchada Rajca

University of Nebraska-Lincoln, srajca1@unl.edu

Andrzej Rajca

University of Nebraska - Lincoln, arajca1@unl.edu

See next page for additional authors

Follow this and additional works at: http://digitalcommons.unl.edu/chemistryrajca

Sato, Hideo; Kathirvelu, Velavan; Spagnol, Gaëlle; Rajca, Suchada; Rajca, Andrzej; Eaton, Sandra S.; and Eaton, Gareth R., "Impact of Electron-Electron Spin Interaction on Electron Spin Relaxation of Nitroxide Diradicals and Tetraradical in Glassy Solvents Between 10 and 300 K" (2008). Andrzej Rajca Publications. 11.

http://digitalcommons.unl.edu/chemistryrajca/11 
Authors

Hideo Sato, Velavan Kathirvelu, Gaëlle Spagnol, Suchada Rajca, Andrzej Rajca, Sandra S. Eaton, and Gareth R. Eaton 


\title{
Author Manuscript
}

Published in final edited form as:

J Phys Chem B. 2008 March 13; 112(10): 2818-2828. doi:10.1021/jp073600u.

\section{Impact of Electron-Electron Spin Interaction on Electron Spin Relaxation of Nitroxide Diradicals and Tetraradical in Glassy Solvents Between 10 and $300 \mathrm{~K}$}

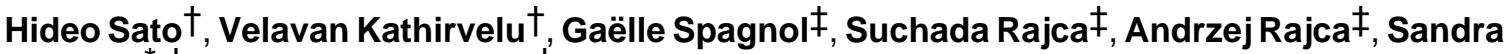 \\ S. Eaton ${ }^{\star}, \dagger$, and Gareth R. Eaton ${ }^{\dagger}$ \\ †Department of Chemistry and Biochemistry, 2101 East Wesley Avenue, University of Denver, \\ Denver, Colorado 80208-2436
}

*Department of Chemistry, University of Nebraska, Lincoln, Nebraska 68588-0304

\begin{abstract}
To determine the impact of electron-electron spin-spin interactions on electron spin relaxation rates, $1 / T_{1}$ and $1 / T_{\mathrm{m}}$ were measured for nitroxide monoradical, diradical, and tetraradical derivatives of 1,3-alternate calix[4]arenes, for two pegylated high-spin nitroxide diradicals, and for an azine-linked nitroxide diradical. The synthesis and characterization by SQUID (superconducting quantum interference device) magnetometry of one of the high-spin diradicals, in which nitroxides are conformationally constrained to be coplanar with the $m$-phenylene unit, is reported. The interspin distances ranged from about 5-9 $\AA$, and the magnitude of the exchange interaction ranged from $>150$ to $>0.1 \mathrm{~K} .1 / T_{1}$ and $1 / T_{\mathrm{m}}$ were measured by long-pulse saturation recovery, three-pulse inversion recovery, and two-pulse echo decay at X-band $(9.5 \mathrm{GHz})$ and Q-band $(35 \mathrm{GHz})$. For a diradical with interspin distance about $9 \AA$, relaxation rates were only slightly faster than for a monoradical with analogous structure. For interspin distances of about 5-6 $\AA$, relaxation rates in glassy solvents up to $300 \mathrm{~K}$ increased in the order monoradical < diradical < tetraradical. Modulation of electron-electron interaction enhanced relaxation via the direct, Raman, and local mode processes. The largest differences in $1 / T_{1}$ were observed below $10 \mathrm{~K}$, where the direct process dominates. For the three diradicals with comparable magnitude of dipolar interaction, $1 / T_{\mathrm{m}}$ and $1 / T_{1}$ were faster for the molecules with more flexible structures. Relaxation rates were faster in the less rigid low-polarity sucrose octaacetate glass than in the more rigid 4:1 toluene/chloroform or in hydrogen-bonded glycerol glasses, which highlights the impact of motion on relaxation.
\end{abstract}

\section{Introduction}

Nitroxide radicals have been widely used as probes of molecular dynamics, including motion of spin labels on polymers and biomolecules, probes in membranes, and details of molecule tumbling in liquids. The anisotropy of the nitroxide $g$ values and hyperfine couplings make EPR spectra of nitroxide radicals at various microwave frequencies sensitive reporters of molecular motion. The impact of motion on electron spin relaxation rates $1 / T_{2}$ and phase memory dephasing rate $1 / T_{\mathrm{m}}$ has been thoroughly analyzed, especially by the Freed lab. ${ }^{1,2}$ Motion partially averages anisotropy in glasses or solids, resulting in changes in $1 / T_{\mathrm{m}} \cdot{ }^{3,4}$ Electron spin relaxation rates are important for many applications of free radicals. For example, site-directed mutagenesis, spin labeling, and EPR double-resonance methods combine to use

\footnotetext{
(C) 2008 American Chemical Society

*Corresponding author. Phone: 303-871-3102. Fax: 303-871-2254. E-mail: seaton@ du.edu.
} 
the interaction between two nitroxide spin labels to measure distances between sites in proteins.

5-7 Both $1 / T_{1}$ and $1 / T_{\mathrm{m}}$ affect the selection of experimental parameters for the distance measurements. Nitroxide polyradicals with $S>1 / 2$ are under investigation as NMR relaxation enhancement reagents, ${ }^{8}$ and there is interest in dinitroxides as dynamic nuclear polarization agents. ${ }^{9}$ Optimization of each of these applications depends upon an understanding of the electron spin relaxation properties. Because of the many possible electron spin relaxation mechanisms, and the wide range of motional regimes in which nitroxides radicals are used, fundamental studies of spin relaxation are needed in many solvents, over large temperature ranges, and at multiple microwave frequencies to provide confident bases for predicting relaxation mechanisms and rates for a new radical or a previously studied radical in a new environment. Very little is known about relaxation rates and mechanisms involved in interactions of two or more radicals.

For nitroxide monoradicals in a glassy or crystalline matrix the dominant contributions to relaxation are the Raman process and a local mode, which modulate spin-orbit coupling. ${ }^{10}$ As the matrix softens, molecular reorientation rates increase and processes that modulate anisotropic hyperfine interaction make significant contributions to relaxation. ${ }^{11,12}$ It is welldocumented that the interaction of a nitroxide radical with a more rapidly relaxing center results in relaxation enhancement that can be used to determine interspin distances, ${ }^{13,14}$ but much less is known about the relaxation enhancement that arises from nitroxide-nitroxide interaction. To address this question a series of diradicals and a tetraradical (Figure 1, Table 1) were studied.

Tetraradical 1a, diradical $\mathbf{1 b}$, and related monoradical $\mathbf{1 c}$ have the 1,3-alternate calix[4]arene structure. In tetraradical 1a, the exchange coupling between nitroxides attached to adjacent phenyl rings is antiferromagnetic $\left(J_{1} / k \sim-1 \mathrm{~K}\right) .{ }^{15}$ The through-space coupling between the diagonal nitroxides at the $\mathrm{N} \cdots \mathrm{N}$ distance of 5-6 $\AA$ in $\mathbf{1 a}$ and $\mathbf{1 b}$ is antiferromagnetic, with a matrix-dependent coupling strength of $J_{2} / k \sim-1 \mathrm{~K} .{ }^{15}$ In tetraradical 1a, the exchange interactions lead to three $S=1$ manifolds and one $S=2$ manifold that are thermally populated throughout the temperature range studied; two of the $S=1$ manifolds are degenerate. ${ }^{15}$

The two $m$-phenylene-based high-spin diradicals $\mathbf{2 a}$ and $\mathbf{2 b}$ were investigated to determine the impact of structure and stronger exchange interaction. Diradical 2a was designed and synthesized to possess a relatively rigid structure with planar conformation and very strong ferromagnetic coupling, to ensure complete population of the $S=1$ state, even at room temperature. ${ }^{16}$ Diradicals $\mathbf{2 b}$ and $\mathbf{2 a}$ have ferromagnetic exchange couplings $J_{1} / k \approx 150 \mathrm{~K}$ and $>150 \mathrm{~K}$, respectively. The azine-linked diradical 3 has a longer interspin distance (about 8-9 $\AA)^{17-19}$ and weaker exchange interaction than for diradicals $\mathbf{1 b}, \mathbf{2 a}$, or $\mathbf{2 b}$. For diradicals $\mathbf{1 b}$, $\mathbf{2 a}, \mathbf{2 b}$, and $\mathbf{3} J$ is larger than the EPR quantum and anisotropies, transitions are observed only within the $S=1$ manifold, and the energies of the EPR transitions are not strongly dependent on $J$.

\section{Methods}

\subsection{Sample Preparation}

4-Hydroxy-2,2,6,6-tetramethylpiperidine-1-oxyl (tempol), $\alpha, \gamma$-bisdiphenylene- $\beta$-phenylallyl (BDPA), and Fremy's salt $\left(\left(\mathrm{SO}_{3}\right)_{2} \mathrm{NO}^{2-}\left(\mathrm{K}^{+}\right)_{2}\right)$ were used as received from Aldrich Chemical Co. Tetraradical $\mathbf{1 a}$ and diradical $\mathbf{1 b}$ were prepared as previously reported; ${ }^{15}$ similar methods were used for preparation of the corresponding calix[4]arene monoradical 1c (Supporting Information). Diradical $\mathbf{2 b}$ was prepared using methods similar to those for the previously reported monopegylated diradical; ${ }^{20}$ synthetic details and magnetic characterization for $\mathbf{2 b}$ will be reported elsewhere. Diradical 3 was prepared as reported previously. ${ }^{21}$ 
Diradical 2a was prepared from the corresponding diamine (1:1 mixture of diastereomers). ${ }^{22}$ $m$-Chloroperbenzoic acid $(57.6 \mathrm{mg}, 0.326 \mathrm{mmol}, 11.7 \mathrm{~mL}$ of $27.8 \mathrm{mM}$ in dichloromethane, 4.1 equiv) was added to the diamine $22(50.0 \mathrm{mg}, 0.0796 \mathrm{mmol}, 1$ equiv) in dichloromethane $(5.0 \mathrm{~mL})$ at $0{ }^{\circ} \mathrm{C}$, in two portions $(2+2.1$ equiv), at an interval of $1 \mathrm{~h}$. After an additional $1 \mathrm{~h}$ at $0{ }^{\circ} \mathrm{C}$, the orange reaction mixture was transferred with acetone, concentrated in vacuo, and then filtered through deactivated silica gel (pentane/acetone, $7: 3)$ at low temperature $\left(-20^{\circ} \mathrm{C}\right)$. (Silica gel was deactivated using 5\% triethylamine in pentane as described previously. ${ }^{16}$ ) The orange band of the product was collected, to give nitroxide diradical $2 \mathbf{a}$ as a red oil $(28.0 \mathrm{mg}$, $53 \%$ ). Because the starting diamine was a mixture of diastereomers, and only this particular band exhibits EPR spectra corresponding to a diradical, it is assumed that 2a is isolated as a mixture of diastereomers with indistinguishable EPR spectra.

For magnetic studies of pegylated diradical 2a in solution, a 2:1 ethanol/water solvent mixture was selected, as it provides good solubility and matrix rigidity for magnetic studies and it permits obtaining well-resolved EPR spectra. Diradical 2a $(0.41 \mathrm{or} 0.80 \mathrm{mg})$ was placed in a homemade $5 \mathrm{~mm}$ o.d. EPR-quality quartz tube (superconducting quantum interference device (SQUID) tube), modified to possess a thin bottom, which is $6 \mathrm{~cm}$ from the end of the tube. ${ }^{15}$ Following vacuum transfers of solvent $(\sim 0.1 \mathrm{~mL})$, the tube was flame-sealed under vacuum. For neat samples, diradical 2a $(7.89 \mathrm{mg})$ was loaded into the SQUID tube using acetone, to form a small band of viscous oil at the thin bottom. The open tube was directly attached to the sample holder. Following the measurements, the tube was completely emptied and ${ }^{1} \mathrm{H}$ NMR spectra in benzene- $d_{6}$ were obtained, indicating $10 \mathrm{~mol} \%$ of residual acetone. Identical sequences of measurements were carried out on the empty tube to provide point-by-point correction for diamagnetism; additional correction for diamagnetism was based upon Pascal constants $\left(\chi \mathrm{dia}=-4.16 \times 10^{-4} \mathrm{emu} \mathrm{mol}^{-1}\right)$.

For EPR studies, a 4:1 toluene/ $\mathrm{CHCl}_{3}$ solvent mixture was selected because it forms a glass with a softening temperature of about $130 \mathrm{~K}$ and each of the radicals is soluble in this mixture. To minimize the impact of intermolecular radical-radical interactions, concentrations were less than $1 \mathrm{mM}$ : tetraradical 1a, $0.21 \mathrm{mM}$; diradical $1 \mathbf{b}, 0.96$ or $0.18 \mathrm{mM}$; monoradical 1c, $\sim 0.5$ $\mathrm{mM}$; diradical 2a, $0.56 \mathrm{mM}$; diradical $2 \mathbf{b}, 0.55 \mathrm{mM}$; diradical 3, $0.5 \mathrm{mM}$. Each of the radicals also dissolves in sucrose octaacetate, which forms a glass with glass transition temperature at $298 \mathrm{~K} .{ }^{23}$ Weighed portions of radical and sucrose octaacetate powder were mixed by gentle grinding. The mixtures were placed in $1 \mathrm{~mm}$ i.d. capillaries, evacuated, and flame-sealed. The mixtures were melted briefly with a heat gun and cooled quickly in water to form a glass. The brief melting period may not be long enough to give a uniform distribution of radicals in the glass, but prolonged heating causes loss of EPR signal. A single capillary tube was used for Q-band experiments. A bundle of three or four capillaries was used for X-band measurements. The concentrations of the BDPA samples in sucrose octaacetate glasses were determined by comparison of the integrated intensities at $125 \mathrm{~K}$ with that for a known concentration of tempol in 1:1 water/glycerol at the same temperature. A solution of Fremy's salt in $1.0 \mathrm{M} \mathrm{KOH}$ solution was mixed 1:1 with glycerol, transferred to a $4 \mathrm{~mm}$ o.d. EPR tube, and stored in liquid nitrogen.

\subsection{SQUID Magnetometry}

A $5 \mathrm{~T}$ ac/dc SQUID magnetometer (Quantum Design MPMS5S), with continuous temperature control and operating in the dc-mode, was used. Magnetization $(M)$ was measured as a function of magnetic field $\left(H=0-5 \times 10^{4} \mathrm{Oe}\right.$ and $T=1.8,3$, and $\left.5 \mathrm{~K}\right)$ and temperature $(T=1.8-290 \mathrm{~K}$ at $H=30000,5000$, or $500 \mathrm{Oe}$ ).

\subsection{EPR Spectroscopy}

$\mathrm{CW}$ spectra, long-pulse saturation recovery (SR) and inversion recovery, and two-pulse spinecho at X-band and Q-band were recorded on a Bruker E580 with a SuperQFT bridge, split 
ring resonators, and a Bruker CF935 cryostat. The magnetic field was calibrated using a $g$ value for lithium phthalocyanine of 2.00225. ${ }^{24} \mathrm{X}$-band SR measurements also were performed with a locally constructed spectrometer ${ }^{25}$ using a $\mathrm{TE}_{102}$ rectangular resonator. A Varian flowthrough dewar and temperature controller and nitrogen gas cooled with liquid nitrogen were used to obtain temperatures above $100 \mathrm{~K}$. Temperatures between 10 and $90 \mathrm{~K}$ were obtained with liquid helium, an Oxford ESR900 flow cryostat, and an ITC601 temperature controller. For the SR experiments the lengths of the saturating pulses were long relative to $T_{1}$ to minimize the effects of spectral diffusion. Above about $80 \mathrm{~K}$ the time constants obtained by inversion recovery and SR are the same, but at lower temperatures shorter time constants were obtained by inversion recovery, which is attributed to contributions from spectral diffusion. The Q of the rectangular resonator is about 3000 , and the dead time following a pulse for SR is about $1.5 \mu \mathrm{s}$. The pulse sequence for inversion recovery was $180-T_{\mathrm{var}}-90-\tau$ - $180-\tau$-echo, and for twopulse echo it was 90- $\tau$-180- $\tau$-echo. Most experiments were performed with an $80 \mathrm{~ns} \pi$ pulse. For monoradical samples at temperatures where instantaneous diffusion made significant contributions to echo decays, smaller turning angles were used. The temperature dependence of relaxation for monoradicals was monitored in the center of the spectrum where contributions from $g_{x x}$ and $g_{y y}$ dominate, and for diradicals it was monitored at the low-field position for $D_{\perp}$.

At Nebraska, routine CW spectra were obtained using a Bruker EMX instrument, equipped with a frequency counter and nitrogen flow temperature control (130-300 K).

CW line shapes in glassy solution were simulated using XSophe. ${ }^{26}$ The $g$ values and nitrogen hyperfine splittings are typical of nitroxide radicals (Supporting Information Table S1). It was assumed that the dipole-dipole interspin vector was along a principal axis of the nitroxide $g$ and $A$ tensor, which was adequate to determine the magnitude of the dipolar couplings. Further refinements involving changes in the relative orientations of the axes were not attempted. The dipolar splittings and line widths are summarized in Table 2. The point dipole interspin distances for $\mathbf{1 b}, \mathbf{2 a}$, and $\mathbf{2 b}$ (Table 1) were calculated from the dipolar splittings.

2.3.1. Determination of Value of $\mathbf{S}$ by Pulse Turning Angle-The microwave power required to achieve a $90^{\circ}$ turning angle depends on the value of $S .{ }^{27}$ The turning angle can be calculated from the expressions $\theta=c \gamma B_{1} t_{\mathrm{p}}$ where $\gamma$ is the magnetogyric ratio, $B_{1}$ is the microwave magnetic field, $t_{\mathrm{p}}$ is the length of the pulse, and $c=\left[S(S+1)-m_{\mathrm{s}}\left(m_{\mathrm{S}}+1\right)\right]^{1 / 2}$. The $B_{1}$ required to produce a $90^{\circ}$ pulse decreased in the order monoradicals $(S=1 / 2)>$ diradicals $(S=1)>$ tetraradical (mixture of $S=1$ and $S=2$ ), which is consistent with the assignments of the spin states. The precision of the turning angle experiments was not sufficient to characterize the populations of $S=1$ and $S=2$ for the tetraradical.

\subsection{Analysis of Saturation Recovery and Inversion Recovery Curves}

Preliminary data analysis was performed by fitting with a single exponential. However, the recovery curves for nitroxide radicals in glassy matrixes are not single exponentials due to the orientation dependence of vibrations, molecular motion, and spin-orbit coupling. ${ }^{28}$ The recovery curves were modeled with a log-normal distribution of $T_{1}$ as defined by eq $1^{29}$

$$
\log -\text { normal distribution }=\sum_{i=1}^{n} \frac{1}{\sigma \sqrt{2 \pi}} \exp \left[-\frac{\left(\log \left[T_{1}^{i}\right]-\log [b]\right)^{2}}{2 \sigma^{2}}\right] \exp \left[-t / T_{1}^{i}\right]
$$

where $\sigma$ is the standard deviation of the distribution on the logarithmic scale and $b$ is the center of the distribution. 
Analogous to the uniform penalty model (UPEN), ${ }^{30,31}$ the relaxation time distribution is sampled at evenly spaced points on a logarithmic scale between minimum and maximum $T_{1}$ values that are determined by the longest and shortest times at which data were acquired, the centers of the distributions, and the distribution widths. The Levenberg-Marquardt method, as implemented in Mathematica, was used to find the solutions. Increasing the number of points in the distribution from 50 to 200 gave no detectable improvement in the fit to the recovery curves, so the number of points was set at 50 .

For magnetically dilute nitroxides in glassy solvents the distribution width $\sigma$ has been found to be $0.27 \pm 0.3$ and approximately independent of temperature below the glass transition temperature. The SR curves for diradicals $(\mathbf{1 b}, \mathbf{2 a}, \mathbf{2 b}, \mathbf{3})$ at magnetic field positions where the monoradical impurity is not detected in the CW spectra and SR curves for monoradical 1c fit well with a single log-normal distribution with $\sigma=0.27 \pm 0.4$. The $\sigma$ for tetraradical 1a was significantly larger $(0.46)$ than those of the diradical and monoradicals. Therefore, the inversion recovery and SR curves for diradicals and monoradicals were analyzed with $\sigma=0.27$, whereas data for the tetraradical were analyzed with $\sigma=0.46$. The value for $T_{1}$ calculated at the center of the distribution is about $0.8(\sigma=0.27)$ or $0.54(\sigma=0.46)$ times the approximate value found by fitting a single exponential to the recovery curves. The quality of the fits to the data with distributions of exponentials is shown in Supporting Information Figure S1. The wider distributions of relaxation rates for the tetraradical than for the monoradical or diradicals (Figure S1) may be due to modulation of electron-electron dipolar interactions for a larger number of conformations or to different values of $T_{1}$ for the three triplet manifolds and one quintet manifold in the tetraradical. ${ }^{15}$

In the center of the spectra for diradicals $\mathbf{1 b}, \mathbf{2} \mathbf{a}$, or $\mathbf{3}$ there are overlapping contributions from monoradical and diradical, so the SR curves were modeled as the sum of two log-normal distributions as described by eqs 1 and 2

weighteddistribution $=C 1($ distribution 1$)+C 2($ distribution 2$)$

where $C 1$ and $C 2$ are the coefficients for the two distributions. For the SR experiments the relative intensities of the monoradical and diradical signals were estimated by integration of the $\mathrm{CW}$ spectra, and the coefficients for analysis of the inversion recovery curves were calculated from field-swept echo-detected spectra. In the analyses of the composite signals the relaxation times for the diradical were fixed at the values observed at the lower-field $g_{x x}$ turning point, where only diradical contributed. Fitting to the sums of distributions of exponentials gave a clearer separation of the contributions from monoradical and diradical than could be obtained with the sum of two exponentials. The trends in temperature dependence of $1 / T_{1}$ are independent of the model that was used to fit the recovery curves.

\subsection{Analysis of Two-Pulse Spin Echo Decays}

Single exponentials were fitted to the two-pulse echo decays. Oscillations due to echo envelope modulation cause some uncertainty in the time constants. In the center of the spectra for diradical 1b, 2a, or $\mathbf{3}$ there are overlapping contributions from monoradical and diradical, so the echo decay curves were modeled as the sum of two exponentials. The ratios of the components were estimated from the echo-detected field-swept spectra.

Echo decays also were fitted with stretched exponentials

$$
Y(\tau)=Y_{0} \exp \left(-\left(\frac{2 \tau}{T_{\mathrm{m}}}\right)^{x}\right)
$$


where $Y_{0}$ is the amplitude at time zero and $\tau$ is the time between pulses.

The echo decay time constant is designated as $T_{\mathrm{m}}$ to indicate that it includes processes such as molecular motion and instantaneous diffusion that take spins off resonance, as well as electronelectron spin-spin interaction. Deviations of the value of $x$ (eq 3 ) from 1 can arise from distributions of exponentials or from changes in the mechanisms of echo dephasing. ${ }^{32}$ Discussions of trends in $1 / T_{\mathrm{m}}$ are based primarily on single-exponential fits because the introduction of two parameters, $T_{\mathrm{m}}$ and $x$, leads to greater scatter.

\subsection{Model for Temperature Dependence of $1 / T_{1}$}

The temperature-dependent relaxation rates were modeled as the sum of contributions from the direct, Raman, and local modes (eq 4) ${ }^{12,33}$

$$
\frac{1}{T_{1}}=A_{\text {direct }}(T+b)+A_{\text {Ram }}\left(\frac{T}{\theta_{\mathrm{D}}}\right)^{9} J_{8}\left(\theta_{\mathrm{D}} / T\right)+A_{\mathrm{loc}} \frac{\exp \left[\Delta_{\mathrm{loc}} / T\right]}{\left(\exp \left[\Delta_{\mathrm{loc}} / T\right]-1\right)^{2}}
$$

where $T$ is temperature in Kelvin, $A_{\text {direct }}$ and $b$ are the coefficients for the contribution from the direct process, $A_{\mathrm{Ram}}$ is the coefficient for the contribution from the Raman process, $\theta_{\mathrm{D}}$ is

the Debye temperature, $J_{8}$ is the transport integral, $J_{8}\left(\theta_{\mathrm{D}} / T\right)=\int_{0}^{\theta_{\mathrm{D}} / T} x^{8}\left(\mathrm{e}^{x} /\left(\mathrm{e}^{x}-1\right)^{2}\right) \mathrm{dx}, A_{\mathrm{loc}}$ is the coefficient for the contribution from local mode, and $\Delta_{\text {loc }}$ is the energy of the local mode. For the diradicals and tetraradicals the coefficients include contributions from modulation of both spin-orbit coupling and electron-electron interaction. Each of these processes results in a distinctive temperature dependence of $1 / T_{1}$. Above the glass transition temperature, molecular reorientation provides effective relaxation enhancement, which is not included in the modeling. The parameters obtained by fitting eq 4 to the experimental data are summarized in Table 3. When the Debye temperatures was allowed to vary, the values in $4: 1$ toluene/ $\mathrm{CHCl}_{3}$ were 104 \pm 15 , so $\theta_{\mathrm{D}}$ was fixed at $100 \mathrm{~K}$ to facilitate comparison of $A_{\mathrm{Ram}}$. The assignment of the process that contributes in sucrose octaacetate glasses above about $100 \mathrm{~K}$ as a local mode, rather than a thermally activated process, is based on the similarity of the relaxation rates at X-band and Q-band. ${ }^{12}$ The energy of the local mode was estimated as $950 \mathrm{~K}\left(650 \mathrm{~cm}^{-1}\right)$ for diradical $2 \mathbf{a}$ in sucrose octaacetate, for which data were measured up to $300 \mathrm{~K}$. The same value of $\Delta_{\text {loc }}=$ $950 \mathrm{~K}$ was used for $\mathbf{2 a}$ in glycerol to permit comparison of the coefficients, $A_{\text {loc }}$.

\subsection{DFT Calculations}

The optimized geometries and vibrational frequencies of nitroxide diradicals were calculated at the unrestricted DFT level (6-31G(d), UB3LYP functional) with a Windows version of Gaussian 03. ${ }^{34}$ Calculations were performed for $\mathbf{4 a}$ and $\mathbf{4 b}$, as models of $\mathbf{2 a}$ and $\mathbf{2} \mathbf{b}$ with fewer atoms. The potential energy surfaces near the minimum energy of the triplet states are nearly flat. Even with the maximum root-mean-square (rms) forces an order of magnitude or more below the "tight" thresholds of Gaussian 03, small displacements with negligible energy changes are still estimated for each structure.

For $\mathbf{4 a}$, frequencies were calculated after completed geometry optimization with the standard thresholds of Gaussian 03. After 138 additional geometry optimization steps, forces and displacements remained essentially unchanged and the forces were at least 1 order of magnitude below the "tight" thresholds. This geometry was in good agreement with the X-ray structure of $\mathbf{4 a} .{ }^{16}$ For anti-4b and syn-4b, the geometry optimizations were completed on the basis of negligible forces with respect to "tight" thresholds, and these geometries were used for frequency calculations. For $\pi$-conjugated organic molecules, the frequencies calculated at the 
B3LYP/6-31(d) level and then scaled by 0.97 show good agreement with experimental data. 34

\section{Results and Discussions}

\subsection{Magnetic Studies}

The magnetization $(M)$ versus magnetic field $(H)$ data at low temperatures $(T=1.8,3,5 \mathrm{~K})$ for diradical 2a in EtOH/water and in the solid state could be fit with the Brillouin functions with a mean-field parameter $(\theta<0)$, i.e., $M$ versus $H /(T-\theta)$ (Figures 2 and 3, inset plots). The fits have two variable parameters, i.e., total spin $(S)$ and magnetization at saturation $\left(M_{\mathrm{sat}}\right)$; the mean-field parameter $\theta$ is adjusted until the $M / M_{\text {sat }}$ versus $H /(T-\theta)$ plots overlap at all temperatures. The quality of the fits is much better for the dilute solution samples, which possess negligibly small values of $|\theta|<0.1 \mathrm{~K}$, indicating nearly ideal paramagnetic behavior. Since $|\theta|$ in dilute solution is smaller by a factor of 10 than the solid-state values, it is almost certain that the values of $\theta<0$ correspond to intermolecular antiferromagnetic coupling. For both solution and solid-state samples, the values of $S \approx 1.0$, determined from the curvature of the Brillouin plots, indicate a triplet $(S=1)$ ground state for $\mathbf{2 a}$.

The $\chi T$ versus $T$ plots support the magnetization results and provide additional information about the strength of ferromagnetic coupling (singlet-triplet energy gap, $2 J / k$ ) for $2 \mathbf{a}$ (Figures 2 and 3, main plots). In particular, the downward curvature of the $\chi T$ versus $T$ plot is much smaller in solution, compared to the solid state. For solid $\mathbf{2 a}$, the $\chi T$ versus $T$ plot in the hightemperature range is flat with $\chi T \approx 0.96 \mathrm{emu} \mathrm{K} \mathrm{mol}^{-1}$, which is near the expected value of 1.00 emu $\mathrm{K} \mathrm{mol}^{-1}$ for a diradical that is entirely in an $S=1$ state. This result implies that even at room temperature 2a is entirely in an $S=1$ state, i.e., $2 \mathrm{~J} / \mathrm{k} \gg 300 \mathrm{~K}$. For $\mathbf{2 a}$ in $\mathrm{EtOH} / \mathrm{H}_{2} \mathrm{O}$, the $\chi T$ versus $T$ plot is flat up to $150 \mathrm{~K}$. The highest temperature of measurement is limited by the rigidity of the solvent matrix; therefore, only a lower limit, $2 J / k \gg 200 \mathrm{~K}$, for the strength of ferromagnetic coupling can be estimated.

\subsection{Comparison of CW EPR Spectra}

The X-band EPR spectrum of monoradical $1 \mathrm{c}$ in $4: 1$ toluene/ $\mathrm{CHCl}_{3}$ at $60 \mathrm{~K}$ (Figure $4 \mathrm{a}$ ) is typical of nitroxides in frozen or glassy solution. The nitrogen hyperfine coupling $\left(A_{z z}=3.08\right.$ $\mathrm{mT}$ at $60 \mathrm{~K})$ is the dominant interaction that defines the spectral shape. The $\left|\Delta m_{\mathrm{s}}\right|=1$ spectrum of diradical $1 \mathrm{~b}$ at $50 \mathrm{~K}$ (Figure $4 \mathrm{a}$ ) is dominated by the zero-field splitting ${ }^{15}$ with $\mid D_{||}$and $\mid$ $D_{\perp} \mid$ of 30.2 and $15.1 \mathrm{mT}$, respectively, which corresponds to a point-dipole distance of $5.7 \AA$. For nitroxides the axis designations are $x$ (along the NO bond), $y$ (perpendicular to NO bond and to $\pi$-orbital), and $z$ (along the nitrogen $\pi$-orbital). ${ }^{35}$ The interspin vector is along the $z$-axis of the nitroxide, which is consistent with the known structure of the diradical (Figure 1). The line widths for diradical $\mathbf{1 b}$ are too large to permit resolution of nitrogen hyperfine interaction. For 1b, a well-resolved $\left|\Delta m_{\mathrm{S}}\right|=2$ (half-field) transition is observed with a nitrogen hyperfine splitting that is half of the value for the monoradical. The observation of a half-field transition is characteristic of dipolar coupled spins. ${ }^{19}$ The monoradical line shape in the center of the spectrum of the diradical $\mathbf{1 b}$ is due to a small impurity of monoradical.

The room-temperature fluid solution spectrum of tetraradical $\mathbf{1 a}$ is a well-resolved nine-line spectrum that is characteristic of strong exchange interaction that makes coupling to all four nitrogens equivalent. ${ }^{15}$ In glassy $4: 1$ toluene $/ \mathrm{CHCl}_{3}$ at $50 \mathrm{~K}$ the spectrum of tetraradical $\mathbf{1 a}$ is an incompletely resolved single line with a peak-to-peak line width of about $2.0 \mathrm{mT}$ (Figure 4a), which is much narrower than the spectrum of diradical $\mathbf{1 b}$ and shows no resolved dipolar coupling. ${ }^{15}$ The tetraradical can be viewed as two pairs of radicals. Within each pair the interspin distance is about 5-6 $\AA$, and the radicals in different pairs are separated by about 9-10 $\AA .{ }^{15}$ When the magnetic field is along the interspin vector for one pair of radicals, it is 
approximately perpendicular to the interspin vector for the other pair, so the two intrapair dipolar couplings are inequivalent. The absence of resolved dipolar splitting in the spectrum for 1a (Figure 4a) indicates that the exchange interaction between the four paramagnetic centers is strong enough to average the inequivalent dipolar couplings, which is consistent with the value of about $|J / k| \sim 1 \mathrm{~K}$ determined by magnetic susceptibility. ${ }^{15}$

The room-temperature fluid solution spectrum of diradical $\mathbf{3}$ exhibits five-line hyperfine splitting that is characteristic of strong exchange and equivalent coupling to both nitroxide nitrogens. The magnitude of the dipolar coupling for $\mathbf{3}$ is smaller than for diradicals $\mathbf{1 b}, \mathbf{2} \mathbf{a}$, or $\mathbf{2 b}$, so the rigid-lattice spectrum extends over a smaller range of magnetic fields (Figure 4b). A single-crystal EPR study of 3 reported $D_{z z}=3.4(0.1), D_{y y}=1.53(0.04)$, and $D_{x x}=1.87$ $(0.05) \mathrm{mT} .{ }^{17}$ These dipolar couplings are of the same order of magnitude as the nitrogen hyperfine splittings, which causes extensive overlap of transitions. In addition there may be several conformations of the nitroxide rings, which make simulation of the $\mathrm{CW}$ spectra difficult.

Figure $4 \mathrm{~b}$ also shows the $\mathrm{CW}$ spectra of diradicals $\mathbf{1 b}, \mathbf{2 a}$, and $\mathbf{2 b}$ in sucrose octaacetate glass at $294 \mathrm{~K}$. The room-temperature spectrum of $\mathbf{1 b}$ is broader than at $50 \mathrm{~K}$, which is attributed to increased motion and distributions of geometries in the relatively flexible diradical. For diradical 2a the maximum dipolar splitting is along the $g_{y y}$ axis (Figure $4 \mathrm{~b}$ and Supporting Information Figure S2) which is consistent with the structure shown in Figure 1. Nitrogen hyperfine splitting of five lines separated by $A_{z z} / 2$ is observed along $g_{z z}$, consistent with $J \gg$ $A_{z z}$. For diradical $\mathbf{2 b}$ the maximum dipolar coupling also is along $g_{y y}$ (consistent with the structure shown in Figure 1), and the nitrogen hyperfine interaction is partially resolved along $g_{z z}$. The weak outermost lines in the spectrum of $\mathbf{2} \mathbf{b}$ that are not reproduced by the simulation (Figure $4 \mathrm{~b}$ ) are attributed to a minor conformer with larger $D_{y y}$. A second conformer also was observed for an analogous diradical in polar solvents. ${ }^{20}$ The smaller line widths for $\mathbf{2 a}$ than for the other diradicals at both $70 \mathrm{~K}$ in toluene/ $\mathrm{CHCl}_{3}$ and at $294 \mathrm{~K}$ in sucrose octaacetate and the small change in line widths between 86 and $294 \mathrm{~K}$ in sucrose octaacetate (Table 1) are consistent with greater rigidity of this diradical.

Even for the relatively rigid diradical $\mathbf{2 a}$ the $\mathrm{CW}$ spectrum changes with temperature (Supporting Information Figure S3a) because of the temperature dependence of the $D_{x x}$ and $D_{z z}$ components of the dipolar coupling (Supporting Information Figure S3b). The temperaturedependent impact of libration on $A_{z z}$ for nitroxide monoradicals has been described, ${ }^{36-38}$ and it is proposed that comparable effects occur for the dipolar couplings. Motion around the $y$ axis averages the $x$ and $z$ components leaving the $y$ component unchanged. This averaging corresponds to libration of the plane of the core of the molecule, which is plausible even in a glassy host.

\subsection{Spin Echo Dephasing, $1 / T_{\mathrm{m}}$}

The spin echo dephasing rate, $1 / T_{\mathrm{m}}$, includes contributions from all processes that take spins off resonance on the time scale of the experiment and therefore provides insight into molecular motion. Low-amplitude vibrations (librations) modulate the orientation of the magnetic axes relative to the external magnetic field and enhance spin echo dephasing proportional to anisotropy. This effect is greatest at positions in the spectrum where a change in orientation causes the greatest change in resonant field. ${ }^{37,39}$ For monoradicals in temperature ranges where librations contribute to dephasing, rates are slowest near the principal magnetic axes and faster at intermediate positions. ${ }^{12,39,40}$ In diradicals, motions that modulate the interspin distance and/or orientation of the interspin vector change the resonance field, which can also contribute to echo dephasing. 
3.3.1. Temperature Dependence of $1 / T_{\mathrm{m}}$-The temperature dependence of $1 / T_{\mathrm{m}}$ for $1 \mathrm{c}$ (Figure 5) is typical of nitroxide monoradicals. ${ }^{12}$ Relaxation rates for 3_mono (data not shown) are similar to those for 1c. At temperatures less than $\sim 50 \mathrm{~K}$, mutual spin-flips of neighboring protons (nuclear spin diffusion) dominate the relaxation and there is little temperature dependence. ${ }^{3,32}$ When the low-temperature data were fitted with eq $3, T_{\mathrm{m}}$ was 2-6 $\mu$ s and the exponent $x$ approached 2 as temperature was decreased. The increase in $1 / T_{\mathrm{m}}$ for $1 \mathbf{c}$ and 3_mono above about $70 \mathrm{~K}$ is due to rotation of methyl groups at rates comparable to inequivalences in the electron-proton couplings that are averaged by rotation. ${ }^{40,41}$ For radicals without methyl groups such as Fremy's salt, $1 / T_{\mathrm{m}}$ shows little temperature dependence below about $110 \mathrm{~K}$ (Figure 5), which supports the assignment of the relaxation enhancement for $\mathbf{1 c}$ to methyl rotation.

Below about $20 \mathrm{~K}$ the relaxation rates, $1 / T_{\mathrm{m}}$, for diradicals $\mathbf{1 b}, \mathbf{2 a}, \mathbf{2 b}, \mathbf{3}$ and tetraradical $\mathbf{1 c}$ are similar to those for monoradicals 1c, 3 _mono, and Fremy's salt $\left(\left(\mathrm{SO}_{3}\right)_{2} \mathrm{NO}^{2-}\right)$, which indicates that electron-electron dipolar interaction does not dominate the low-temperature limiting values of $1 / T_{\mathrm{m}}$. The values of the exponent $x$ (eq 3 ) are about 2 as expected when nuclear spin diffusion dominates dephasing. Above about $20 \mathrm{~K}$ the relaxation rates, $1 / T_{\mathrm{m}}$, increase in the order monoradical $\mathbf{1 c}<$ diradicals $\mathbf{2 a}<\mathbf{2} \mathbf{b}<\mathbf{1 b}<$ tetraradical 1a (Figure 5). The values of $x$ (eq 3) decrease with increasing temperature (Supporting Information Figure S4) as expected when a dynamic process dominates dephasing. Since the impact of methyl rotation on dephasing for the diradicals or tetraradical is expected to be similar to that for the monoradicals, the enhanced relaxation for the diradicals is attributed to modulation of the electron-electron interactions. The rms values of the dipolar couplings $\left(\sqrt{0.33\left(D_{x x}{ }^{2}+D_{y y}{ }^{2}+D_{z z}^{2}\right)}\right.$, Table 1) for the three diradicals are 2a, $20.4 \mathrm{mT} ; \mathbf{2 b}, 18.3 \mathrm{mT} ; \mathbf{1 b}, 21.4 \mathrm{mT}$. Since the dipolar couplings are so similar and the trends in $1 / T_{\mathrm{m}}$ do not correlate with trends in the dipolar couplings or in the values of $|J / h|$, the trend in dephasing rates $(\mathbf{2} \mathbf{a}<\mathbf{2} \mathbf{b}<\mathbf{1 b})$ is attributed to increasing motion that modulates the dipolar couplings. Although electron-electron dipolar coupling is not observed in the $\mathrm{CW}$ spectrum of tetraradical 1a, modulation of spin-spin interaction is still an effective relaxation process. ${ }^{42}$ Modulation of multiple dipolar interactions, exchange interactions, and interconversion between the multiple spin states may contribute to enhanced echo dephasing for $\mathbf{1 a}$.

3.3.2. Dependence of $1 / T_{\mathrm{m}}$ on Position in the CW Spectrum-The dependence of $1 /$ $T_{\mathrm{m}}$ on position in the spectrum was examined at $86 \mathrm{~K}$, which is a low enough temperature that there is relatively little contribution of methyl rotation to the echo dephasing. Experiments were performed at Q-band to enhance the orientation selection. Even at Q-band the dominant anisotropy is the dipolar splitting. At $86 \mathrm{~K}$ the dephasing rates for $\mathbf{2 a}$ increase in the order glycerol $<4: 1$ toluene/ $\mathrm{CHCl}_{3}<$ sucrose octaacetate (Figure 6), which is the order of decreasing glass rigidity. In glycerol $1 / T_{\mathrm{m}}$ for diradical $2 \mathrm{a}$ exhibits little dependence on position in the spectrum, even in the center of the spectrum where 2a_mono contributes (Figure 6). The weak dependence on position in the spectrum and the similarity of $1 / T_{\mathrm{m}}$ for monoradical and diradical indicate that motions that modulate the electron-electron dipolar coupling make little contribution to $T_{\mathrm{m}}$ in this relatively rigid glass at $86 \mathrm{~K}$. For the same diradical in the less rigid low-polarity sucrose octaacetate glass the relaxation rates are about 3 times faster than in glycerol and exhibit substantial dependence on position in the spectrum (Figure 6). The rates are slower in the region where the monoradical signal dominates and near the principal axes of the dipolar interaction. Faster rates are observed at intermediate orientations where the same magnitude of motion causes a larger change in resonance field. This is the pattern that is expected when modulation of electron-electron dipolar interaction by librational motion makes a substantial contribution to echo dephasing. 


\subsection{Spin-Lattice Relaxation, $1 / T_{1}$}

3.4.1. Temperature Dependence-The relaxation rates for 3 in $4: 1$ toluene/ $\mathrm{CHCl}_{3}$ and in sucrose octaacetate between about 20 and $298 \mathrm{~K}$ are only slightly faster than for 3_mono (Figure 7). Below about $20 \mathrm{~K}$ in sucrose octaacetate the substantial contribution from the direct process is attributed to a nonuniform distribution of radicals in the glass. Between about 20 and $100 \mathrm{~K}$ the rates in both solvents are dominated by the two-phonon Raman process. ${ }^{12}$ The faster relaxation rates in the low-polarity relatively soft sucrose octaacetate glass than in the polar and more rigid 4:1 toluene/ $\mathrm{CHCl}_{3}$ are typical of nitroxide radicals ${ }^{10,12,28}$ and demonstrate the impact of the glassy matrix on the phonon modes that contribute to Raman relaxation. Above about $100 \mathrm{~K}$ the $4: 1$ toluene/ $\mathrm{CHCl}_{3}$ glass softens, and tumbling-dependent processes make increasingly important contributions to relaxation. By contrast, the sucrose octaacetate remains glassy up to room temperature. The relaxation rates for $\mathbf{3}$ in sucrose octaacetate between 100 and $300 \mathrm{~K}$ are similar at X- and Q-band, which is consistent with assignment of the Raman and local mode processes. The local mode makes increasingly significant contributions at higher temperatures (Figure 7). The similarity in relaxation rates for 3 and 3_mono in temperature ranges where three different relaxation processes dominate (Figure 7) shows that the modulation of electron-electron interactions of the magnitude that are present in $\mathbf{3}$ makes only modest contributions to spin lattice relaxation for a nitroxide radical by each of these processes.

The interspin distances are shorter and the exchange interactions larger for $\mathbf{1 b}, \mathbf{2 a}$, and $\mathbf{2 b}$ than for 3 (Table 1), and the spin-spin interactions have a greater impact on $1 / T_{1}$ than for 3 (Figure 8). The largest differences in relaxation rates are observed at the lowest temperatures. For comparison with the impact of intermolecular dipolar interaction on $1 / T_{1}$, data are shown in Figure 9 for BDPA in sucrose octaacetate. At low concentration $(1.0$ or $0.1 \mathrm{mM})$ the slope of the log-log plot of the relaxation rates versus temperature for BDPA is approximately 2 , as expected for the high-temperature limit of the Raman process. ${ }^{12}$ At these low BDPA concentrations the direct process makes a small contribution below about $100 \mathrm{~K}$ (Figure 9). At higher concentrations the temperature dependence is weaker and can be fit to the eq $1 / T_{1}=a$ $(T+b)$, which is characteristic of the direct process. For organic radicals in glassy solvents the coefficient $a$ increases linearly with the square of the concentration of the radicals (data not shown). The contribution from the Raman process to the relaxation for dilute BDPA ( $g=$ 2.0026) samples (Figure 8) is more than an order of magnitude smaller ${ }^{10}$ than the Raman process for the mononitroxide ( $g \sim 2.006$ ) radicals (Figures 7 and 8 ), so the same magnitude of direct process that is significant for BDPA at $100 \mathrm{~K}$ is significant for the nitroxides only at much lower temperatures. Below about $20 \mathrm{~K}$ the weak dependence of relaxation rate on temperature for the diradicals and tetraradicals (Figure 8) is attributed to an intramolecular direct process. The bulk concentrations of the diradical and tetraradical samples $(<1 \mathrm{mM})$ were much lower than the $44 \mathrm{mM}$ BDPA sample, so intermolecular contributions from the direct process are much smaller. The coefficients for the direct process increased in the order monoradical < diradicals < tetraradicals (Table 3 ), which is consistent with increasing local spin concentrations.

Between about 20 and $120 \mathrm{~K}$ the dominant contribution to relaxation is the Raman process. For the radicals with the same structures, the coefficients for the Raman process increase in the order monoradical $\mathbf{1 c}<$ diradical $\mathbf{1 b}<$ tetraradical 1a (Table 3). For these molecules the distribution of phonon energies is approximately constant, and the coefficients for the diradical and tetraradical include modulation of the electron-electron interaction in addition to modulation of the spin-orbit coupling. The order-of-magnitude larger value of $A_{\text {Ram }}$ for tetraradical 1a reflects the larger number of dipolar interactions and/or modulation of the energies of the multiple spin states. For diradical 2a, $A_{\text {Ram }}$ increases in the order glycerol < 4:1 toluene/ $\mathrm{CHCl}_{3}<$ sucrose octaacetate which is the order of decreasing intermolecular 
interactions within the glassy solvents and increasingly softer glasses. For 3_mono, $A_{\operatorname{Ram}}$ is larger than for $\mathbf{1 c}$ or $\mathbf{2 a}$ _mono because of the smaller molecular size. ${ }^{10} A_{\mathrm{Ram}}$ for $\mathbf{3}$ is only slightly larger than for 3_mono (Table 3), consistent with the small impact of electron-electron interaction on $1 / T_{1}$ at this interspin distance.

In 4:1 toluene/ $\mathrm{CHCl}_{3}$ above $130 \mathrm{~K}$, the viscosity of the solvent decreases rapidly with increasing temperature and the increasing rates of molecular reorientation provide additional relaxation pathways (Figure 8). This contribution increases in the order monoradical 1c < diradical $\mathbf{1 b}<$ tetraradical $\mathbf{1 a}$. In the monoradical, reorientation primarily modulates the anisotropy of the nitrogen hyperfine interaction. For the diradical and tetraradical, reorientation also modulates the electron-electron interactions, which are more numerous for the tetraradical than for the diradical. Above the glass transition temperatures relaxation rates for the diradical and tetraradical are too short to measure by SR.

To characterize processes that contribute to spin lattice relaxation in glasses with higher glass transition temperatures, data were obtained in sucrose octaacetate or glycerol (Figure 10). Between about 20 and $100 \mathrm{~K}$ the relaxation rates in these glasses are dominated by the Raman process, and trends in $A_{\mathrm{Ram}}$ are similar to trends in $4: 1$ toluene/ $\mathrm{CHCl}_{3}, \mathbf{2 a}<\mathbf{2 b}<\mathbf{1 b}$ (Table 3). The larger values of $A_{\text {Ram }}$ for $\mathbf{3}$ mono and $\mathbf{3}$ are again attributed to smaller size. The smaller value of $A_{\text {Ram }}$ for $\mathbf{2 a}$ in glycerol than in sucrose octaacetate is due to decreased motion in the more rigid glycerol glass.

Above about $100 \mathrm{~K}$ the spin lattice relaxation rates for diradical 2a in glycerol or sucrose octaacetate and for $\mathbf{2 b}$ in sucrose octaacetate are more strongly temperature-dependent than at lower temperatures, which indicates that there is an additional relaxation process. The contributions from this process are the same at X-band and Q-band which is consistent with a local mode and inconsistent with a thermally activated process. ${ }^{12,43}$ The values of $A_{\text {loc }}$ for 2a in glycerol and sucrose octaacetate are similar, and much larger than for 2a_mono. The larger coefficients for the diradicals indicate that this process is dominated by modulation of the electron-electron interaction. The solvent dependence of $A_{\mathrm{Ram}}$ and solvent independence of $A_{\text {loc }}$ for 2a is different from the behavior for monoradicals, where the contributions from the Raman and local processes are correlated. ${ }^{10}$ The energy of the local mode was estimated as $950 \mathrm{~K}\left(650 \mathrm{~cm}^{-1}\right)$. Below about $1450 \mathrm{~cm}^{-1}$ there are many vibrational modes for $\mathbf{4 a}$ (a model for $\mathbf{2 a}$ ) and for anti-4b and syn-4b (models for $\mathbf{2 b}$ ) that modulate the interspin distance and orientation of the interspin vector. The apparent energy of the local mode falls approximately in the middle of the range and may be a weighted average for several modes. In sucrose octaacetate the larger contribution from the Raman process for $\mathbf{1 b}$ than for $\mathbf{2 a}$ or $\mathbf{2 b}$ (Figure 10) makes the relaxation rates for $\mathbf{1 b}$ sufficiently fast that a local mode contribution with magnitude similar to that for $\mathbf{2 a}$ or $\mathbf{2} \mathbf{b}$ would have little impact on $1 / T_{1}$ for $\mathbf{1 b}$. The differences in the vibrational modes of $\mathbf{1 b}$ also may make the local mode less effective than for $\mathbf{2 a}$ or $\mathbf{2} \mathbf{b}$. For diradical 3 the local mode that contributes above about $250 \mathrm{~K}$ is the same as for $\mathbf{3}$ mono and modulates spin-orbit coupling rather than electron-electron interaction.

At $296 \mathrm{~K}$ in sucrose octaacetate $T_{1}$ for diradicals $\mathbf{1 b}, \mathbf{2 a}$, and $\mathbf{2 b}$ are $1.9,1.5,1.2 \mu \mathrm{s}$, respectively. This temperature is below the glass transition temperature for sucrose octaacetate, so molecular tumbling is too slow to make a significant contribution to the spin-lattice relaxation. ${ }^{11}$ Although at lower temperatures $1 / T_{1}$ for $\mathbf{1 b}$ is much faster than for $\mathbf{2 a}$ or $\mathbf{2 b}$, the substantial contribution of a local mode to the relaxation for $\mathbf{2} \mathbf{a}$ and $\mathbf{2 b}$ is not observed for $\mathbf{1 b}$, and the relaxation rates for the $\mathbf{1 b}, \mathbf{2} \mathbf{a}$, and $\mathbf{2 b}$ are more similar near room temperature than at lower temperatures. These $T_{1}$ values are substantially shorter than $T_{1}$ for $\mathbf{2 a}$ _mono and $\mathbf{1 c}$, which are 16 and 13 $\mu$ s. For diradical 3 , the relaxation rates at room temperatures are still about the same as for 3_mono. 


\subsection{Molecular Flexibility}

To test the suggestion that the faster relaxation rates $\left(1 / T_{1}\right.$ and $\left.1 / T_{\mathrm{m}}\right)$ for $\mathbf{2} \mathbf{b}$ than for $\mathbf{2} \mathbf{a}$ were due to differences in flexibility, optimized geometries and vibrational frequencies were calculated at the unrestricted DFT level (6-31G(d), UB3LYP functional) for model compounds $\mathbf{4 a}$, syn-4b, and anti-4b. There are numerous vibrational modes that impact the interspin distance and orientation of the interspin vector. To get a sense of rigidity, a comparison was based on the six lowest-energy modes (Table 4). The antisymmetric out-of-plane breathing mode has a relatively large amplitude of displacement for the nitroxide oxygens and modulates the relative orientations of the two N-O groups. It is an example of a mode that would be expected to modulate dipolar interaction and be effective in spin-lattice relaxation. This mode has a relatively high frequency of $53.5 \mathrm{~cm}^{-1}$ in $\mathbf{4 a}$ compared with $6.6 \mathrm{~cm}^{-1}$ in syn-4b. In anti-4b this mode corresponds to a combination of the two lowest frequency modes (15.3 and $22.0 \mathrm{~cm}^{-1}$ ) (Table 4). The other low-frequency modes have relatively small amplitudes on the $\mathrm{N}-\mathrm{O}$ atoms and are expected to be much less effective in modulating dipolar interactions. Calculations were not attempted for the much larger calixarenes. Calixarenes $1 \mathbf{a}$ and $\mathbf{1 b}$ possess tert-alkylarylnitroxides that are analogous to $\mathbf{2 b}$, which are expected to contribute to flexibility analogous to $\mathbf{2 b}$. The saturated aliphatic linkages in the calixarenes provide additional lowenergy vibrations that can modulate the spin-spin interaction. These considerations support the proposal that molecular flexibility increases in the order $\mathbf{2} \mathbf{a}<\mathbf{2} \mathbf{b}<\mathbf{1 b}$.

\subsection{Summary of Trends}

For diradical 3 with interspin distance about $9 \AA$, relaxation rates are only slightly faster than for the analogous monoradical 3_mono, which indicates that the impact of nitroxide-nitroxide interaction on electron spin relaxation extends to relatively short distances compared with the relaxation enhancement by rapidly relaxing metals that extends to tens of angstroms. ${ }^{14}$ The inherently slower relaxation rates for the nitroxides makes them less effective in relaxation enhancement. Within the series of diradicals with interspin distances in the range of 5-6 , both $1 / T_{\mathrm{m}}$ and $1 / T_{1}$ increase in the order $\mathbf{2 a}<\mathbf{2} \mathbf{b}<\mathbf{1 b}$. This trend does not correlate with trends in the exchange interactions, $\mathbf{1 b}(J / k=1 \mathrm{~K})<\mathbf{2 b}(J / k \approx 150 \mathrm{~K})<\mathbf{2 a}(J / k>150 \mathrm{~K})$, which suggests that modulation of the exchange interaction is not the dominant contribution to the relaxation. The trends in $1 / T_{1}$ and $1 / T_{\mathrm{m}}$ are therefore attributed to modulation of the dipolar interaction, which is greater for more flexible molecules and for less rigid glasses. The dipolar couplings are small $\left(0.01-0.03 \mathrm{~cm}^{-1}\right)$ relative to thermal and vibrational energies. Although dipolar coupling is not observed in the $\mathrm{CW}$ spectra of the tetraradical, relaxation rates are much faster than for the diradicals. EPR transition energies depend strongly on the electron-electron dipolar coupling, so modulation of the multiple dipolar couplings provides an effective spin relaxation pathway. For the tetraradical the presence of multiple spin states may also contribute to relaxation enhancement.

\section{Conclusion}

Nitroxide-nitroxide interaction at a distance of about $9 \AA$ has little impact on electron spin relaxation in glassy solids. Modulation of the larger electron-electron dipolar interaction at 5-6 $\AA$ is a major contributor to both $1 / T_{1}$ and $1 / T_{\mathrm{m}}$ for diradicals and a tetraradical. The relaxation enhancement is greater in less rigid nonpolar solvents and greater for the tetraradical than for the diradicals. The largest impact on $1 / T_{1}$ is observed below about $20 \mathrm{~K}$ where the direct process dominates. For both monoradicals and diradicals in the low-polarity sucrose octaacetate glass, the Raman process is enhanced relative to that observed in polar hydrogen-bonded glycerol. In glassy solvents at higher temperatures, modulation of the dipolar interaction by a local mode dominates the relaxation for $\mathbf{2} \mathbf{a}$ and $\mathbf{2 b}$ and is solvent-independent. Above the glass softening temperature, modulation of the large dipolar coupling by faster reorientation provides very efficient relaxation pathways and $1 / T_{\mathrm{m}}$ and $1 / T_{1}$ increase rapidly. For the tetraradical, the 
additional energy levels that arise from the multiple exchange interactions, as well as the multiple dipolar interactions, may contribute to enhanced relaxation rates.

\section{Supplementary Material}

Refer to Web version on PubMed Central for supplementary material.

\section{Acknowledgment}

Financial support of this work by NIH/NIBIB EB002807 (G.R.E. and S.S.E.), NSF/CHE-0414936(A.R.), and AFOSR/ FA9550-04-1-0056 (A.R.) is gratefully acknowledged.

We thank Dr. Sumit Mukherjee for providing samples of tetraradical 1a and diradical 1b. Dr. B. M. Sawant prepared 3 in 1983 at the University of Denver.

\section{References and Notes}

(1). Budil DE, Lee S, Saxena S, Freed JH. J. Magn. Reson., Ser. A 1996;120:155.

(2). Freed JH. Biol. Magn. Reson 2005;24:239.

(3). Brown, IM. Electron spin echo studies of relaxation processes in molecular solids. In: Kevan, L.; Schwartz, RN., editors. Time Domain Electron Spin Resonance. John Wiley; New York: 1979. p. 195

(4). Salikhov, KM.; Tsvetkov, YD. Electron spin-echo studies of interactions in solids. In: Kevan, L.; Schwartz, RN., editors. Time Domain Electron Spin Resonance. Wiley; New York: 1979. p. 232

(5). Hubbell WL, Cafiso DS, Altenbach C. Nat. Struct. Biol 2000;7:735. [PubMed: 10966640]

(6). Berliner, LJ.; Eaton, GR.; Eaton, SS., editors. Distance Measurements in Biological Systems by EPR. Vol. 19. Kluwer; New York: 2000. p. 614

(7). Jeschke G. ChemPhysChem 2002;3:927. [PubMed: 12503132]

(8). Winalski CS, Shortkroff S, Mulkern RV, Schneider E, Rosen GM. Magn. Reson. Med 2002;48:965. [PubMed: 12465105]

(9). Armstrong BD, Han S. J. Chem. Phys 2007;127:104508/1. [PubMed: 17867762]

(10). Sato H, Kathirvelu V, Fielding AJ, Bottle SE, Blinco JP, Micallef AS, Eaton SS, Eaton GR. Mol. Phys 2007; 105:2137.

(11). Owenius R, Terry GE, Williams MJ, Eaton SS, Eaton GR. J. Phys. Chem. B 2004;108:9475.

(12). Eaton SS, Eaton GR. Biol. Magn. Reson 2000;19:29.

(13). Kulikov AV, Likhtenshtein GI. Adv. Mol. Relax. Interact. Processes 1977;10:47.

(14). Eaton SS, Eaton GR. Biol. Magn. Reson 2000;19:347.

(15). Rajca A, Mukherjee S, Pink M, Rajca S. J. Am. Chem. Soc 2006;128:13497. [PubMed: 17031963]

(16). Rajca A, Takahashi M, Pink M, Spagnol G, Rajca S. J. Am. Chem. Soc 2007;129:10159. [PubMed: 17655296]

(17). Nakajima A. Bull. Chem. Soc. Jpn 1973;46:1129.

(18). Michon J, Michon P, Rassat A. Nouv. J. Chim 1978;2:619.

(19). Eaton SS, More KM, Sawant BM, Eaton GR. J. Am. Chem. Soc 1983;105:6560.

(20). Spagnol G, Shiraishi K, Rajca S, Rajca A. Chem. Commun 2005:5047.

(21). Sawant BM, Eaton GR, Eaton SS. J. Magn. Reson 1981;45:162.

(22). Spagnol G, Rajca A, Rajca S. J. Org. Chem 2007;72:1867. [PubMed: 17266379]

(23). Hurrey ML, Wallen SL. Langmuir 2006;22:7324. [PubMed: 16893233]

(24). Brinkmann M, Andre JJ. J. Mater. Chem 1999;9:1511.

(25). Quine RW, Eaton SS, Eaton GR. Rev. Sci. Instrum 1992;63:4251.

(26). Hanson GR, Gates KE, Noble CJ, Griffin M, Mitchell A, Benson S. J. Inorg. Biochem 2004;98:903. [PubMed: 15134936]

(27). Eaton SS, Eaton GR. J. Magn. Reson., Ser. A 1995;117:62. 
(28). Du J-L, Eaton GR, Eaton SS. J. Magn. Reson., Ser. A 1995;115:213.

(29). Sato H, Filas BA, Eaton SS, Eaton GR, Romanyukha AA, Hayes R, Rossi AM. Radiat. Meas 2007;42:997.

(30). Borgia GC, Brown RJS, Fantazzini P. J. Magn. Res 1998;132:65.

(31). Borgia GC, Brown RJS, Fantazzini P. J. Magn. Res 2000;147:273.

(32). Zecevic A, Eaton GR, Eaton SS, Lindgren M. Mol. Phys 1998;95:1255.

(33). Zhou Y, Mitri R, Eaton GR, Eaton SS. Curr. Top. Biophys 1999;23:63.

(34). Frisch, MJ.; Trucks, GW.; Schlegel, HB.; Scuseria, GE.; Robb, MA.; Cheeseman, JR.; Montgomery, JA., Jr.; Vreven, T.; Kudin, KN.; Burant, JC.; Millam, JM.; Iyengar, SS.; Tomasi, J.; Barone, V.; Mennucci, B.; Cossi, M.; Scalmani, G.; Rega, N.; Petersson, GA.; Nakatsuji, H.; Hada, M.; Ehara, M.; Toyota, K.; Fukuda, R.; Hasegawa, J.; Ishida, M.; Nakajima, T.; Honda, Y.; Kitao, O.; Nakai, H.; Klene, M.; Li, X.; Knox, JE.; Hratchian, HP.; Cross, JB.; Bakken, V.; Adamo, C.; Jaramillo, J.; Gomperts, R.; Stratmann, RE.; Yazyev, O.; Austin, AJ.; Cammi, R.; Pomelli, C.; Ochterski, JW.; Ayala, PY.; Morokuma, K.; Voth, GA.; Salvador, P.; Dannenberg, JJ.; Zakrzewski, VG.; Dapprich, S.; Daniels, AD.; Strain, MC.; Farkas, O.; Malick, DK.; Rabuck, AD.; Raghavachari, K.; Foresman, JB.; Ortiz, JV.; Cui, Q.; Baboul, AG.; Clifford, S.; Cioslowski, J.; Stefanov, BB.; Liu, G.; Liashenko, A.; Piskorz, P.; Komaromi, I.; Martin, RL.; Fox, DJ.; Keith, T.; Al-Laham, MA.; Peng, CY.; Nanayakkara, A.; Challacombe, M.; Gill, PMW.; Johnson, B.; Chen, W.; Wong, MW.; Gonzalez, C.; Pople, JA. Gaussian 03, revision C.02. Gaussian, Inc.; Wallingford, CT: 2004.

(35). Lajzerowicz-Bonneteau, J. Molecular structure of nitroxides. In: Berliner, LJ., editor. Spin Labeling: Theory and Applications. Academic Press; New York: 1975. p. 239

(36). Dzuba SA. Phys. Lett. A 1996;213:77.

(37). Dzuba SA. Spectrochim. Acta, Part A 2000;56:227.

(38). Freed, JH. Theory of slow tumbling ESR spectra of nitroxides. In: Berliner, LJ., editor. Spin Labeling: Theory and Applications. Academic Press; New York: 1976. p. 53

(39). Du JL, More KM, Eaton SS, Eaton GR. Isr. J. Chem 1992;32:351.

(40). Tsvetkov YD, Dzuba SA. Appl. Magn. Reson 1990;1:179.

(41). Nakagawa K, Candelaria MB, Chik WWC, Eaton SS, Eaton GR. J. Magn. Reson 1992;98:81.

(42). Abragam, A.; Bleaney, B. Electron Paramagnetic Resonance of Transition Ions. Oxford University Press; Oxford: 1970. Spin-spin interactions; p. 552

(43). Zhou Y, Bowler BE, Eaton GR, Eaton SS. J. Magn. Reson 1999;139:165. [PubMed: 10388595] 

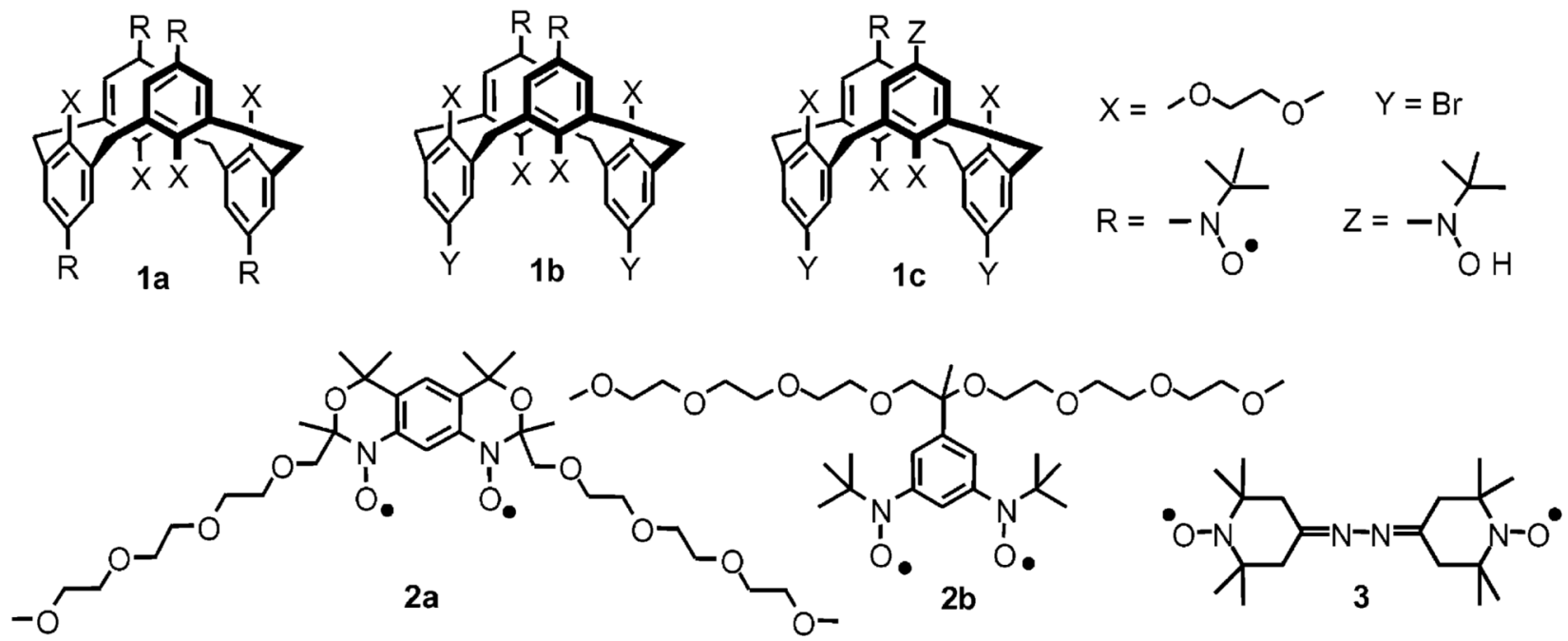

Figure 1.

Structures of nitroxide tetraradical 1a, diradical 1b, and monoradical 1c derivatives of 1,3alternate calix[4]arene, pegylated nitroxide diradicals $\mathbf{2 a}$ and $\mathbf{2 b}$, and azine diradical $\mathbf{3}$. The small amount of monoradical that is present in samples of $\mathbf{2} \mathbf{a}$ is designated as $\mathbf{2} \mathbf{a} \_\mathbf{m o n o}$. monoradical formed by partial reduction of $\mathbf{3}$ is designated as $\mathbf{3} \_$mono. 


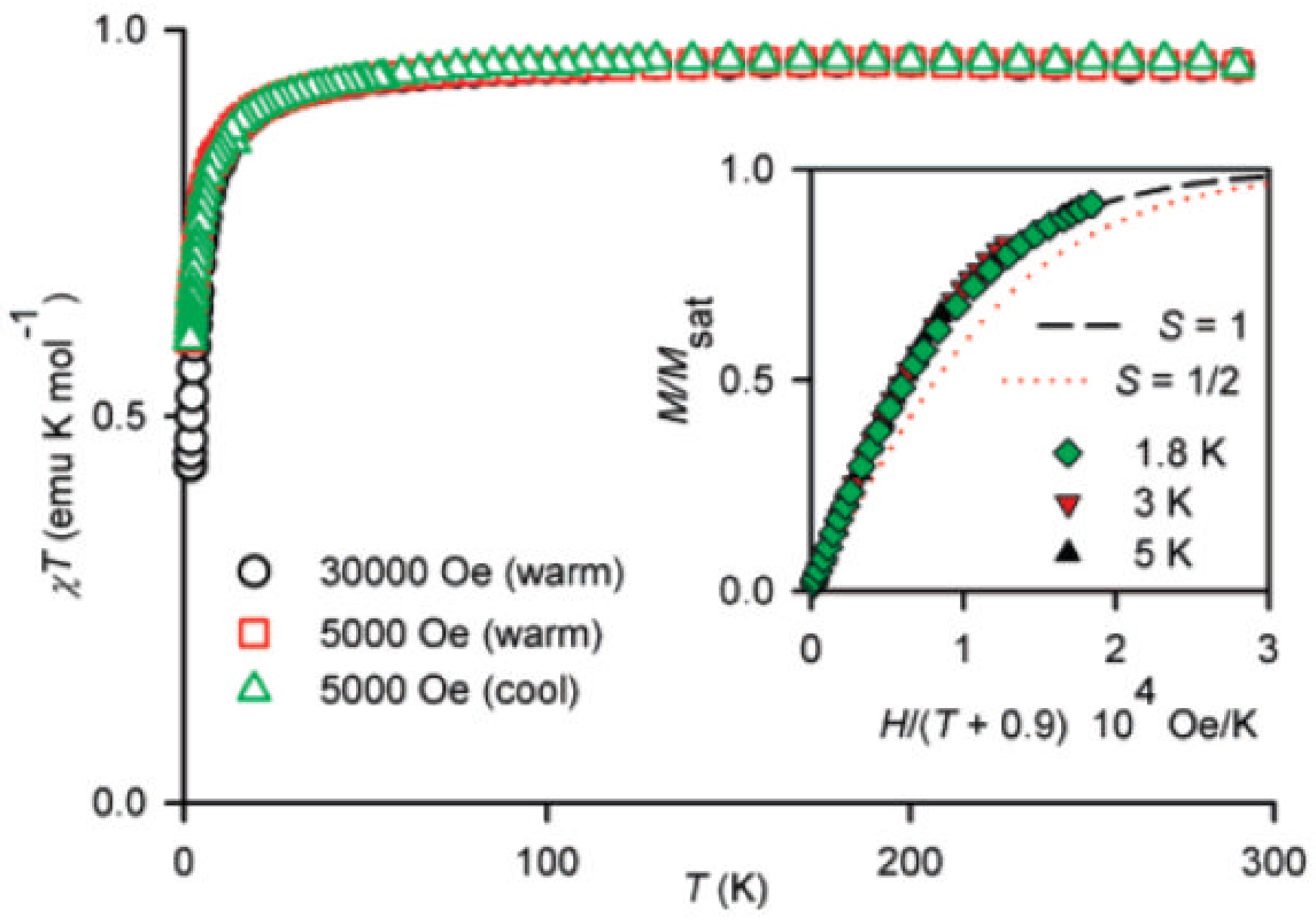

Figure 2.

SQUID magnetometry for solid diradical 2a. The main plot corresponds to $\chi T$ vs $T$ in both cooling and warming modes, with $\chi T \approx 0.96 \mathrm{emu} \mathrm{K} \mathrm{mol}{ }^{-1}$ in the high-temperature range. The inset plot corresponds to $M / M_{\text {sat }}$ vs $H /(T-\theta)$, with dotted and dashed lines showing plots of Brillouin functions with $S=1 / 2$ and $S=1$, respectively; numerical fits to the Brillouin functions with $\theta=-0.9 \mathrm{~K}$ give $S \approx 1.0$ at $1.8,3$, and $5 \mathrm{~K}$. 


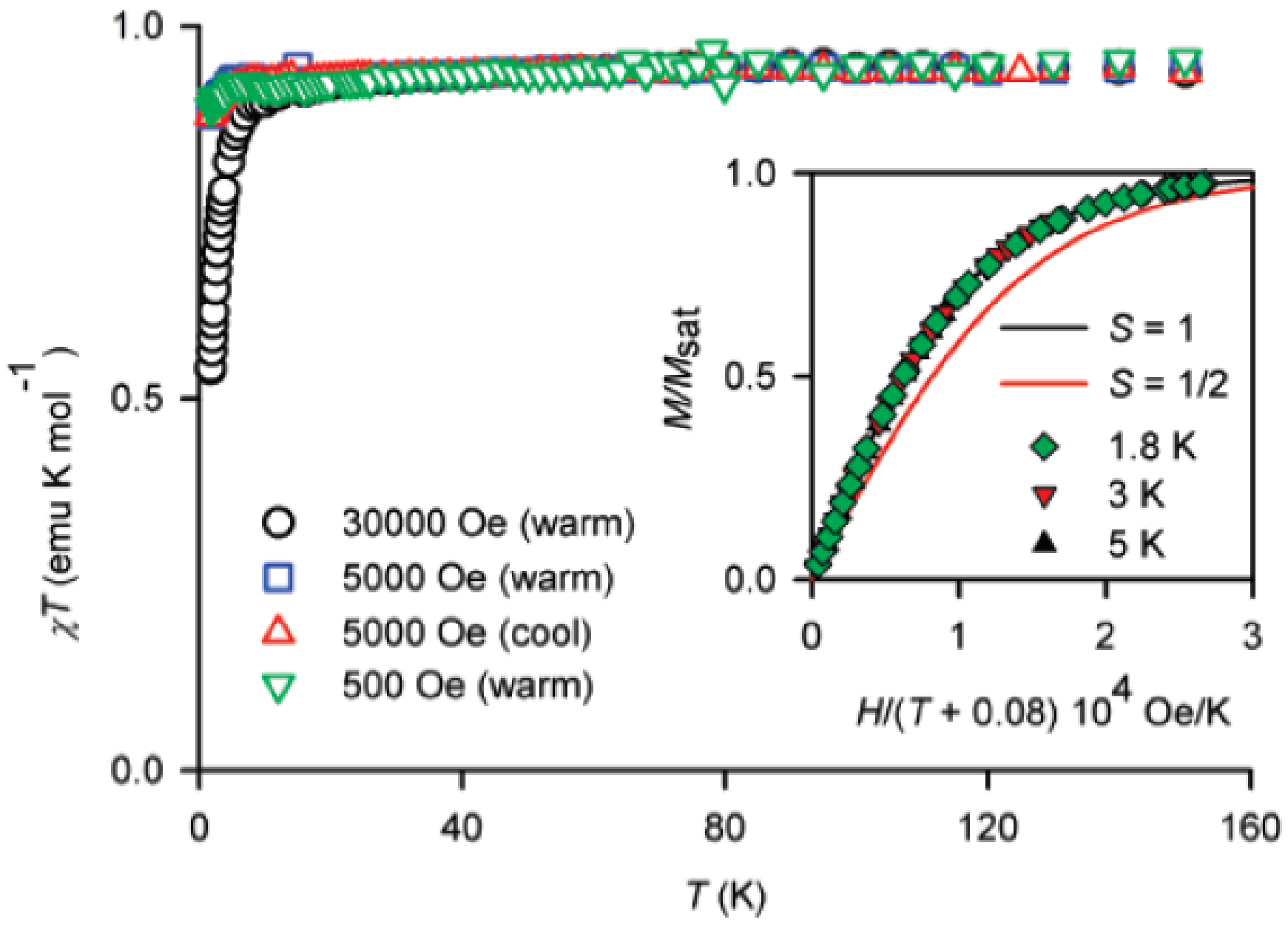

Figure 3.

SQUID magnetometry for $\sim 10 \mathrm{mM}$ diradical $2 \mathbf{a}$ in $\mathrm{EtOH} / \mathrm{H}_{2} \mathrm{O}(2: 1)$. The main plot corresponds to $\chi T$ vs $T$ in both cooling and warming modes, with $\chi T \approx 0.94 \mathrm{emu} \mathrm{K} \mathrm{mol}^{-1}$ in the hightemperature range. The inset plot corresponds to $M / M_{\text {sat }}$ vs $H /(T-\theta)$, with solid lines showing plots of Brillouin functions with $S=1 / 2$ and $S=1$; numerical fits to the Brillouin functions with $\theta=-0.08 \mathrm{~K}$ give $S=1.00$ and $M_{\text {sat }} \approx 0.93 \mu_{\mathrm{B}}$ (per nitroxide site) at $1.8,3$, and $5 \mathrm{~K}$. 


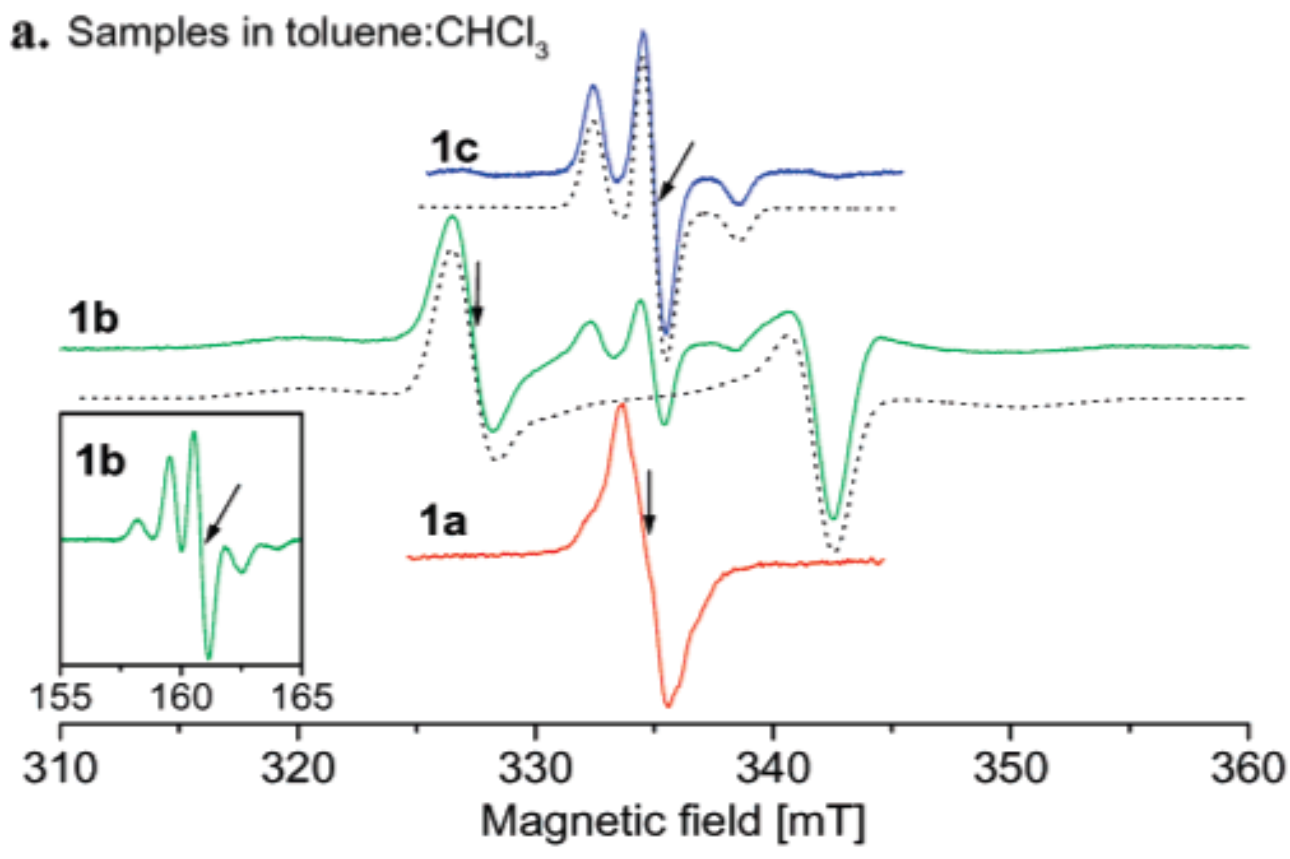

\section{b. Samples in sucrose octaacetate}

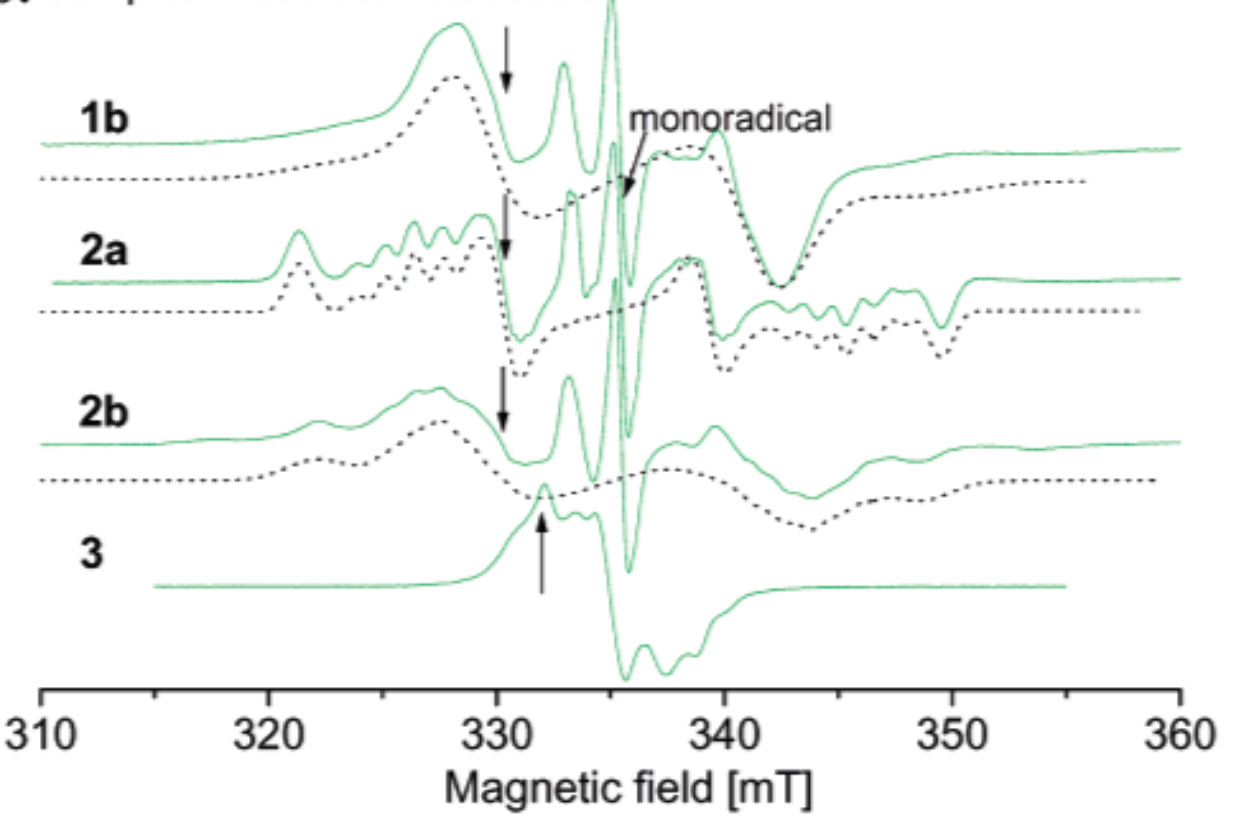

Figure 4.

(a) X-band $\mathrm{CW}$ spectra in toluene/ $\mathrm{CHCl}_{3}$ mixture (4:1) of nitroxide tetraradical $1 \mathrm{a}$ at $50 \mathrm{~K}$, diradical $1 \mathbf{b}$ at $50 \mathrm{~K}$, and monoradical $1 \mathrm{c}$ at $60 \mathrm{~K}$. (b) CW spectra at $294 \mathrm{~K}$ in sucrose octaacetate of diradicals $\mathbf{1 b}, \mathbf{2} \mathbf{a}, \mathbf{2} \mathbf{b}$, and $\mathbf{3}$. The arrows mark the positions in the spectra where the measurements of $T_{1}$ and $T_{\mathrm{m}}$ were performed. Simulated spectra are shown as dashed lines. 


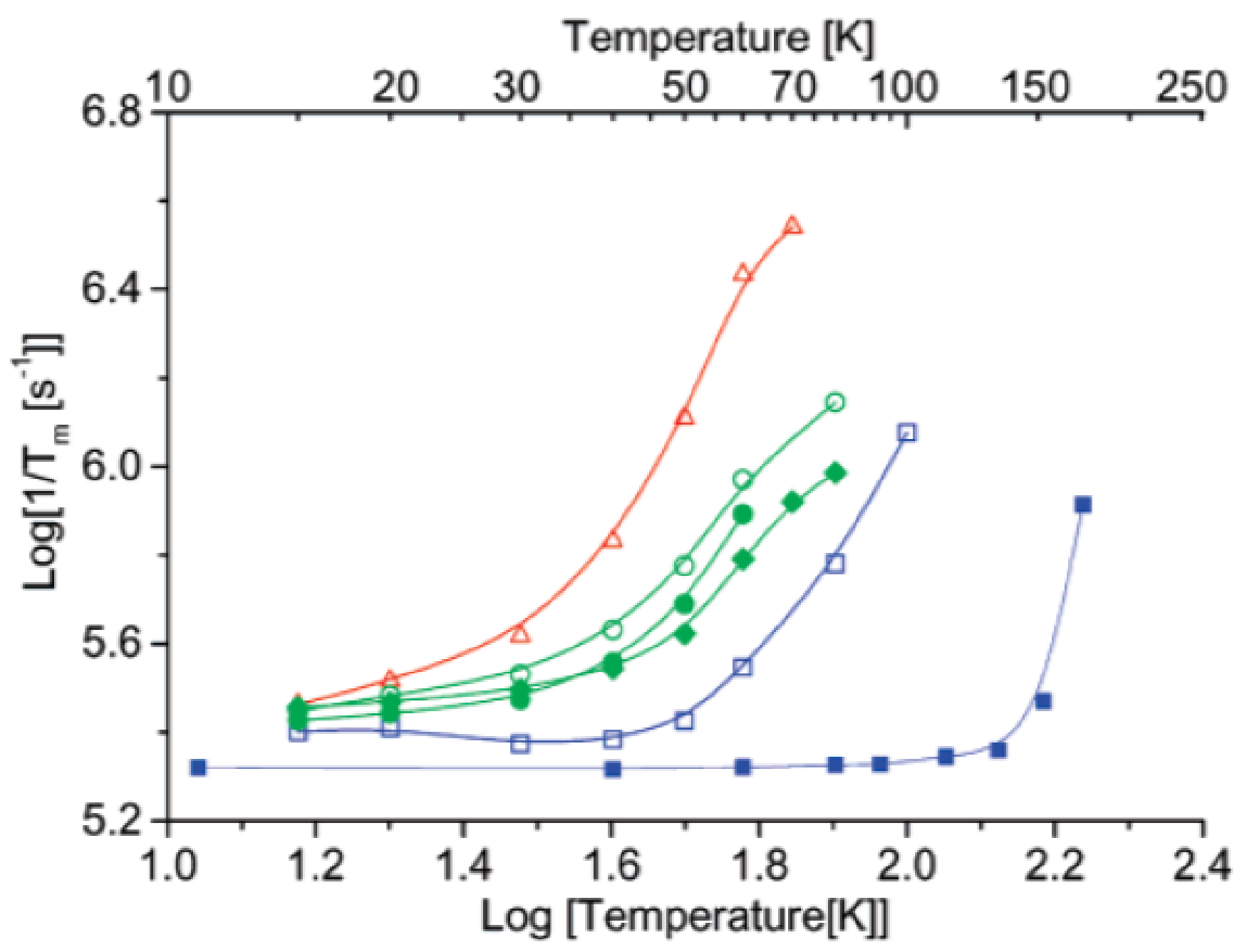

Figure 5.

Temperature dependence of $1 / T_{\mathrm{m}}$ at X-band: (red open triangles) tetraradical 1a, (green open circles) diradical 1b, (green solid diamonds) diradical $\mathbf{2 a}$, (green solid circles) diradical $\mathbf{2 b}$, and (blue open squares) monoradical 1c, in $4: 1$ toluene/ $\mathrm{CHCl}_{3}$, and (blue solid squares) Fremy's salt in water/glycerol. Relaxation rates were estimated by a single-exponential fit. Lines connect the data points. The positions in the $\mathrm{CW}$ spectra at which relaxation rates were measured are shown in Figure 4. 


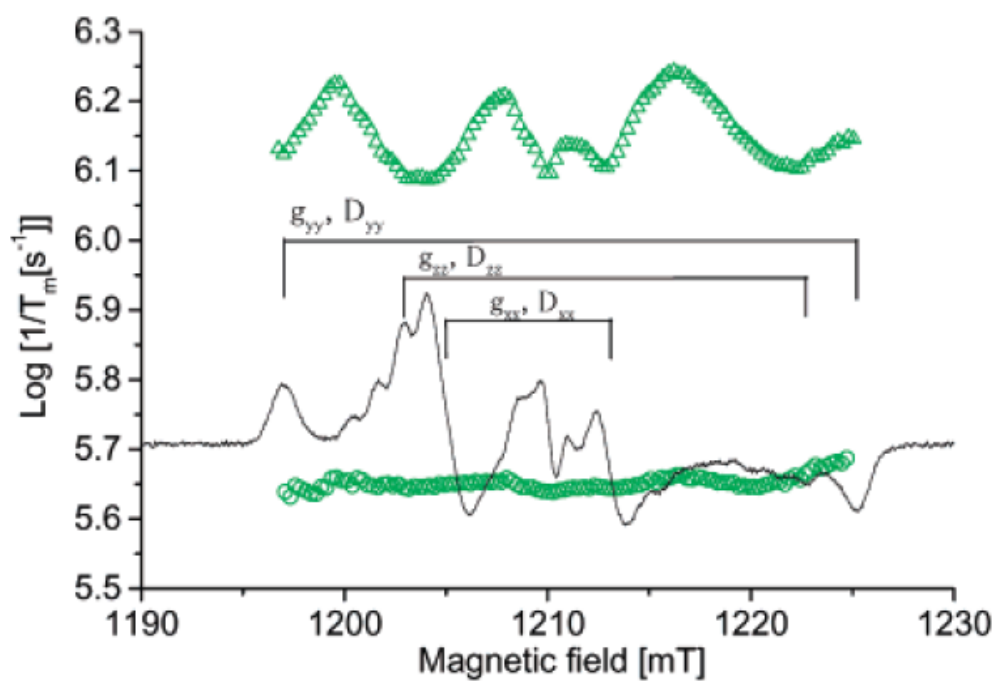

Figure 6.

Dependence of $1 / T_{\mathrm{m}}$ for diradical 2a on position in the spectrum at $86 \mathrm{~K}$ at Q-band in (green circles) glycerol and (green triangles) sucrose octaacetate. Relaxation rates were estimated by a single-exponential fit. The plots of relaxation rates are superimposed on the Q-band CW spectrum in sucrose octaacetate. 


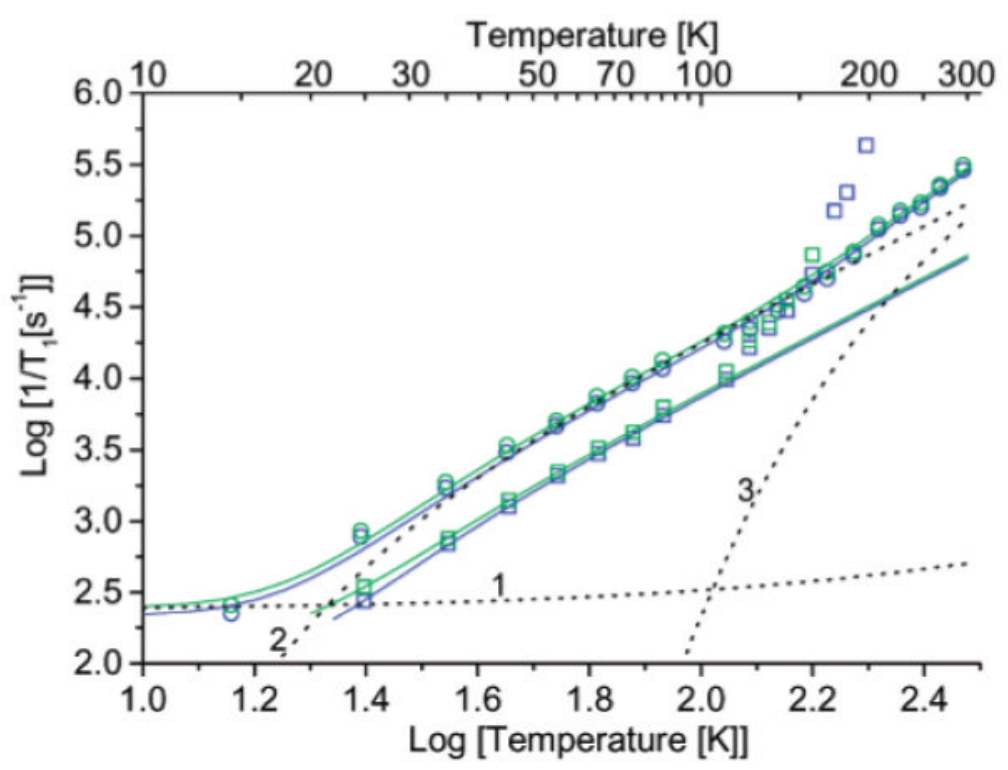

Figure 7.

Comparison of the temperature dependence of $1 / T_{1}$ in $4: 1$ toluene/ $\mathrm{CHCl}_{3}$ for (green squares) $\mathbf{3}$ and (blue squares) 3_mono and in sucrose octaacetate for (green circles) $\mathbf{3}$ and (blue circles) 3a_mono. The dashed lines 1, 2, and 3 are the contributions to the relaxation of $\mathbf{3}$ in sucrose octaacetate calculated for the direct, Raman, and local mode processes, respectively. 


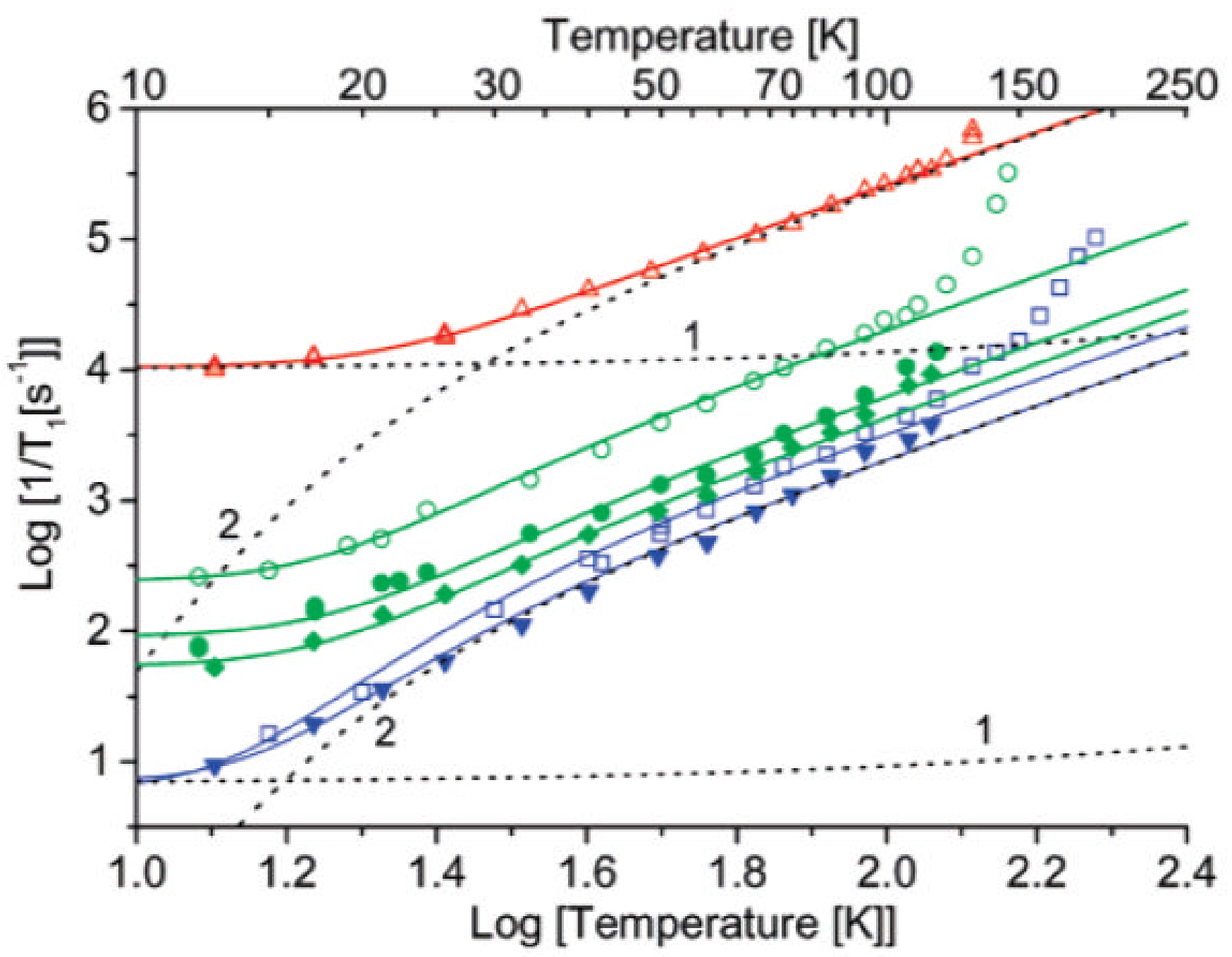

Figure 8.

Spin lattice relaxation $1 / T_{1}$ in $4: 1$ toluene/ $\mathrm{CHCl}_{3}$ at $\mathrm{X}$-band: (red triangles) tetraradical 1a, diradicals ((green open circles) $\mathbf{1 b}$, (green solid circles) $\mathbf{2 b}$, and (green diamonds) 2a) and monoradicals (blue squares) 1c and (blue triangles) 2a_mono) measured by saturation recovery (SR). The positions in the spectra where the data were recorded are marked in Figure $4 \mathrm{~b}$. The dashed lines 1 and 2 are the contributions to the relaxation of $\mathbf{1 a}$ and $\mathbf{1 c}$ calculated for the direct and Raman processes, respectively. The solid lines are calculated using the fit parameters listed in Table 3 and Supporting Information Table S1. 


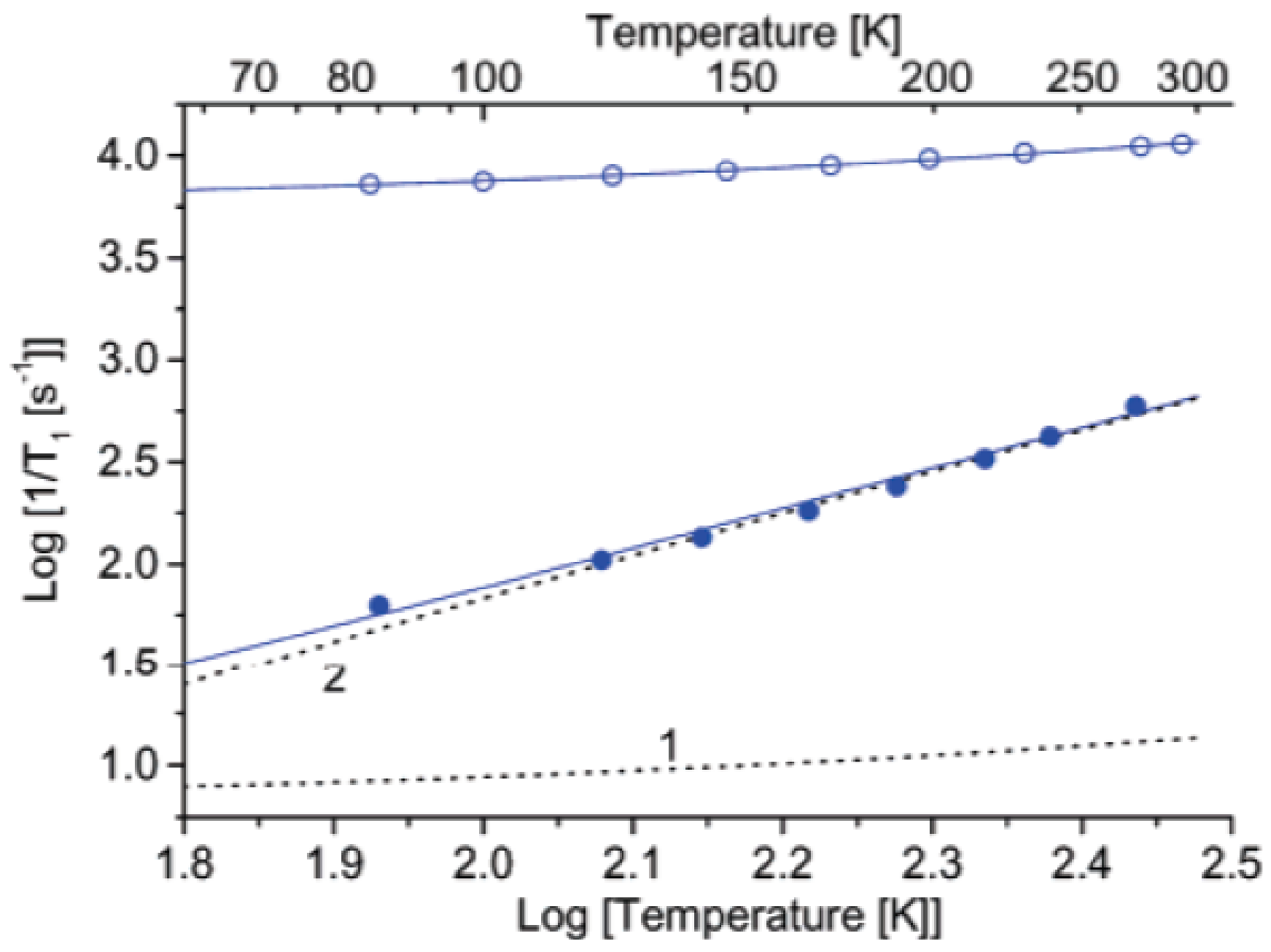

Figure 9.

Temperature dependence of $1 / T_{1}$ for (blue open circles) $44 \mathrm{mM}$ BDPA and (blue solid circles) 1.1 or $0.1 \mathrm{mM}$ BDPA in sucrose octaacetate measured by SR at Q-band. The dashed lines 1 and 2 are the contributions to relaxation calculated for the direct and Raman processes, respectively. 


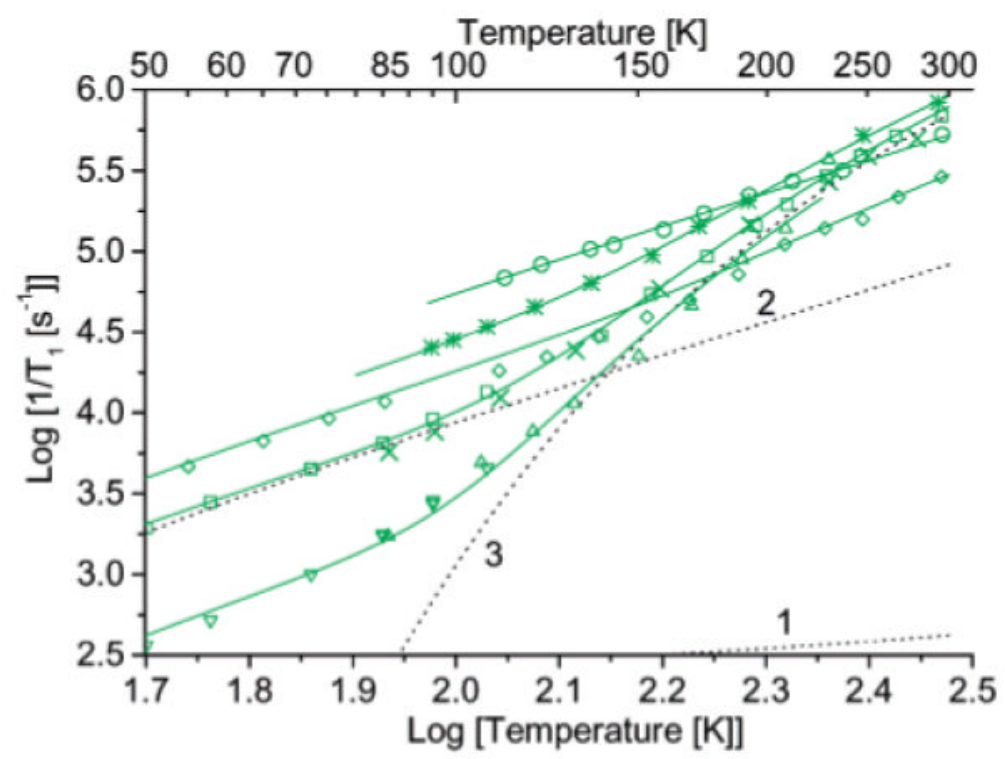

Figure 10.

Temperature dependence of $1 / T_{1}$ for diradicals in sucrose octaacetate: (green circles) $\mathbf{1 b}$ by SR at X-band, (green squares) 2a by SR at X-band, (green crosses) 2a by inversion recovery at Q-band, (green asterisks) $\mathbf{2 b}$ by inversion recovery at X-band, (green diamonds) 3 by saturation recovery (SR) at X-band. Temperature dependence in glycerol: (green down triangles) 2a by SR at X-band and (green up triangles) 2a by SR at Q-band. The positions in the spectra where the data were recorded are marked in Figure $4 \mathrm{~b}$. The solid lines are fit lines calculated with the parameters in Table 3. The dashed lines 1, 2, and 3 are the contributions to relaxation for $\mathbf{2 a}$ in sucrose octaacetate calculated for the direct, Raman, and local mode processes, respectively. 
TABLE 1

Interspin Distances and Exchange Interactions

\begin{tabular}{llll}
\hline compd & $\mathbf{S}$ & $\boldsymbol{r}(\mathbf{\AA})$ & $|\boldsymbol{J} / \boldsymbol{k}|(\mathbf{K})$ \\
\hline $\mathbf{1 a}$ & $2,1^{a}$ & $5-6^{b}$ & $\sim 1^{a}$ \\
$\mathbf{1 b}$ & 1 & $5-6^{c}$ & $\sim 1^{a}$ \\
$\mathbf{2 a}$ & 1 & $5-6^{d}$ & $>150$ \\
$\mathbf{2 b}$ & 1 & $6.0^{e}$ & $\sim 150$ \\
$\mathbf{3}$ & 1 & $8-9^{f}$ & $>0.1$ \\
\hline
\end{tabular}

${ }^{a}$ Determined by magnetic susceptibility (ref 15 ).

${ }^{b}$ Calculated from the X-ray crystal structure ( $(\mathrm{ref} 15)$.

${ }^{c}$ Estimated interspin distances calculated from the dipolar splitting, the X-ray crystal structure, and the relative intensity of the half-field transitions are 5.7, 5-6, and $5.7 \AA$, respectively (ref 15).

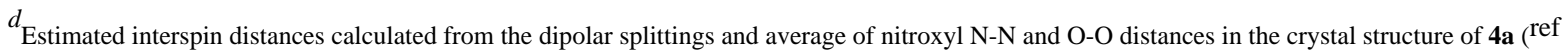

16 ) (which does not account for spin delocalization into the aromatic ring) are 5.8 and $4.8 \AA$, respectively.

$e^{e}$ The interspin distance calculated from the dipolar splitting is 6.0 A. For the two isomers the average of N-N and O-O distances in the structures calculated by DFT are 4.9 and $6.2 \AA$, respectively.

$f_{\text {Determined from dipolar splittings ( }}$ (ef 18), single-crystal EPR (ref 17), and the relative intensity of the half-field transitions ( ${ }^{\text {ref }} 19$ ). 


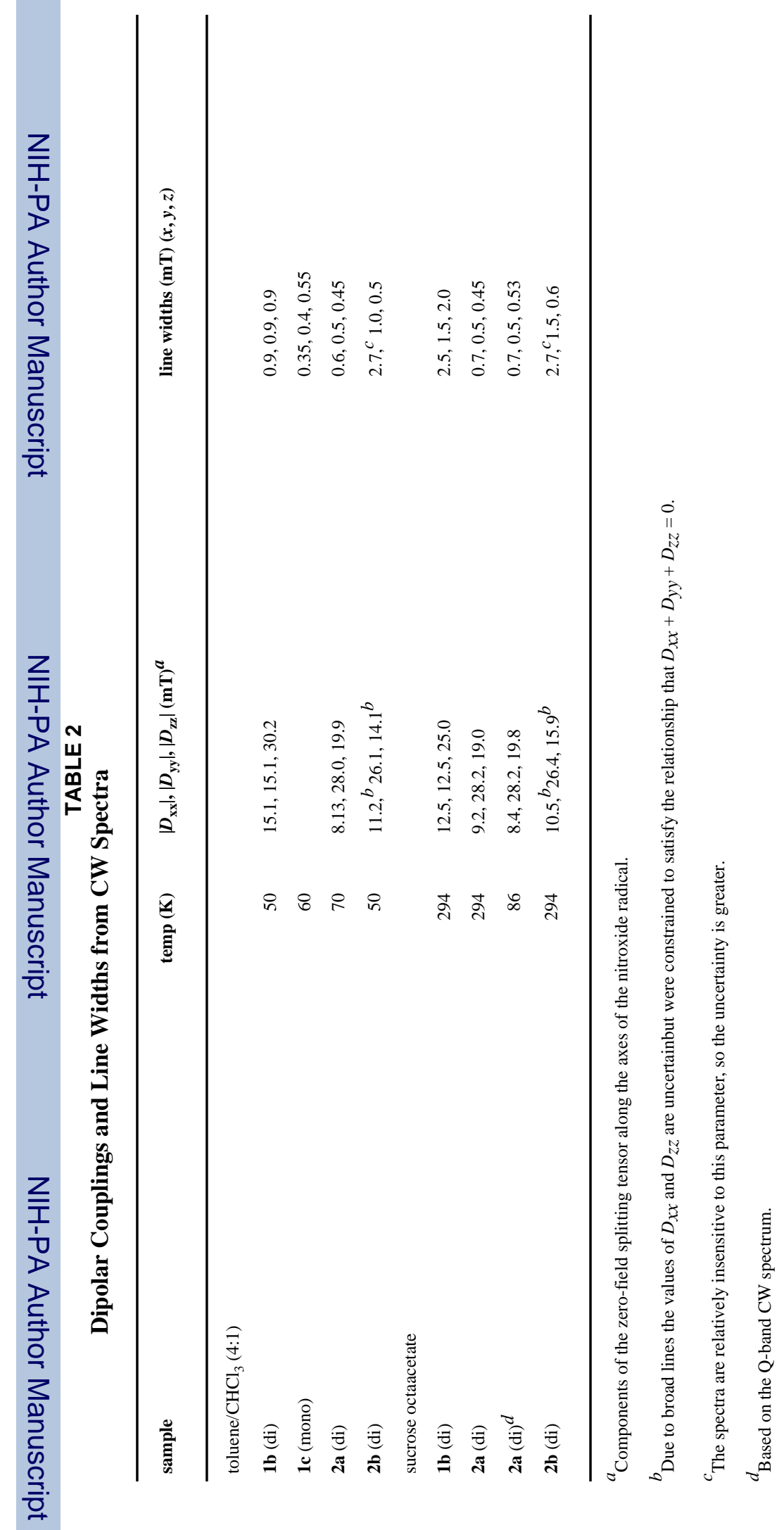


TABLE 3

Fit Parameters for Temperature Dependence of $1 / T_{1}$

\begin{tabular}{|c|c|c|c|c|}
\hline structure & solvent & $\operatorname{direct}^{a}$ & $\operatorname{Raman}^{b}$ & local mode ${ }^{c}$ \\
\hline $1 \mathbf{a}$ (tetra) & 4:1 toluene/ $\mathrm{CHCl}_{3}$ & 37 & $184 \times 10^{4}$ & \\
\hline $\mathbf{1 b}(\mathrm{di})$ & 4:1 toluene/ $\mathrm{CHCl}_{3}$ & 0.88 & $14 \times 10^{4}$ & \\
\hline $2 a(d i)$ & 4:1 toluene/ $\mathrm{CHCl}_{3}$ & 0.2 & $3.1 \times 10^{4}$ & \\
\hline $2 \mathbf{b}(\mathrm{di})$ & 4:1 toluene/ $\mathrm{CHCl}_{3}$ & 0.33 & $4.6 \times 10^{4}$ & \\
\hline 3 & 4:1 toluene/ $\mathrm{CHCl}_{3}$ & $d$ & $5.7 \times 10^{4}$ & \\
\hline 1c (mono) & 4:1 toluene/ $\mathrm{CHCl}_{3}$ & 0.02 & $2.4 \times 10^{4}$ & \\
\hline 2a_mono & 4:1 toluene/ $\mathrm{CHCl}_{3}$ & 0.02 & $1.5 \times 10^{4}$ & \\
\hline 3_mono & 4:1 toluene/ $\mathrm{CHCl}_{3}$ & $d$ & $5.4 \times 10^{4}$ & \\
\hline $\mathbf{1 b}(\mathrm{di})$ & sucrose octaacetate & $e$ & $41 \times 10^{4}$ & \\
\hline $\mathbf{2 a}(\mathrm{di})$ & sucrose octaacetate & $e$ & $6.5 \times 10^{4}$ & $15 \times 10^{6}$ \\
\hline $2 \mathbf{b}(\mathrm{di})$ & sucrose octaacetate & $e$ & $21 \times 10^{4}$ & $14 \times 10^{6}$ \\
\hline 3 & sucrose octaacetate & $e$ & $13 \times 10^{4}$ & $2.8 \times 10^{6}$ \\
\hline 2a_mono & sucrose octaacetate & $e$ & $3.2 \times 10^{4}$ & $0.64 \times 10^{6}$ \\
\hline 3_mono & sucrose octaacetate & $e$ & $12 \times 10^{4}$ & $2.8 \times 10^{6}$ \\
\hline 2a (di) & glycerol & $<0.02$ & $1.5 \times 10^{4}$ & $13 \times 10^{6}$ \\
\hline
\end{tabular}

\footnotetext{
${ }^{a}$ Direct process from dipolar interaction; $\left.1 / T_{1}\right) a(T+270)$.

${ }^{b}$ Raman process with Debye temperature fixed at $100 \mathrm{~K}$.

${ }^{c}$ Local mode with a fixed vibration energy of $950 \mathrm{~K}$.

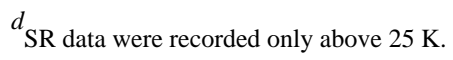

${ }^{e}$ SR data in sucrose octaacetate were recorded primarily at temperatures where the contribution from the direct process was not significant.
} 
TABLE 4

Lowest Vibrational Frequencies for Triplet States of Model Nitroxide Diradicals Calculated at the UB3LYP/ 6-31G(d) Level

W Animations of selected vibrational modes of W 4a, W syn-4b, and W anti-4b in JMol format are available.

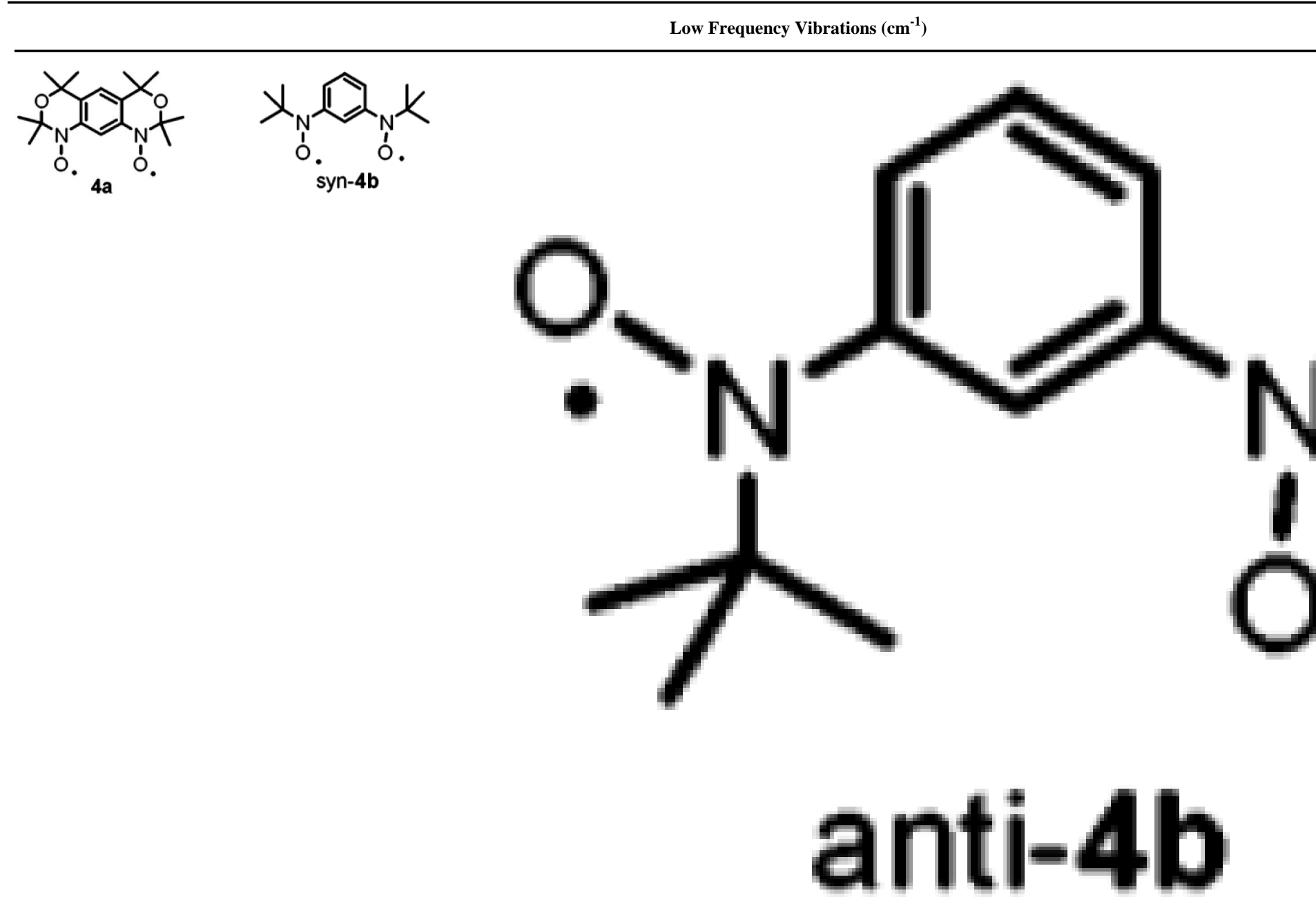

\begin{tabular}{ccc}
\hline 29.7 & $6.6^{*}$ & $15.3^{*}$ \\
31.2 & 10.5 & $22.0^{*}$ \\
$53.5^{*}$ & 43.9 & 41.0 \\
78.2 & 68.1 & 68.7 \\
127.2 & 84.0 & 76.1 \\
127.9 & 105.0 & 92.5 \\
\hline
\end{tabular}

\footnotetext{
* Antisymmetric out-of-plane breathing mode, which is an example of a vibration that modulates electron-electron dipolar coupling.
} 


\section{Supporting Information}

\section{Impact of the modulation of electron-electron dipolar interaction on electron spin relaxation of nitroxide diradicals and tetraradical in glassy solvents between 10 and $300 \mathrm{~K}$}

\section{Hideo Sato, Velavan Kathirvelu, Gaëlle Spagnol, Suchada Rajca, Andrzej Rajca, Sandra S. Eaton, and Gareth R. Eaton}

\section{Department of Chemistry and Biochemistry, University of Denver, Denver, CO 80208-2436 and Department of Chemistry, University of Nebraska, Lincoln, NE 68588-0304}

\section{Table of Content}

(1) Preparation of calix[4]arene nitroxide monoradical 1c.

(2) Table S1. g values and nitrogen hyperfine couplings

(3) Figure S1. Saturation recovery curves and fit line calculated for a log-normal distributions of $T_{1}$ for tetraradical 1a, diradical $\mathbf{1 b}$ and monoradical $1 \mathbf{c}$ in $4: 1$ toluene: $\mathrm{CHCl}_{3}$ at $50 \mathrm{~K}$.

(4) Figure S2: EPR spectrum of $\mathbf{2 a}$ in EtOH/water (2:1) at $140 \mathrm{~K}$.

(5) Figure S3: Temperature dependence of dipolar splittings for $\mathbf{2 a}$ in sucrose octaacetate.

(6) Figure S4: Temperature dependence of exponent $x$ (Equation [3] for spin echo decays in 4:1 toluene: $\mathrm{CHCl}_{3}$.

(7) Figure S5: Dependence of $1 / T_{1}$ on position in the spectrum of tempone and $\mathbf{2 a}$ in glycerol or sucrose octaacetate at $86 \mathrm{~K}$.

(8) Figure S6: Dependence of $1 / T_{1}$ on position in the spectrum of 3 in $4: 1$ toluene: $\mathrm{CHCl}_{3}$ or sucrose octaacetate at $86 \mathrm{~K}$.

(9) Discussion of Figures S5 and S6.

(10) DFT calculations on nitroxide diradicals $\mathbf{4 a}$, anti-4b, and syn-4b.

\section{Preparation of Calix[4]arene Nitroxide Monoradical 1c.}
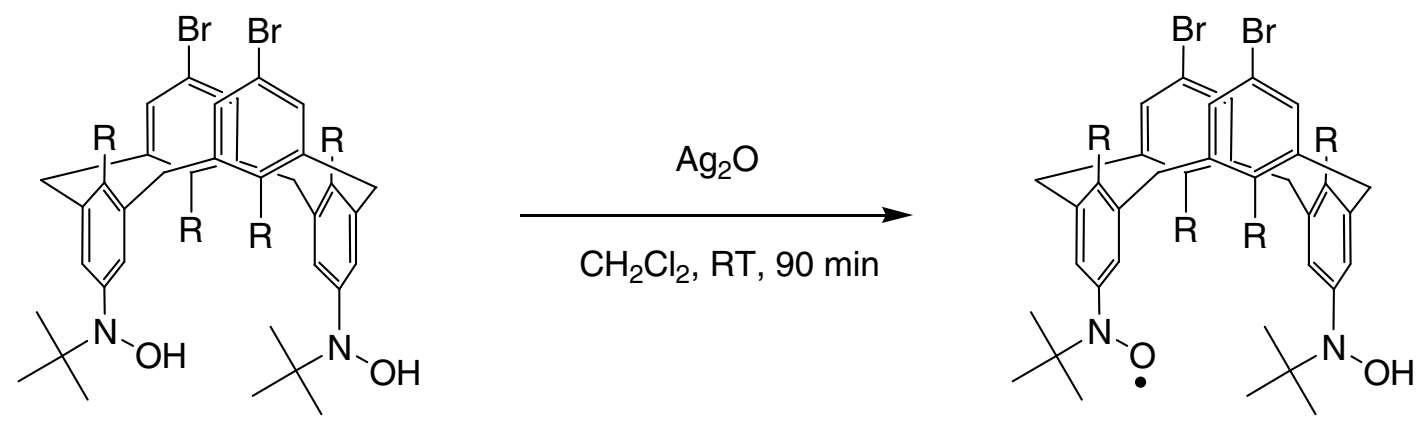

$\mathrm{R}=\mathrm{OCH}_{2} \mathrm{CH}_{2} \mathrm{OCH}_{3}$

A solution of the dihydroxylamine $(34.9 \mathrm{mg}, 0.0353 \mathrm{mmol}, 1$ equiv) in degassed chloroform (3.0 $\mathrm{mL}$ ) was added onto freshly prepared silver oxide (328 mg, $1.41 \mathrm{mmol}, 40$ equiv). The reaction mixture, protected from light, was stirred vigorously at room temperature for $\sim 90 \mathrm{~min}$. The crude mixture was centrifuged and the supernatant liquid was filtered through a $0.45-\mu \mathrm{m}$ filter (Fisher) to remove silver oxide. Concentration under reduced pressure gave a dark orange solid (33.1 $\mathrm{mg}$ ), which was purified by flash chromatography (TLC-grade silica gel, gradient hexane/ether, 7:3 to 5:5). The silica pad was kept at low temperature, between -5 and $0^{\circ} \mathrm{C}$, by a sleeve filled with EtOH cooled with dry ice. The target material was collected as a pale orange pinkish band $(1.3 \mathrm{mg})$. The EPR spectrum of 1c in glassy 4:1 toluene: $\mathrm{CHCl}_{3}$ is shown in Figure 5a, top trace. The $\mathrm{g}$ and $\mathrm{A}$ values are included in Table S1. 


\section{Table S1}

$\mathrm{g}$ values and Nitrogen Hyperfine Couplings

\begin{tabular}{l|lll}
\hline Sample & $\begin{array}{l}\text { Temp } \\
(\mathrm{K})\end{array}$ & $g_{\mathrm{xx}}, g_{\mathrm{yy}}, g_{\mathrm{zz}}$ & $\begin{array}{l}A_{\mathrm{zz}} \\
(\mathrm{G})^{\mathrm{a}}\end{array}$ \\
\hline $\begin{array}{l}\text { Toluene: } \mathrm{CHCl}_{3} \\
(4: 1)\end{array}$ & & & \\
1b (di) & 50 & $2.0093,2.0058,2.0026$ & $15.4^{\mathrm{b}}$ \\
1c (mono) & 60 & $2.0091,2.0056,2.0024$ & 30.8 \\
2a (di) & 70 & $2.0089,2.0055,2.0024$ & 12.5 \\
2b (di) & 50 & $2.0091,2.0060,2.0025$ & 12 \\
\hline sucrose octaacetate & & & \\
1b (di) & 294 & $2.0080,2.0043,2.0022$ & $15.4^{\mathrm{b}}$ \\
2a (di) & 294 & $2.0089,2.0054,2.0025$ & 12.5 \\
2a (di) & & & \\
2b (di) & 86 & $2.0087,2.0050,2.0021$ & 12.7 \\
\hline
\end{tabular}

${ }^{a}$ Hyperfine values $A_{\mathrm{xx}}$ and $A_{\mathrm{yy}}$ were not resolved but were assumed to be in the range of 2 to $3 \mathrm{G}$, which is half the value for the monoradical.

${ }^{\mathrm{b}} A_{\mathrm{zz}}$ was not resolved in the spectrum and was assumed to be half the value for the monoradical. 


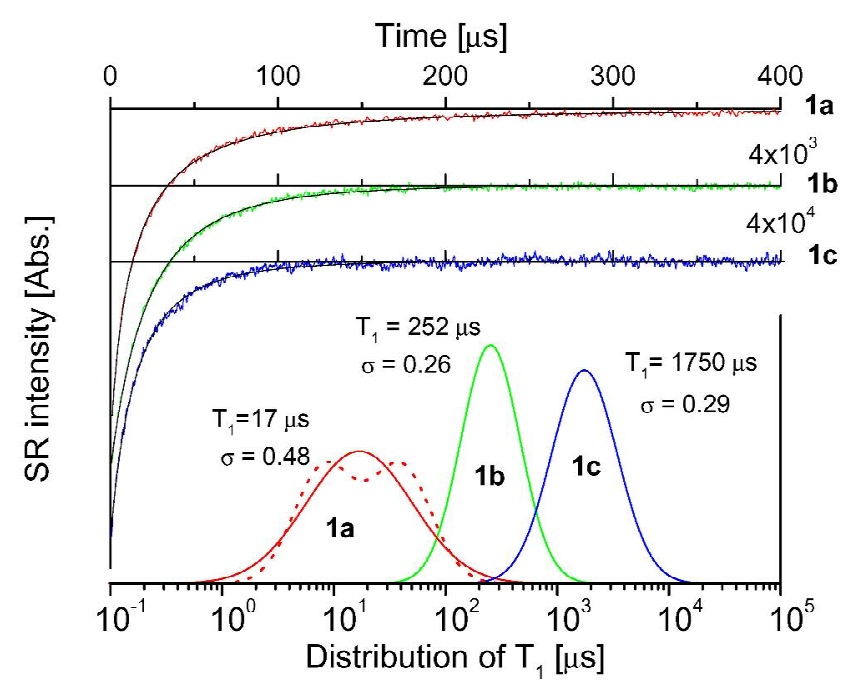

Figure S1. Saturation recovery curves and fit line calculated for a log-normal distributions of $T_{1}$ for tetraradical 1a, diradical $\mathbf{1 b}$ and monoradical $\mathbf{1 c}$ in $4: 1$ toluene: $\mathrm{CHCl}_{3}$ at $50 \mathrm{~K}$. The distributions, distribution widths and values of $T_{1}$ are shown in the lower part of the figure. An alternate modeling of the data for tetraradical 1a as the sum of two distributions is also shown.

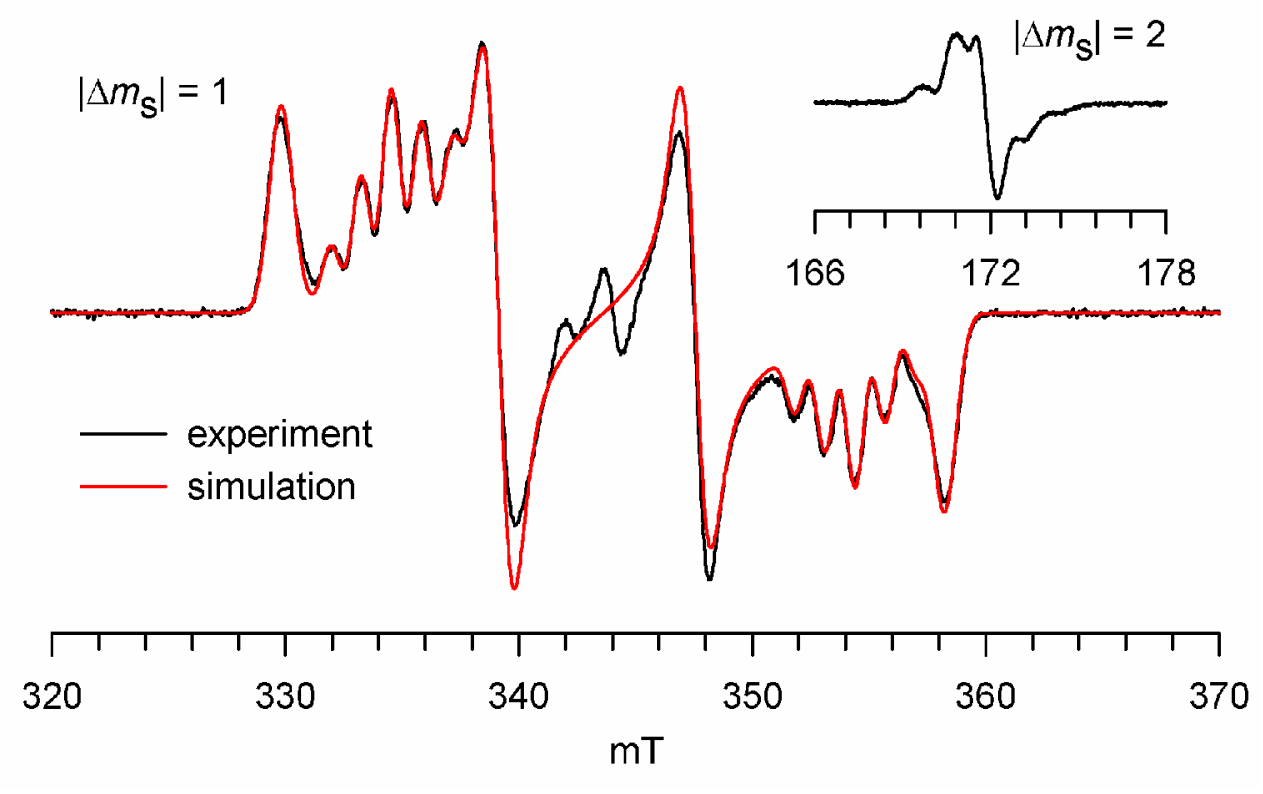

Figure S2. EPR (X-Band, $9.6545 \mathrm{GHz})$ spectrum of $0.7 \mathrm{mM}$ nitroxide diradical 2a in ethanol/water (2 : 1) at $140 \mathrm{~K}$. The spectral simulation of the $\left|\Delta m_{\mathrm{s}}\right|=1$ region is shown as red trace. The fitting parameters for the spectral simulation to the $S=1$ state are: $|D / h c|=1.328 \times 10^{-2} \mathrm{~cm}^{-1},|E / h c|=1.75 \times$ $10^{-3} \mathrm{~cm}^{-1},\left|A_{\mathrm{yy}} / 2 h c\right|=1.20 \times 10^{-3} \mathrm{~cm}^{-1}, g_{\mathrm{x}}=2.0086, g_{\mathrm{y}}=2.0022, g_{\mathrm{z}}=2.0051$, Gaussian line $\left(L_{\mathrm{x}}=10 \mathrm{G}\right.$, $L_{\mathrm{y}}=7.5 \mathrm{G}, L_{\mathrm{z}}=10 \mathrm{G}$ ). The center lines correspond to an $S=1 / 2$ (monoradical) impurity. The molecular $x$-, $y$-, and $z$-axes for this spectral simulation are set to correspond to the increasing values of the principal components for the spin-spin magnetic dipole tensor, as implemented in WINEPR SimFonia 1.25 . 
a.

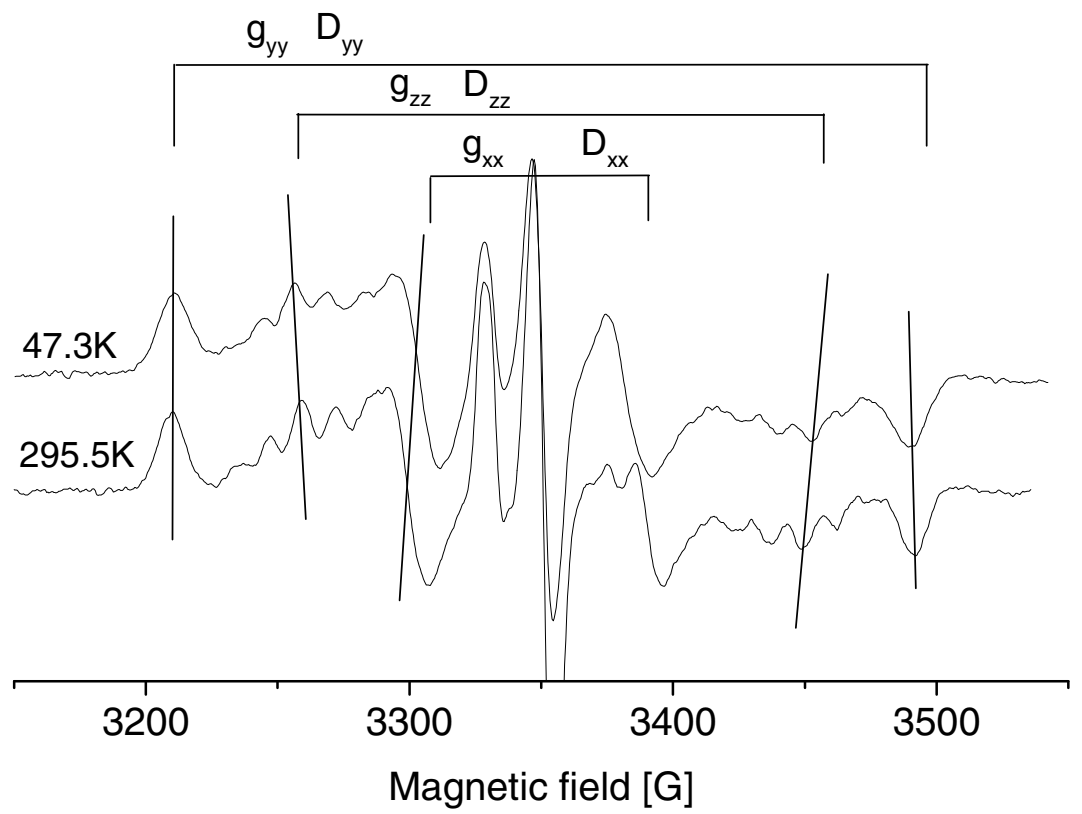

b.

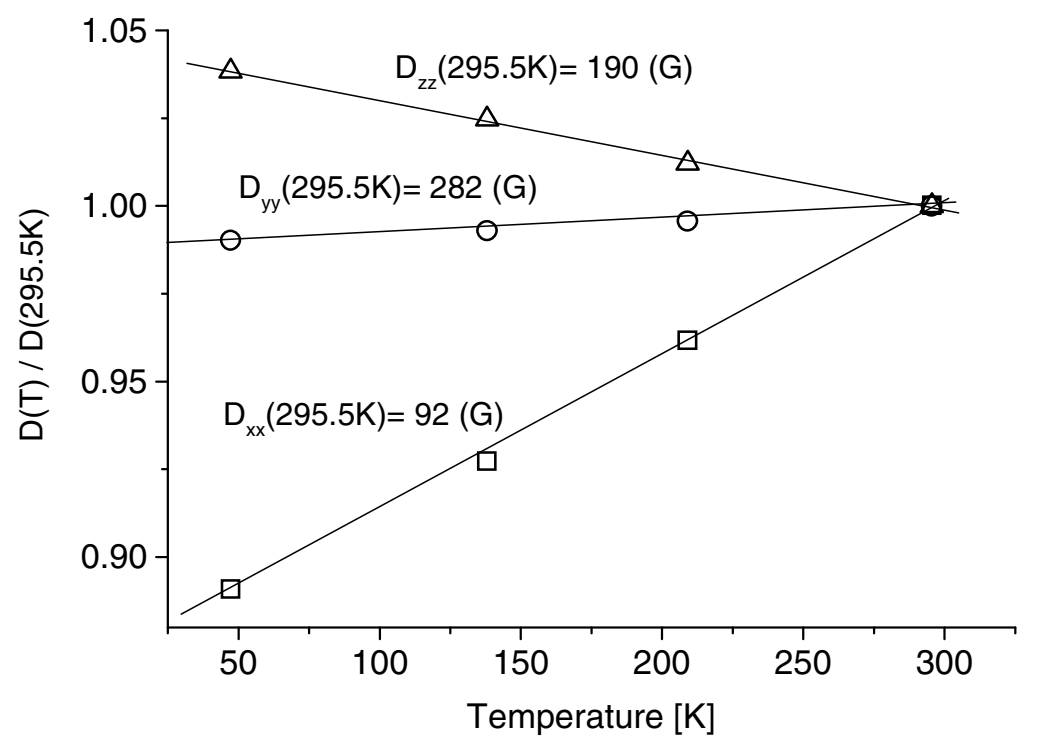

Figure S3. (a) Temperature dependence of X-band CW spectra of diradical 2a in sucrose octaacetate; (b) temperature dependence of dipolar couplings $D_{\mathrm{xx}}, D_{\mathrm{yy}}$ and $D_{\mathrm{zz}}$ normalized to the values at $295.5 \mathrm{~K}$. 


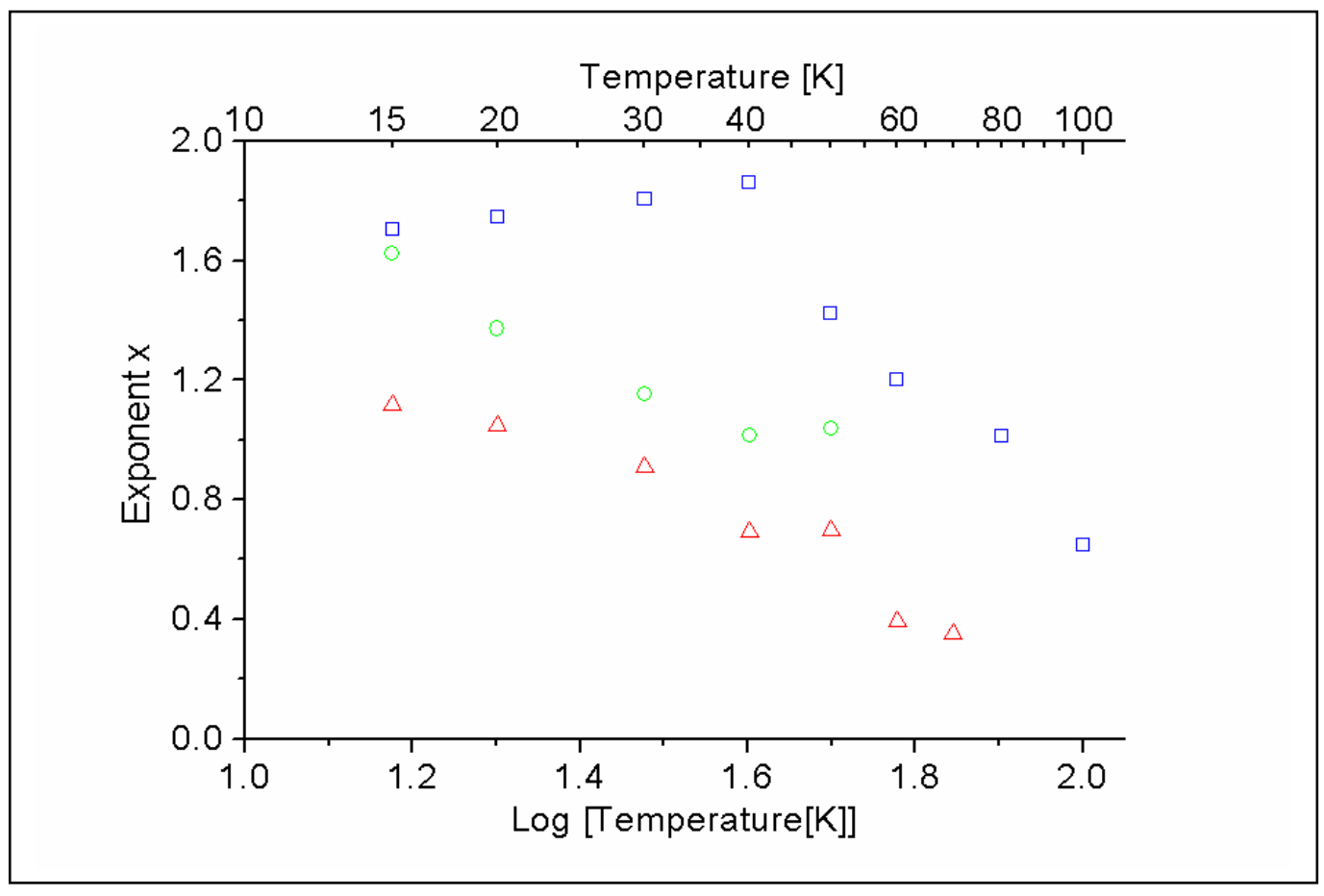

Figure S4: Temperature dependence of exponent $x$ (Equation [3] for spin echo decays for $(\triangle)$ tetraradical 1a, (O) diradical 1b, and $(\square)$ monoradical 1c in 4:1 toluene: $\mathrm{CHCl}_{3}$.

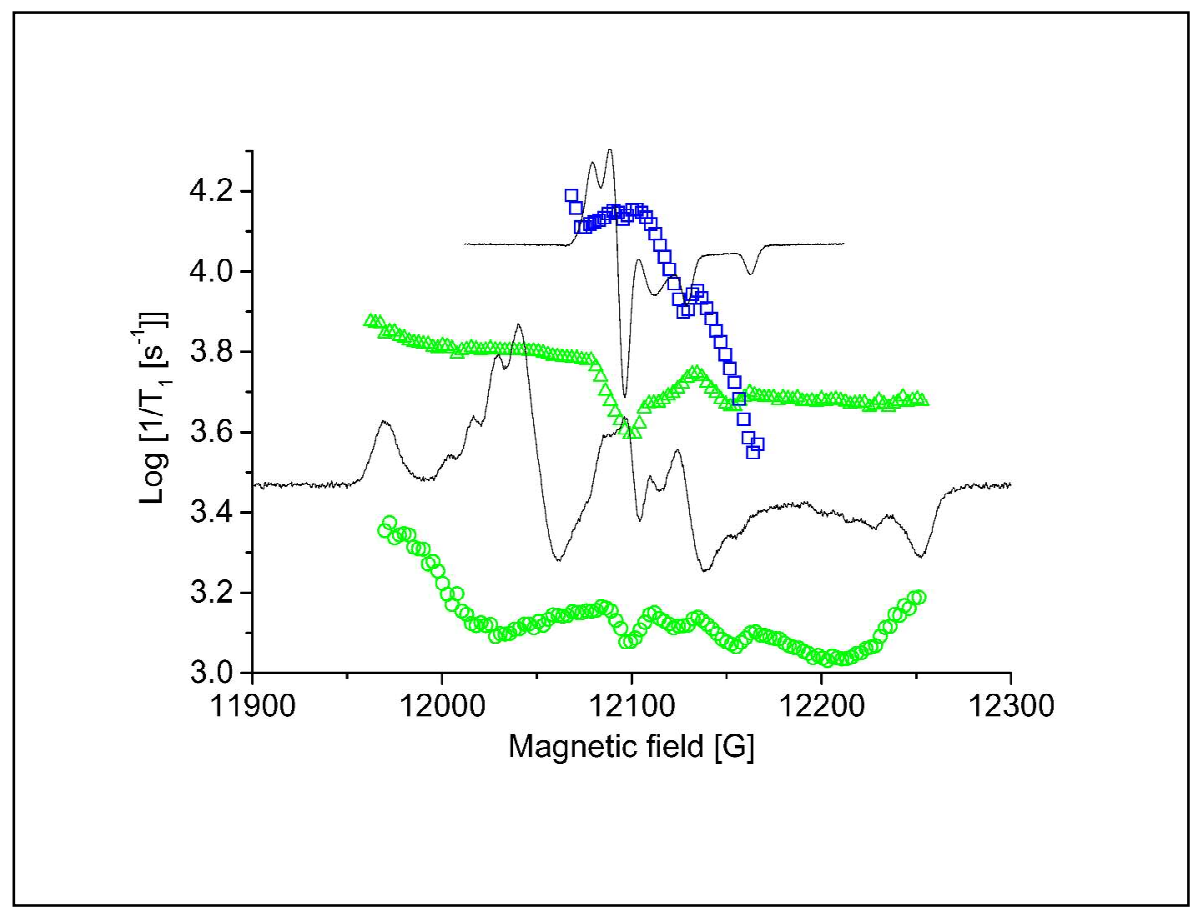

Figure S5. Dependence of $1 / \mathrm{T}_{1}$ on position in Q-band spectra at $86 \mathrm{~K}$ : ( $\square$ ) tempone in sucrose octaacetate, $(\bigcirc)$ diradical $\mathbf{2 a}$ in glycerol, and $(\triangle)$ diradical $\mathbf{2 a}$ in sucrose octaacetate. Relaxation rates were estimated by a single exponential fit. The relaxation rates are superimposed on $\mathrm{CW}$ spectra in sucrose octaacetate. 


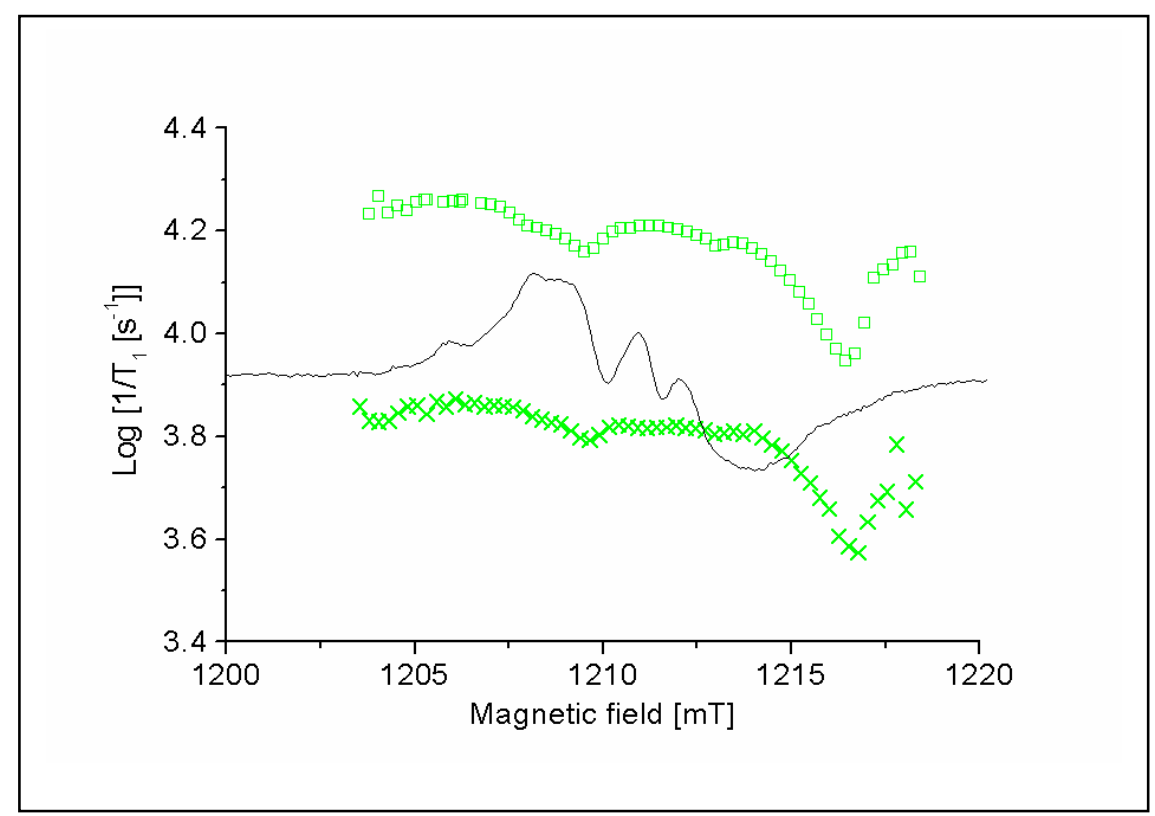

Figure S6. Dependence of $1 / \mathrm{T}_{1}$ on position for diradical 3 in Q-band spectra at $86 \mathrm{~K}:$ ( $\square$ ) in sucrose octaacetate and (x) in 4:1 toluene: $\mathrm{CHCl}_{3}$. Relaxation rates were estimated by a single exponential fit. The relaxation rates are superimposed on $\mathrm{CW}$ spectra in sucrose octaacetate.

\section{Discussion of Figures S5 and S6.}

Dependence of $1 / \mathbf{T}_{1}$ on Position in the $\mathbf{C W}$ Spectra. To enhance orientation selectivity these experiments were performed primarily at Q-band. The variation with position in the spectrum of $1 / T_{1}$ for nitroxide radicals has been reported at X-band. ${ }^{1}$ The maximum rates, which are observed near $g_{\mathrm{xx}}$ and $g_{\mathrm{yy}}$, are about a factor of 4 faster than the minimum rates that are observed at $g_{\mathrm{zz}}$. This dependence is clearly resolved at Q-band for tempone in sucrose octaacetate at $86 \mathrm{~K}$ (Figure S5) where the Raman process is the dominant contribution to $1 / T_{1}$. The rates are similar at X-band and Q-band as expected for the Raman process This orientation dependence, which persists with increasing temperature until the tumbling process dominates, is due to the orientation dependence of spin-orbit coupling or of vibrations. $^{1}$

The relaxation rates for diradical $2 \mathbf{a}$ in the relatively rigid glycerol glass at $86 \mathrm{~K}$ at Q-band are shown in Figure S5. The variation with position in the spectrum is only about a factor of 2, which is substantially smaller than for mono-nitroxides. Rates are faster toward the extremes of the spectrum, which is along the $g_{y y}$ axis of the nitroxide and slower near the $g_{z z}$ axis, as in the monoradical. The slightly slower relaxation at the monoradical position (the center of the spectrum) is due to the overlap of the monoradical contribution (2a_mono). In sucrose octaacetate, the relaxation for $\mathbf{2 a}$ is faster than in glycerol due to a larger contribution from modulation of the dipole-dipole interaction, which is not strongly dependent on the position in the spectrum (Figure S5). In toluene: $\mathrm{CHCl}_{3}$ solution at X-band the relaxation rates at $50 \mathrm{~K}$ for $\mathbf{1 b}, \mathbf{2 a}, \mathbf{2 b}$ show little orientation dependence, similar to that observed for diradical $\mathbf{2 a}$ in sucrose octaacetate.

Well-defined half-field transitions were observed for the diradicals. ${ }^{2}$ At 15 to $80 \mathrm{~K}$ it was not possible to observe a spin echo, which is attributed to short values of $T_{\mathrm{m}}$. Values of $T_{1}$ were measured by saturation recovery. Signal-to-noise is lower than for the allowed transitions so higher observe powers were used at half-field to observe the recovery, which introduces additional uncertainty in the values. Within that uncertainty, values of $T_{1}$ at half-field are similar to those for the allowed transitions. In $\mathrm{CW}$ experiments it has been observed that it is more difficult to saturate the half-field transitions than 
the allowed transitions. ${ }^{3}$ The present results show that the difference in power saturation of the transitions is not due to differences in $T_{1}$, but must arise from shorter $T_{2}$ and/or the low transition probability for the forbidden transition.

The small dependence of $1 / T_{1}$ on position in the spectrum for $\mathbf{3}$ is shown in figure S6. The orientation dependence is much less than for monoradicals. Since the nitroxyl rings are non-planar the $\mathrm{z}$ axes, which are long the $\mathrm{p}-\pi$ orbital of the nitroxyl nitrogen are not coincident. When the magnetic field is along the $\mathrm{z}$ axis for one half of the diradical, which would give a longer $\mathrm{T}_{1}$ for the monoradical, the field is at an intermediate orientation for the other half of the diradical which would give a shorter $\mathrm{T}_{1}$. Thus the exchange interaction averages the extremes of monoradical relaxation times.

(1) Du, J.-L.; Eaton, G. R.; Eaton, S. S. J. Magn. Reson. A 1995, 115, 213.

(2) Rajca, A.; Mukherjee, S.; Pink, M.; Rajca, S. J. Am. Chem. Soc. 2006, 128, 13497.

(3) Eaton, S. S.; Eaton, G. R. J. Amer. Chem. Soc. 1982, 104, 5002.

DFT calculations on nitroxide diradical anti-4b at the UB3LYP/6-31G(d) level with Gaussian 03. File: DiNO_C5dft.log

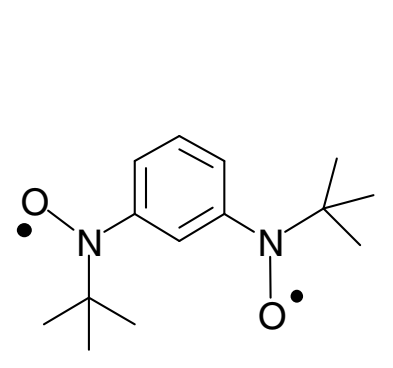

anti-4b
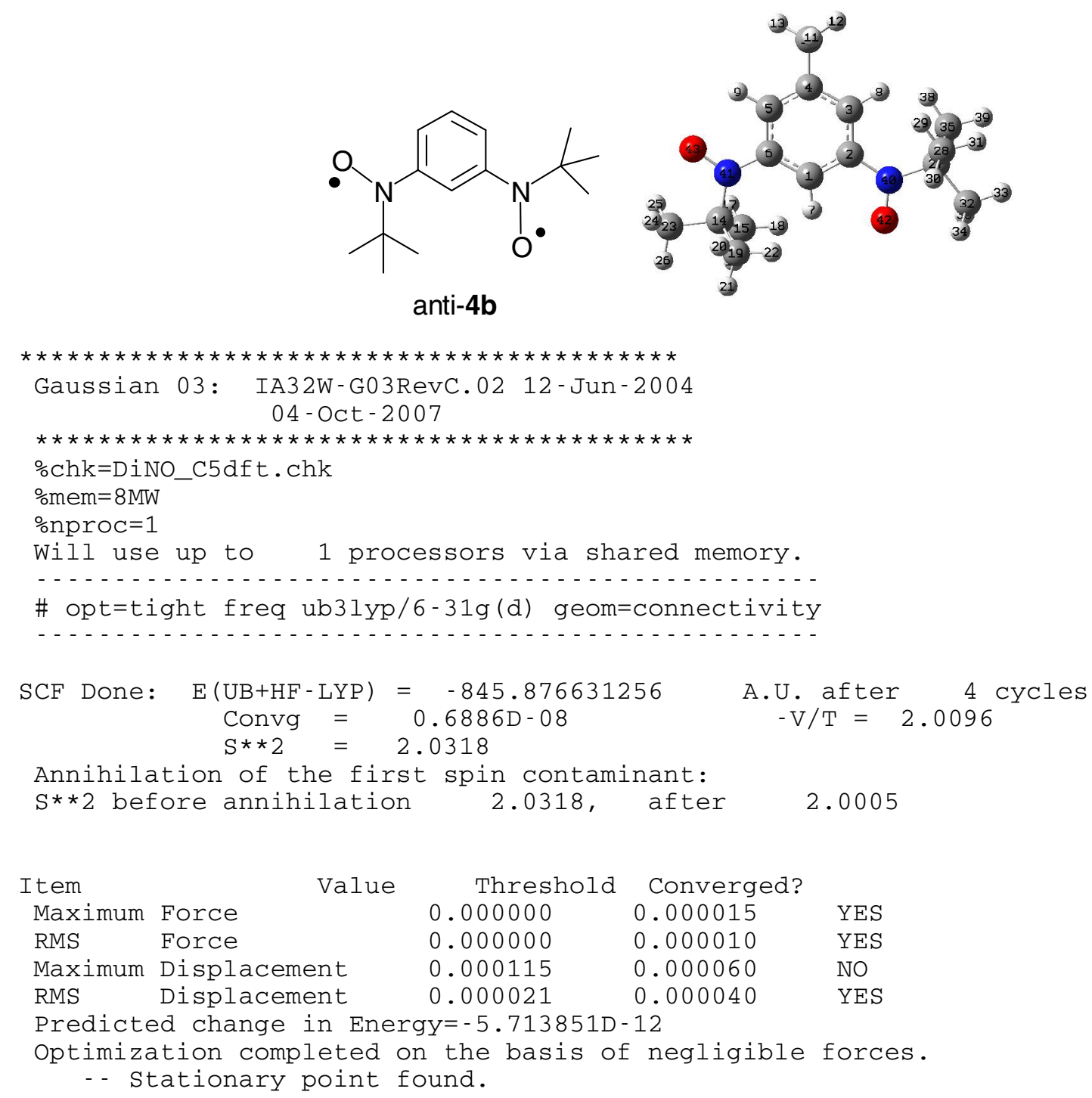

$\mathrm{S} * * 2$ before annihilation 2.0318, after 2.0005

A.U. after 4 cycles$$
-\mathrm{V} / \mathrm{T}=2.0096
$$ 


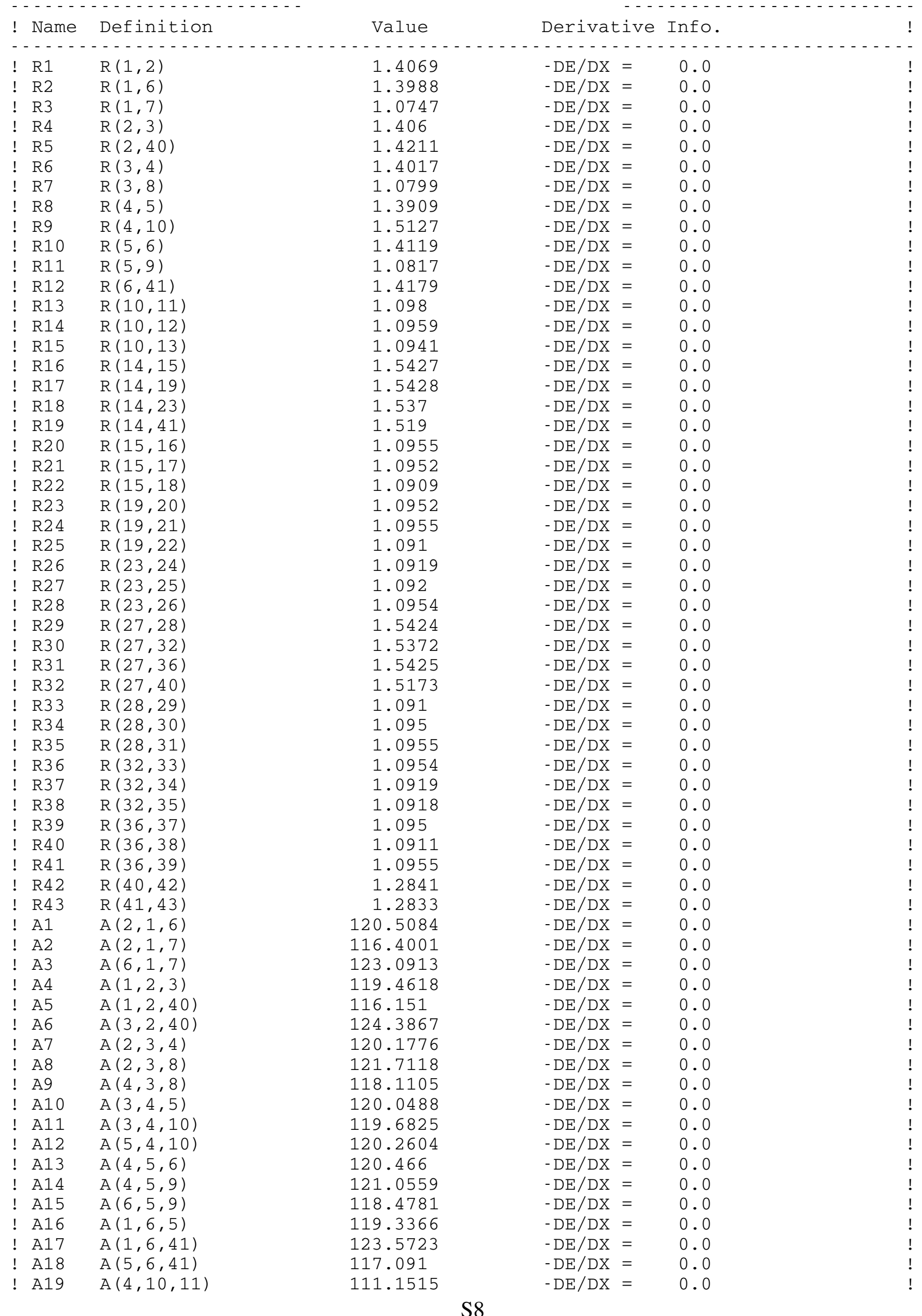




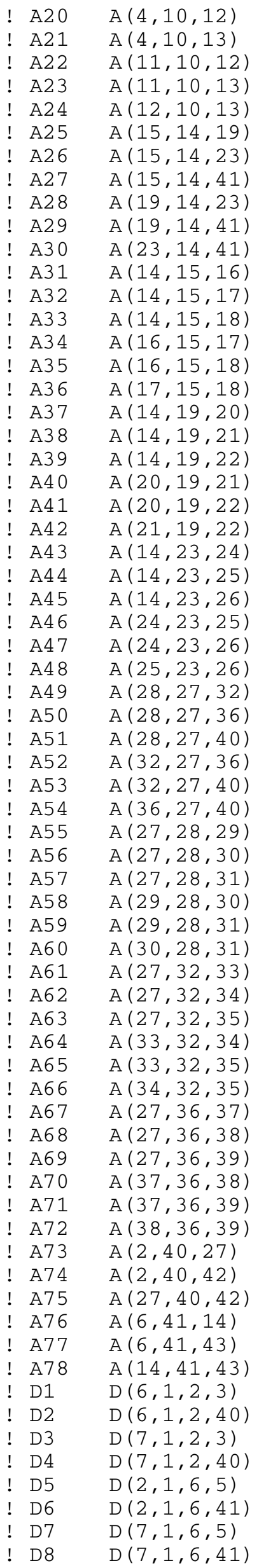

\begin{tabular}{|c|c|c|c|}
\hline 111.5226 & -DE/DX & $=$ & 0.0 \\
\hline 111.2896 & $-\mathrm{DE} / \mathrm{DX}$ & $=$ & 0.0 \\
\hline 107.2114 & - DE/DX & $=$ & 0.0 \\
\hline 107.4197 & $-\mathrm{DE} / \mathrm{DX}$ & $=$ & 0.0 \\
\hline 108.0446 & -DE/DX & $=$ & 0.0 \\
\hline 112.7117 & $-\mathrm{DE} / \mathrm{DX}$ & $=$ & 0.0 \\
\hline 108.2595 & $-\mathrm{DE} / \mathrm{DX}$ & $=$ & 0.0 \\
\hline 110.1333 & $-\mathrm{DE} / \mathrm{DX}$ & $=$ & 0.0 \\
\hline 108.2718 & $-\mathrm{DE} / \mathrm{DX}$ & $=$ & 0.0 \\
\hline 110.0962 & $-\mathrm{DE} / \mathrm{DX}$ & $=$ & 0.0 \\
\hline 107.1794 & - DE/DX & $=$ & 0.0 \\
\hline 109.0136 & $-\mathrm{DE} / \mathrm{DX}$ & $=$ & 0.0 \\
\hline 110.0739 & - DE/DX & $=$ & 0.0 \\
\hline 113.8163 & $-\mathrm{DE} / \mathrm{DX}$ & $=$ & 0.0 \\
\hline 107.9942 & $-D E / D X$ & $=$ & 0.0 \\
\hline 107.6358 & $-\mathrm{DE} / \mathrm{DX}$ & $=$ & 0.0 \\
\hline 108.1283 & $-\mathrm{DE} / \mathrm{DX}$ & $=$ & 0.0 \\
\hline 110.0654 & -DE/DX & $=$ & 0.0 \\
\hline 109.0358 & - DE/DX & $=$ & 0.0 \\
\hline 113.7949 & -DE/DX & $=$ & 0.0 \\
\hline 108.0014 & $-\mathrm{DE} / \mathrm{DX}$ & $=$ & 0.0 \\
\hline 108.1293 & - DE/DX & $=$ & 0.0 \\
\hline 107.6368 & $-\mathrm{DE} / \mathrm{DX}$ & $=$ & 0.0 \\
\hline 111.5889 & -DE/DX & $=$ & 0.0 \\
\hline 111.5714 & $-\mathrm{DE} / \mathrm{DX}$ & $=$ & 0.0 \\
\hline 108.151 & $-D E / D X$ & $=$ & 0.0 \\
\hline 107.9152 & $-\mathrm{DE} / \mathrm{DX}$ & $=$ & 0.0 \\
\hline 108.778 & - DE/DX & $=$ & 0.0 \\
\hline 108.7685 & - DE/DX & $=$ & 0.0 \\
\hline 108.138 & -DE/DX & $=$ & 0.0 \\
\hline 112.8889 & $-\mathrm{DE} / \mathrm{DX}$ & $=$ & 0.0 \\
\hline 110.0898 & $-\mathrm{DE} / \mathrm{DX}$ & $=$ & 0.0 \\
\hline 108.1404 & - DE/DX & $=$ & 0.0 \\
\hline 107.3676 & $-\mathrm{DE} / \mathrm{DX}$ & $=$ & 0.0 \\
\hline 110.0269 & - DE/DX & $=$ & 0.0 \\
\hline 113.7676 & $-\mathrm{DE} / \mathrm{DX}$ & $=$ & 0.0 \\
\hline 110.0302 & -DE/DX & $=$ & 0.0 \\
\hline 109.1743 & $-\mathrm{DE} / \mathrm{DX}$ & $=$ & 0.0 \\
\hline 107.9248 & $-\mathrm{DE} / \mathrm{DX}$ & $=$ & 0.0 \\
\hline 107.7548 & - DE/DX & $=$ & 0.0 \\
\hline 108.0147 & $-D E / D X$ & $=$ & 0.0 \\
\hline 108.0989 & -DE/DX & $=$ & 0.0 \\
\hline 111.5815 & $-\mathrm{DE} / \mathrm{DX}$ & $=$ & 0.0 \\
\hline 111.6002 & -DE/DX & $=$ & 0.0 \\
\hline 108.784 & $-\mathrm{DE} / \mathrm{DX}$ & $=$ & 0.0 \\
\hline 108.7895 & - DE/DX & $=$ & 0.0 \\
\hline 107.9198 & $-\mathrm{DE} / \mathrm{DX}$ & $=$ & 0.0 \\
\hline 110.0074 & - DE/DX & $=$ & 0.0 \\
\hline 113.7542 & $-\mathrm{DE} / \mathrm{DX}$ & $=$ & 0.0 \\
\hline 109.2073 & - DE/DX & $=$ & 0.0 \\
\hline 107.9161 & $-\mathrm{DE} / \mathrm{DX}$ & $=$ & 0.0 \\
\hline 108.0223 & -DE/DX & $=$ & 0.0 \\
\hline 107.7601 & $-\mathrm{DE} / \mathrm{DX}$ & $=$ & 0.0 \\
\hline 125.9013 & - DE/DX & $=$ & 0.0 \\
\hline 117.4558 & -DE/DX & $=$ & 0.0 \\
\hline 116.6428 & -DE/DX & $=$ & 0.0 \\
\hline 125.9136 & -DE/DX & $=$ & 0.0 \\
\hline 117.2672 & $-\mathrm{DE} / \mathrm{DX}$ & $=$ & 0.0 \\
\hline 116.8192 & -DE/DX & $=$ & 0.0 \\
\hline-0.0012 & $-\mathrm{DE} / \mathrm{DX}$ & $=$ & 0.0 \\
\hline 179.769 & - DE/DX & $=$ & 0.0 \\
\hline 179.8294 & $-\mathrm{DE} / \mathrm{DX}$ & $=$ & 0.0 \\
\hline 0.0617 & - DE/DX & $=$ & 0.0 \\
\hline-0.0758 & - DE/DX & $=$ & 0.0 \\
\hline 179.8304 & - DE/DX & $=$ & 0.0 \\
\hline 179.8948 & - DE/DX & $=$ & 0.0 \\
\hline 0.0114 & $-D E / D X$ & $=$ & 0.0 \\
\hline
\end{tabular}




\begin{tabular}{|c|c|c|}
\hline & D9 & $D(1,2,3,4)$ \\
\hline ! & D10 & $D(1,2,3,8)$ \\
\hline & D11 & $D(40,2,3,4)$ \\
\hline & $\mathrm{D} 12$ & $\mathrm{D}(40,2,3,8)$ \\
\hline & D13 & $D(1,2,40,27)$ \\
\hline & D14 & $\mathrm{D}(1,2,40,42)$ \\
\hline & D15 & $D(3,2,40,27)$ \\
\hline & D16 & $D(3,2,40,42)$ \\
\hline & $\mathrm{D} 17$ & $D(2,3,4,5)$ \\
\hline & D18 & $D(2,3,4,10)$ \\
\hline ! & D19 & $D(8,3,4,5)$ \\
\hline & D2 0 & $D(8,3,4,10)$ \\
\hline ! & $\mathrm{D} 21$ & $D(3,4,5,6)$ \\
\hline ! & D22 & $D(3,4,5,9)$ \\
\hline ! & D23 & $D(10,4,5,6)$ \\
\hline ! & D24 & $\mathrm{D}(10,4,5,9)$ \\
\hline ! & $\mathrm{D} 25$ & $\mathrm{D}(3,4,10,11)$ \\
\hline ! & D2 6 & $\mathrm{D}(3,4,10,12)$ \\
\hline ! & D27 & $\mathrm{D}(3,4,10,13)$ \\
\hline ! & D2 8 & $D(5,4,10,11)$ \\
\hline ! & D29 & $\mathrm{D}(5,4,10,12)$ \\
\hline ! & D30 & $\mathrm{D}(5,4,10,13)$ \\
\hline ! & D31 & $\mathrm{D}(4,5,6,1)$ \\
\hline ! & D32 & $D(4,5,6,41)$ \\
\hline ! & D33 & $D(9,5,6,1)$ \\
\hline ! & D34 & $\mathrm{D}(9,5,6,41)$ \\
\hline ! & D3 5 & $D(1,6,41,14)$ \\
\hline ! & D36 & $D(1,6,41,43)$ \\
\hline ! & D37 & $D(5,6,41,14)$ \\
\hline ! & D38 & $D(5,6,41,43)$ \\
\hline ! & D39 & $\mathrm{D}(19,14,15,16)$ \\
\hline ! & $\mathrm{D} 40$ & $\mathrm{D}(19,14,15,17)$ \\
\hline ! & D4 1 & $\mathrm{D}(19,14,15,18)$ \\
\hline ! & $\mathrm{D} 42$ & $\mathrm{D}(23,14,15,16)$ \\
\hline ! & D43 & $\mathrm{D}(23,14,15,17)$ \\
\hline ! & D4 4 & $\mathrm{D}(23,14,15,18)$ \\
\hline ! & D4 5 & $\mathrm{D}(41,14,15,16)$ \\
\hline ! & $\mathrm{D} 46$ & $\mathrm{D}(41,14,15,17)$ \\
\hline ! & D4 7 & $\mathrm{D}(41,14,15,18)$ \\
\hline ! & D4 8 & $\mathrm{D}(15,14,19,20)$ \\
\hline ! & D49 & $\mathrm{D}(15,14,19,21)$ \\
\hline ! & D50 & $\mathrm{D}(15,14,19,22)$ \\
\hline ! & D51 & $\mathrm{D}(23,14,19,20)$ \\
\hline ! & D52 & $\mathrm{D}(23,14,19,21)$ \\
\hline ! & D53 & $\mathrm{D}(23,14,19,22)$ \\
\hline ! & D54 & $\mathrm{D}(41,14,19,20)$ \\
\hline ! & D55 & $\mathrm{D}(41,14,19,21)$ \\
\hline ! & D56 & $\mathrm{D}(41,14,19,22)$ \\
\hline ! & D57 & $\mathrm{D}(15,14,23,24)$ \\
\hline ! & D58 & $D(15,14,23,25)$ \\
\hline ! & D59 & $\mathrm{D}(15,14,23,26)$ \\
\hline ! & D60 & $\mathrm{D}(19,14,23,24)$ \\
\hline ! & D61 & $\mathrm{D}(19,14,23,25)$ \\
\hline ! & D62 & $\mathrm{D}(19,14,23,26)$ \\
\hline ! & D63 & $\mathrm{D}(41,14,23,24)$ \\
\hline ! & D64 & $\mathrm{D}(41,14,23,25)$ \\
\hline ! & D65 & $D(41,14,23,26)$ \\
\hline ! & D66 & $\mathrm{D}(15,14,41,6)$ \\
\hline ! & D67 & $\mathrm{D}(15,14,41,43)$ \\
\hline ! & D68 & $\mathrm{D}(19,14,41,6)$ \\
\hline ! & D69 & $\mathrm{D}(19,14,41,43)$ \\
\hline ! & D70 & $\mathrm{D}(23,14,41,6)$ \\
\hline ! & D71 & $\mathrm{D}(23,14,41,43)$ \\
\hline ! & D72 & $\mathrm{D}(32,27,28,29)$ \\
\hline ! & D73 & $\mathrm{D}(32,27,28,30)$ \\
\hline ! & D74 & $D(32,27,28,31)$ \\
\hline & D75 & $\mathrm{D}(36,27,28,29)$ \\
\hline
\end{tabular}

\begin{tabular}{|c|c|c|c|}
\hline 0.2229 & - DE/DX & $=$ & 0.0 \\
\hline-179.659 & - DE/DX & $=$ & 0.0 \\
\hline 179.9702 & -DE/DX & $=$ & 0.0 \\
\hline 0.0883 & - DE/DX & $=$ & 0.0 \\
\hline-179.2618 & - DE/DX & $=$ & 0.0 \\
\hline 0.6091 & - DE/DX & $=$ & 0.0 \\
\hline 0.9833 & - DE/DX & $=$ & 0.0 \\
\hline-179.1458 & - DE/DX & $=$ & 0.0 \\
\hline-0.3678 & - DE/DX & $=$ & 0.0 \\
\hline 178.5862 & - DE/DX & $=$ & 0.0 \\
\hline 179.5183 & - DE/DX & $=$ & 0.0 \\
\hline-1.5277 & $-D E / D X$ & $=$ & 0.0 \\
\hline 0.2904 & -DE/DX & $=$ & 0.0 \\
\hline-179.6559 & $-\mathrm{DE} / \mathrm{DX}$ & $=$ & 0.0 \\
\hline-178.6575 & - DE/DX & $=$ & 0.0 \\
\hline 1.3962 & - DE/DX & $=$ & 0.0 \\
\hline-80.3422 & -DE/DX & $=$ & 0.0 \\
\hline 39.2375 & - DE/DX & $=$ & 0.0 \\
\hline 159.9703 & - DE/DX & $=$ & 0.0 \\
\hline 98.6095 & - DE/DX & $=$ & 0.0 \\
\hline-141.8108 & $-\mathrm{DE} / \mathrm{DX}$ & $=$ & 0.0 \\
\hline-21.0779 & - DE/DX & $=$ & 0.0 \\
\hline-0.0689 & - DE/DX & $=$ & 0.0 \\
\hline-179.9811 & - DE/DX & $=$ & 0.0 \\
\hline 179.8788 & $-\mathrm{DE} / \mathrm{DX}$ & $=$ & 0.0 \\
\hline-0.0334 & - DE/DX & $=$ & 0.0 \\
\hline-0.6165 & $-\mathrm{DE} / \mathrm{DX}$ & $=$ & 0.0 \\
\hline 179.4199 & - DE/DX & $=$ & 0.0 \\
\hline 179.2917 & - DE/DX & $=$ & 0.0 \\
\hline-0.6719 & - DE/DX & $=$ & 0.0 \\
\hline 61.7935 & - DE/DX & $=$ & 0.0 \\
\hline-179.9247 & $-\mathrm{DE} / \mathrm{DX}$ & $=$ & 0.0 \\
\hline-58.3639 & - DE/DX & $=$ & 0.0 \\
\hline-57.9418 & - DE/DX & $=$ & 0.0 \\
\hline 60.34 & - DE/DX & $=$ & 0.0 \\
\hline-178.0992 & $-\mathrm{DE} / \mathrm{DX}$ & $=$ & 0.0 \\
\hline-174.8282 & - DE/DX & $=$ & 0.0 \\
\hline-56.5464 & $-\mathrm{DE} / \mathrm{DX}$ & $=$ & 0.0 \\
\hline 65.0144 & -DE/DX & $=$ & 0.0 \\
\hline 179.8856 & - DE/DX & $=$ & 0.0 \\
\hline-61.8156 & - DE/DX & $=$ & 0.0 \\
\hline 58.3448 & - DE/DX & $=$ & 0.0 \\
\hline-60.3862 & - DE/DX & $=$ & 0.0 \\
\hline 57.9126 & - DE/DX & $=$ & 0.0 \\
\hline 178.073 & $-\mathrm{DE} / \mathrm{DX}$ & $=$ & 0.0 \\
\hline 56.4867 & $-\mathrm{DE} / \mathrm{DX}$ & $=$ & 0.0 \\
\hline 174.7855 & $-\mathrm{DE} / \mathrm{DX}$ & $=$ & 0.0 \\
\hline-65.0541 & - DE/DX & $=$ & 0.0 \\
\hline-179.246 & $-\mathrm{DE} / \mathrm{DX}$ & $=$ & 0.0 \\
\hline-58.4372 & $-\mathrm{DE} / \mathrm{DX}$ & $=$ & 0.0 \\
\hline 61.1473 & - DE/DX & $=$ & 0.0 \\
\hline 58.2683 & - DE/DX & $=$ & 0.0 \\
\hline 179.0772 & - DE/DX & $=$ & 0.0 \\
\hline-61.3384 & - DE/DX & $=$ & 0.0 \\
\hline-60.4702 & - DE/DX & $=$ & 0.0 \\
\hline 60.3386 & - DE/DX & $=$ & 0.0 \\
\hline 179.9231 & - DE/DX & $=$ & 0.0 \\
\hline-61.9619 & $-\mathrm{DE} / \mathrm{DX}$ & $=$ & 0.0 \\
\hline 118.0018 & - DE/DX & $=$ & 0.0 \\
\hline 62.9288 & - DE/DX & $=$ & 0.0 \\
\hline-117.1074 & - DE/DX & $=$ & 0.0 \\
\hline-179.5192 & $-\mathrm{DE} / \mathrm{DX}$ & $=$ & 0.0 \\
\hline 0.4445 & - DE/DX & $=$ & 0.0 \\
\hline 179.3379 & - DE/DX & $=$ & 0.0 \\
\hline-59.4311 & - DE/DX & $=$ & 0.0 \\
\hline 58.9463 & -DE/DX & $=$ & 0.0 \\
\hline 59.7387 & - DE/DX & $=$ & 0.0 \\
\hline
\end{tabular}




\begin{tabular}{|c|c|c|c|c|c|c|c|}
\hline ! & D76 & $D(36,27,28,30)$ & -179.0304 & $-\mathrm{DE} / \mathrm{DX}$ & $=$ & 0.0 & ! \\
\hline ! & D7 7 & $D(36,27,28,31)$ & -60.6529 & $-\mathrm{DE} / \mathrm{DX}$ & $=$ & 0.0 & ! \\
\hline ! & D78 & $D(40,27,28,29)$ & -63.6439 & $-\mathrm{DE} / \mathrm{DX}$ & $=$ & 0.0 & ! \\
\hline ! & D79 & $D(40,27,28,30)$ & 57.587 & $-\mathrm{DE} / \mathrm{DX}$ & $=$ & 0.0 & ! \\
\hline ! & D80 & $D(40,27,28,31)$ & 175.9644 & $-\mathrm{DE} / \mathrm{DX}$ & $=$ & 0.0 & ! \\
\hline$!$ & D81 & $D(28,27,32,33)$ & -61.176 & $-\mathrm{DE} / \mathrm{DX}$ & $=$ & 0.0 & ! \\
\hline ! & D82 & $D(28,27,32,34)$ & 58.4002 & $-\mathrm{DE} / \mathrm{DX}$ & $=$ & 0.0 & ! \\
\hline$!$ & D83 & $D(28,27,32,35)$ & 179.2298 & $-\mathrm{DE} / \mathrm{DX}$ & $=$ & 0.0 & ! \\
\hline$!$ & D84 & $D(36,27,32,33)$ & 61.3727 & - DE/DX & $=$ & 0.0 & ! \\
\hline ! & D85 & $D(36,27,32,34)$ & -179.0512 & $-\mathrm{DE} / \mathrm{DX}$ & $=$ & 0.0 & ! \\
\hline$!$ & D86 & $D(36,27,32,35)$ & -58.2216 & $-\mathrm{DE} / \mathrm{DX}$ & $=$ & 0.0 & ! \\
\hline$!$ & D87 & $D(40,27,32,33)$ & -179.9381 & $-\mathrm{DE} / \mathrm{DX}$ & $=$ & 0.0 & ! \\
\hline ! & D88 & $D(40,27,32,34)$ & -60.3619 & $-\mathrm{DE} / \mathrm{DX}$ & $=$ & 0.0 & ! \\
\hline$!$ & D89 & $D(40,27,32,35)$ & 60.4676 & - DE/DX & $=$ & 0.0 & ! \\
\hline$!$ & D9 0 & $D(28,27,36,37)$ & 179.0137 & $-\mathrm{DE} / \mathrm{DX}$ & $=$ & 0.0 & ! \\
\hline ! & D91 & $D(28,27,36,38)$ & -59.7927 & $-\mathrm{DE} / \mathrm{DX}$ & $=$ & 0.0 & ! \\
\hline$!$ & D92 & $D(28,27,36,39)$ & 60.6205 & $-\mathrm{DE} / \mathrm{DX}$ & $=$ & 0.0 & ! \\
\hline$!$ & D93 & $D(32,27,36,37)$ & 59.4159 & $-\mathrm{DE} / \mathrm{DX}$ & $=$ & 0.0 & ! \\
\hline ! & D94 & $D(32,27,36,38)$ & -179.3905 & $-\mathrm{DE} / \mathrm{DX}$ & $=$ & 0.0 & ! \\
\hline$!$ & D95 & $D(32,27,36,39)$ & -58.9773 & - DE/DX & $=$ & 0.0 & ! \\
\hline ! & D96 & $D(40,27,36,37)$ & -57.5689 & $-\mathrm{DE} / \mathrm{DX}$ & $=$ & 0.0 & ! \\
\hline$!$ & D97 & $D(40,27,36,38)$ & 63.6248 & $-\mathrm{DE} / \mathrm{DX}$ & $=$ & 0.0 & ! \\
\hline ! & D98 & $D(40,27,36,39)$ & -175.962 & $-\mathrm{DE} / \mathrm{DX}$ & $=$ & 0.0 & ! \\
\hline$!$ & D99 & $\mathrm{D}(28,27,40,2)$ & 61.7512 & $-\mathrm{DE} / \mathrm{DX}$ & $=$ & 0.0 & ! \\
\hline$!$ & D100 & $D(28,27,40,42)$ & -118.1207 & - DE/DX & $=$ & 0.0 & ! \\
\hline$!$ & D101 & $D(32,27,40,2)$ & 179.248 & $-\mathrm{DE} / \mathrm{DX}$ & $=$ & 0.0 & ! \\
\hline$!$ & D102 & $D(32,27,40,42)$ & -0.6239 & - DE/DX & $=$ & 0.0 & ! \\
\hline ! & D103 & $D(36,27,40,2)$ & -63.2863 & $-\mathrm{DE} / \mathrm{DX}$ & $=$ & 0.0 & \\
\hline$!$ & D104 & $D(36,27,40,42)$ & 116.8418 & $-\mathrm{DE} / \mathrm{DX}$ & $=$ & 0.0 & \\
\hline
\end{tabular}

GradGradGradGradGradGradGradGradGradGradGradGradGradGradGradGradGradGrad

Input orientation:

\begin{tabular}{|c|c|c|c|c|c|}
\hline \multirow{2}{*}{$\begin{array}{l}\text { Center } \\
\text { Number }\end{array}$} & \multirow{2}{*}{$\begin{array}{l}\text { Atomic } \\
\text { Number }\end{array}$} & \multirow{2}{*}{$\begin{array}{c}\text { Atomic } \\
\text { Type }\end{array}$} & \multicolumn{3}{|c|}{ Coordinates (Angstroms) } \\
\hline & & & $\mathrm{X}$ & $\mathrm{Y}$ & $\mathrm{Z}$ \\
\hline & & & 10 & 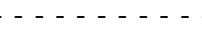 & $\ldots-\ldots$ \\
\hline 1 & 6 & 0 & 0.128374 & 0.157637 & -0.020905 \\
\hline 2 & 6 & 0 & 0.067122 & -0.279707 & 1.314933 \\
\hline 3 & 6 & 0 & 1.259655 & -0.539036 & 2.013031 \\
\hline 4 & 6 & 0 & 2.498554 & -0.358180 & 1.382891 \\
\hline 5 & 6 & 0 & 2.551496 & 0.071561 & 0.061111 \\
\hline 6 & 6 & 0 & 1.362980 & 0.334720 & -0.654258 \\
\hline 7 & 1 & 0 & -0.812330 & 0.338349 & -0.508166 \\
\hline 8 & 1 & 0 & 1.254900 & -0.881186 & 3.037285 \\
\hline 9 & 1 & 0 & 3.498439 & 0.211189 & -0.442766 \\
\hline 10 & 6 & 0 & 3.775143 & -0.609653 & 2.154397 \\
\hline 11 & 1 & 0 & 4.027743 & 0.247387 & 2.792587 \\
\hline 12 & 1 & 0 & 3.684312 & -1.484800 & 2.807704 \\
\hline 13 & 1 & 0 & 4.620504 & -0.776353 & 1.480134 \\
\hline 14 & 6 & 0 & 0.362122 & 1.091956 & -2.949712 \\
\hline 15 & 6 & 0 & -0.501601 & -0.163423 & -3.190413 \\
\hline 16 & 1 & 0 & -1.258811 & 0.064336 & -3.948588 \\
\hline 17 & 1 & 0 & 0.120928 & -0.981088 & -3.568941 \\
\hline 18 & 1 & 0 & -1.022061 & -0.517510 & -2.299435 \\
\hline 19 & 6 & 0 & -0.456500 & 2.284154 & -2.412468 \\
\hline 20 & 1 & 0 & 0.197296 & 3.148637 & -2.255640 \\
\hline 21 & 1 & 0 & -1.212685 & 2.561839 & -3.154873 \\
\hline 22 & 1 & 0 & -0.974405 & 2.075746 & -1.475155 \\
\hline 23 & 6 & 0 & 0.994146 & 1.505568 & -4.288319 \\
\hline 24 & 1 & 0 & 1.630707 & 2.385716 & -4.177116 \\
\hline 25 & 1 & 0 & 1.601965 & 0.702585 & -4.710428 \\
\hline 26 & 1 & 0 & 0.185808 & 1.741279 & -4.988957 \\
\hline 27 & 6 & 0 & -1.555839 & -0.874503 & 3.280308 \\
\hline 28 & 6 & 0 & -0.979435 & 0.135148 & 4.293921 \\
\hline 29 & 1 & 0 & 0.109373 & 0.201618 & 4.277617 \\
\hline 30 & 1 & 0 & -1.381068 & 1.134688 & 4.097400 \\
\hline & & & S11 & & \\
\hline
\end{tabular}




$\begin{array}{rrrrrr}31 & 1 & 0 & -1.281097 & -0.158355 & 5.305340 \\ 32 & 6 & 0 & -3.086326 & -0.876119 & 3.424044 \\ 33 & 1 & 0 & -3.332040 & -1.192466 & 4.443606 \\ 34 & 1 & 0 & -3.506832 & 0.116967 & 3.253075 \\ 35 & 1 & 0 & -3.555477 & -1.565467 & 2.719266 \\ 36 & 6 & 0 & -1.050113 & -2.313119 & 3.512753 \\ 37 & 1 & 0 & -1.500661 & -2.991476 & 2.780755 \\ 38 & 1 & 0 & 0.033878 & -2.414758 & 3.441810 \\ 39 & 1 & 0 & -1.352080 & -2.644196 & 4.512449 \\ 40 & 7 & 0 & -1.234354 & -0.433077 & 1.864736 \\ 41 & 7 & 0 & 1.500232 & 0.768764 & -1.997069 \\ 42 & 8 & 0 & -2.233852 & -0.174290 & 1.101268 \\ 43 & 8 & 0 & 2.692390 & 0.901278 & -2.453176 \\ -\ldots \ldots \ldots & \ldots \ldots \ldots-\ldots \ldots\end{array}$

\section{DFT calculations on nitroxide diradical syn-4b at the UB3LYP/6-31G(d) level with Gaussian 03}

File: DiNO_C4dft.log
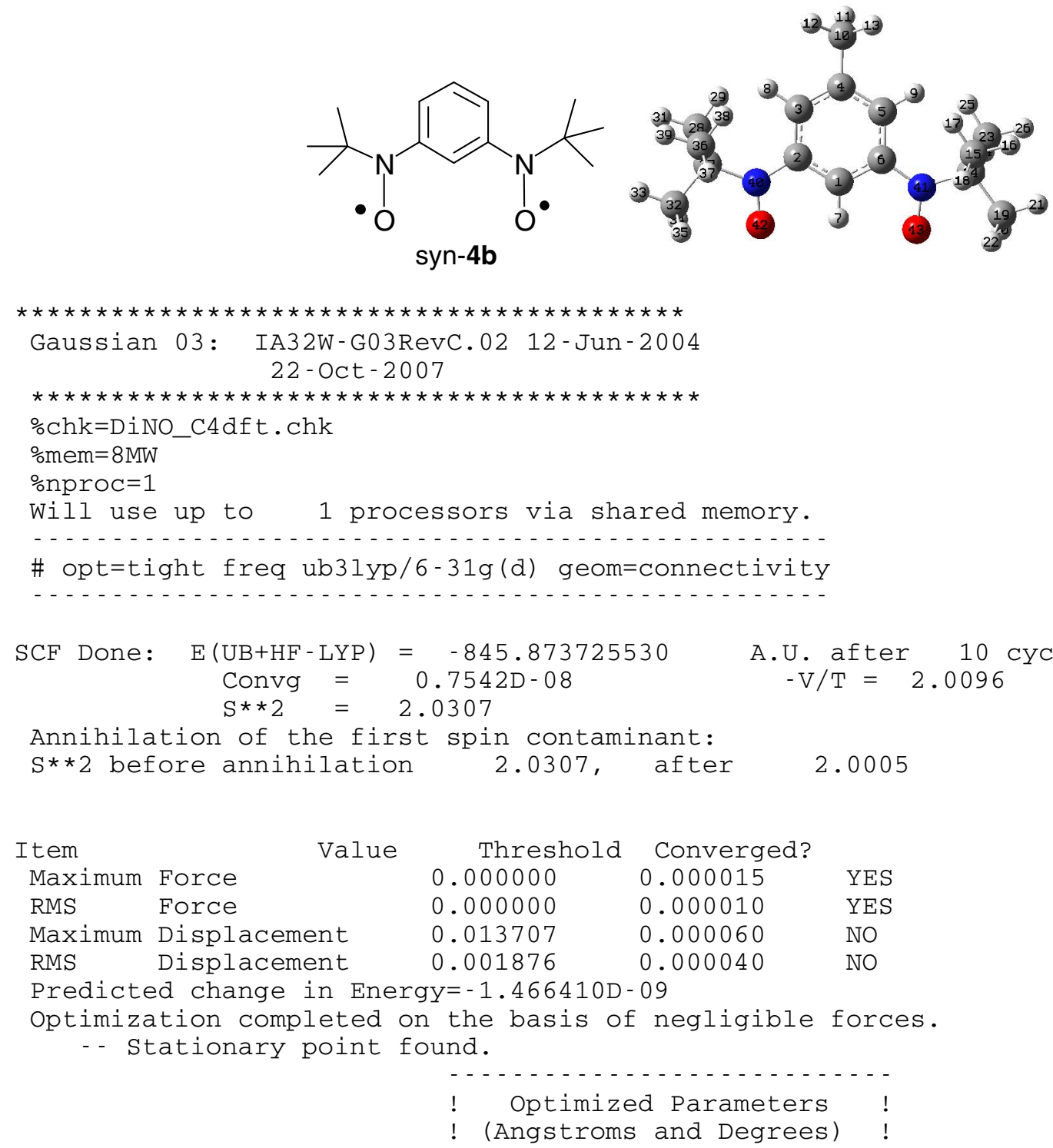


\begin{tabular}{|c|c|c|c|c|c|c|}
\hline$!$ & Name & Definition & Value & Derivative & Info. & $!$ \\
\hline ! & R1 & $R(1,2)$ & 1.402 & $-\mathrm{DE} / \mathrm{DX}=$ & 0.0 & ! \\
\hline ! & R2 & $R(1,6)$ & 1.402 & $-\mathrm{DE} / \mathrm{DX}=$ & 0.0 & ! \\
\hline ! & R3 & $\mathrm{R}(1,7)$ & 1.078 & $-\mathrm{DE} / \mathrm{DX}=$ & 0.0 & ! \\
\hline ! & $\mathrm{R} 4$ & $R(2,3)$ & 1.4096 & $-\mathrm{DE} / \mathrm{DX}=$ & 0.0 & ! \\
\hline ! & R5 & $R(2,40)$ & 1.4206 & $-\mathrm{DE} / \mathrm{DX}=$ & 0.0 & ! \\
\hline ! & R6 & $R(3,4)$ & 1.3967 & $-\mathrm{DE} / \mathrm{DX}=$ & 0.0 & ! \\
\hline ! & R7 & $R(3,8)$ & 1.0798 & $-\mathrm{DE} / \mathrm{DX}=$ & 0.0 & ! \\
\hline ! & R8 & $R(4,5)$ & 1.3966 & $-\mathrm{DE} / \mathrm{DX}=$ & 0.0 & ! \\
\hline ! & R9 & $R(4,10)$ & 1.5132 & $-\mathrm{DE} / \mathrm{DX}=$ & 0.0 & ! \\
\hline ! & R10 & $R(5,6)$ & 1.4097 & $-\mathrm{DE} / \mathrm{DX}=$ & 0.0 & ! \\
\hline ! & R11 & $R(5,9)$ & 1.0798 & $-\mathrm{DE} / \mathrm{DX}=$ & 0.0 & ! \\
\hline ! & R12 & $R(6,41)$ & 1.4206 & $-\mathrm{DE} / \mathrm{DX}=$ & 0.0 & ! \\
\hline$!$ & R13 & $R(10,11)$ & 1.0981 & $-\mathrm{DE} / \mathrm{DX}=$ & 0.0 & ! \\
\hline ! & R14 & $R(10,12)$ & 1.0951 & $-\mathrm{DE} / \mathrm{DX}=$ & 0.0 & ! \\
\hline ! & R15 & $R(10,13)$ & 1.0951 & $-\mathrm{DE} / \mathrm{DX}=$ & 0.0 & ! \\
\hline ! & $\mathrm{R} 16$ & $R(14,15)$ & 1.5423 & $-\mathrm{DE} / \mathrm{DX}=$ & 0.0 & ! \\
\hline ! & R17 & $R(14,19)$ & 1.5372 & $-\mathrm{DE} / \mathrm{DX}=$ & 0.0 & ! \\
\hline ! & R18 & $R(14,23)$ & 1.543 & $-\mathrm{DE} / \mathrm{DX}=$ & 0.0 & ! \\
\hline ! & R19 & $\mathrm{R}(14,41)$ & 1.5176 & $-\mathrm{DE} / \mathrm{DX}=$ & 0.0 & ! \\
\hline ! & R2 0 & $R(15,16)$ & 1.0956 & $-\mathrm{DE} / \mathrm{DX}=$ & 0.0 & ! \\
\hline ! & R21 & $R(15,17)$ & 1.0909 & $-\mathrm{DE} / \mathrm{DX}=$ & 0.0 & ! \\
\hline ! & R22 & $R(15,18)$ & 1.095 & $-\mathrm{DE} / \mathrm{DX}=$ & 0.0 & ! \\
\hline ! & R23 & $R(19,20)$ & 1.0914 & $-\mathrm{DE} / \mathrm{DX}=$ & 0.0 & ! \\
\hline ! & $\mathrm{R} 24$ & $R(19,21)$ & 1.0955 & $-\mathrm{DE} / \mathrm{DX}=$ & 0.0 & ! \\
\hline ! & R2 5 & $R(19,22)$ & 1.0921 & $-\mathrm{DE} / \mathrm{DX}=$ & 0.0 & ! \\
\hline ! & R2 6 & $R(23,24)$ & 1.0949 & $-\mathrm{DE} / \mathrm{DX}=$ & 0.0 & ! \\
\hline ! & R2 7 & $R(23,25)$ & 1.0913 & $-\mathrm{DE} / \mathrm{DX}=$ & 0.0 & ! \\
\hline ! & R2 8 & $R(23,26)$ & 1.0956 & $-\mathrm{DE} / \mathrm{DX}=$ & 0.0 & ! \\
\hline$!$ & R29 & $R(27,28)$ & 1.543 & $-\mathrm{DE} / \mathrm{DX}=$ & 0.0 & ! \\
\hline ! & R30 & $R(27,32)$ & 1.5372 & $-\mathrm{DE} / \mathrm{DX}=$ & 0.0 & ! \\
\hline ! & R31 & $R(27,36)$ & 1.5422 & $-\mathrm{DE} / \mathrm{DX}=$ & 0.0 & ! \\
\hline ! & R32 & $R(27,40)$ & 1.5176 & $-\mathrm{DE} / \mathrm{DX}=$ & 0.0 & ! \\
\hline ! & R33 & $R(28,29)$ & 1.0913 & $-\mathrm{DE} / \mathrm{DX}=$ & 0.0 & ! \\
\hline ! & R34 & $R(28,30)$ & 1.0949 & $-\mathrm{DE} / \mathrm{DX}=$ & 0.0 & ! \\
\hline ! & R35 & $R(28,31)$ & 1.0956 & $-\mathrm{DE} / \mathrm{DX}=$ & 0.0 & ! \\
\hline ! & R36 & $R(32,33)$ & 1.0955 & $-\mathrm{DE} / \mathrm{DX}=$ & 0.0 & ! \\
\hline ! & R37 & $R(32,34)$ & 1.0914 & $-\mathrm{DE} / \mathrm{DX}=$ & 0.0 & ! \\
\hline ! & R3 8 & $R(32,35)$ & 1.0921 & $-\mathrm{DE} / \mathrm{DX}=$ & 0.0 & ! \\
\hline$!$ & R39 & $R(36,37)$ & 1.095 & $-\mathrm{DE} / \mathrm{DX}=$ & 0.0 & ! \\
\hline ! & $\mathrm{R} 40$ & $R(36,38)$ & 1.0909 & $-\mathrm{DE} / \mathrm{DX}=$ & 0.0 & ! \\
\hline ! & $\mathrm{R} 41$ & $R(36,39)$ & 1.0955 & $-\mathrm{DE} / \mathrm{DX}=$ & 0.0 & ! \\
\hline ! & $\mathrm{R} 42$ & $R(40,42)$ & 1.2823 & $-\mathrm{DE} / \mathrm{DX}=$ & 0.0 & ! \\
\hline ! & $\mathrm{R} 43$ & $R(41,43)$ & 1.2823 & $-\mathrm{DE} / \mathrm{DX}=$ & 0.0 & $!$ \\
\hline ! & $\mathrm{A} 1$ & $A(2,1,6)$ & 120.7063 & $-\mathrm{DE} / \mathrm{DX}=$ & 0.0 & ! \\
\hline ! & $\mathrm{A} 2$ & $A(2,1,7)$ & 119.6461 & $-\mathrm{DE} / \mathrm{DX}=$ & 0.0 & ! \\
\hline ! & A3 & $A(6,1,7)$ & 119.6464 & $-\mathrm{DE} / \mathrm{DX}=$ & 0.0 & \\
\hline ! & A4 & $A(1,2,3)$ & 119.3258 & $-\mathrm{DE} / \mathrm{DX}=$ & 0.0 & \\
\hline ! & A5 & $A(1,2,40)$ & 116.681 & $-\mathrm{DE} / \mathrm{DX}=$ & 0.0 & ! \\
\hline ! & A 6 & $A(3,2,40)$ & 123.9926 & $-\mathrm{DE} / \mathrm{DX}=$ & 0.0 & \\
\hline ! & A 7 & $\mathrm{~A}(2,3,4)$ & 120.2365 & $-\mathrm{DE} / \mathrm{DX}=$ & 0.0 & \\
\hline ! & A 8 & $A(2,3,8)$ & 121.6546 & $-\mathrm{DE} / \mathrm{DX}=$ & 0.0 & \\
\hline ! & A9 & $A(4,3,8)$ & 118.1052 & $-\mathrm{DE} / \mathrm{DX}=$ & 0.0 & \\
\hline ! & A10 & $A(3,4,5)$ & 120.1657 & $-\mathrm{DE} / \mathrm{DX}=$ & 0.0 & \\
\hline ! & A11 & $A(3,4,10)$ & 119.9055 & $-\mathrm{DE} / \mathrm{DX}=$ & 0.0 & \\
\hline ! & A12 & $A(5,4,10)$ & 119.9076 & $-\mathrm{DE} / \mathrm{DX}=$ & 0.0 & \\
\hline ! & A13 & $A(4,5,6)$ & 120.2384 & $-\mathrm{DE} / \mathrm{DX}=$ & 0.0 & \\
\hline ! & A 14 & $A(4,5,9)$ & 118.1012 & $-\mathrm{DE} / \mathrm{DX}=$ & 0.0 & \\
\hline ! & A15 & $A(6,5,9)$ & 121.6568 & $-\mathrm{DE} / \mathrm{DX}=$ & 0.0 & \\
\hline ! & A16 & $A(1,6,5)$ & 119.3228 & $-\mathrm{DE} / \mathrm{DX}=$ & 0.0 & \\
\hline ! & A17 & $A(1,6,41)$ & 116.6804 & $-\mathrm{DE} / \mathrm{DX}=$ & 0.0 & \\
\hline ! & A18 & $A(5,6,41)$ & 123.9964 & $-\mathrm{DE} / \mathrm{DX}=$ & 0.0 & \\
\hline ! & A19 & $A(4,10,11)$ & 111.221 & $-\mathrm{DE} / \mathrm{DX}=$ & 0.0 & \\
\hline ! & A20 & $A(4,10,12)$ & 111.4995 & $-\mathrm{DE} / \mathrm{DX}=$ & 0.0 & \\
\hline ! & A21 & $A(4,10,13)$ & 111.4995 & $-\mathrm{DE} / \mathrm{DX}=$ & 0.0 & \\
\hline
\end{tabular}




\begin{tabular}{|c|c|c|}
\hline & A22 & $A(11,10,12)$ \\
\hline & A23 & $A(11,10,13)$ \\
\hline & A2 4 & $A(12,10,13)$ \\
\hline & A2 5 & $A(15,14,19)$ \\
\hline & A26 & $A(15,14,23)$ \\
\hline & A 27 & $A(15,14,4$ \\
\hline & A2 8 & $A(19,14,23$ \\
\hline & A29 & $A(19,14,41$ \\
\hline & A30 & $\mathrm{A}(23,14,4$ \\
\hline & A31 & $\mathrm{A}(14,15,1$ \\
\hline & A 32 & $\mathrm{~A}(14,15,1)$ \\
\hline & A33 & $A(14,15,1$ \\
\hline & A34 & $A(16,15,1$ \\
\hline & A35 & $\mathrm{A}(16,15,1$ \\
\hline & A36 & $A(17,15,1$ \\
\hline & A 37 & $A(14,19,2$ \\
\hline & A38 & $A(14,19,2$ \\
\hline & A39 & $A(14,19,2$ \\
\hline & A4 0 & $A(20,19,2$ \\
\hline & A 41 & $A(20,19,2$ \\
\hline & A4 2 & $A(21,19,22$ \\
\hline & A43 & $A(14,23,24$ \\
\hline & A4 4 & $A(14,23,2$ \\
\hline & A4 5 & $A(14,23,2$ \\
\hline & A4 6 & $\mathrm{~A}(2$ \\
\hline & A4 7 & $A(24,23,2$ \\
\hline & A4 8 & $A(25,23,26$ \\
\hline & A49 & $A(28$, \\
\hline & A 50 & $A(28$, \\
\hline & A 51 & $A(28,27,4$ \\
\hline & A 52 & $\mathrm{~A}($ \\
\hline & A 53 & $A(32,27,4$ \\
\hline & A 54 & $A(36,27,4$ \\
\hline & A 55 & $A(27,28,29$ \\
\hline & A 56 & $A(27,28,3$ \\
\hline & A 57 & $A(27,28$, \\
\hline & A 58 & $A(29,28$, \\
\hline & A 59 & $A(29,28$, \\
\hline & A 60 & $A(30,28$, \\
\hline & A61 & A ( \\
\hline & A 62 & $A(27,32,3$ \\
\hline & A 63 & $A(27$, \\
\hline & A 64 & A $(33$, \\
\hline & A 65 & A ( \\
\hline & A 66 & A $(34$, \\
\hline & A 67 & $A(27$, \\
\hline & A68 & $\mathrm{A}($ \\
\hline & A 69 & $A(27$, \\
\hline & A 70 & $A(37$, \\
\hline & A 71 & $\mathrm{~A}($ \\
\hline & A 72 & 38,36 , \\
\hline & A73 & $A(2,40,2)$ \\
\hline & A 74 & $\mathrm{~A}(2,40,4$ \\
\hline & A 75 & $A(27,40$, \\
\hline & A 76 & $\mathrm{~A}(6,41,1$ \\
\hline & A77 & $\mathrm{A}(6,41,43$ \\
\hline & A 78 & $\mathrm{~A}(14,41$, \\
\hline & D1 & $D(6,1$, \\
\hline & D2 & $\mathrm{D}(6,1,2,4$ \\
\hline & D3 & $D(7,1,2,3$ \\
\hline & D4 & $\mathrm{D}(7,1,2$, \\
\hline & D5 & $\mathrm{D}(2,1,6,5$ \\
\hline & D6 & $\mathrm{D}(2,1,6,4]$ \\
\hline & D7 & $\mathrm{D}(7,1,6,5$ \\
\hline & D8 & $\mathrm{D}(7,1,6$, \\
\hline & D9 & \\
\hline & $\mathrm{D} 10$ & \\
\hline
\end{tabular}

107.2662

107.2677

107.8684

108.0895

112.8586

110.2137

108.205

107.2873

109.9928

109.1436

113.8279

110.0402

107.7503

107.9933

107.9073

111.6082

108.18

111.4333

108.856

107.9141

108.7864

109.9649

113.6868

109.2733

107.943

108.0692

107.7357

108.2076

112.8567

109.9893

108.0894

107.2861

110.2178

113.6835

109.964

109.2757

107.9443

107.7352

108.0705

108.1812

111.6102

111.4315

108.8563

108.7846

107.9142

110.042

113.8286

109.1412

107.9076

107.9926

107.7503

125.898

117.4357

116.6608

125.8993

117.4364

116.6591

0.5235

$-179.7436$

$-179.8764$

- 0.1435

$-0.5207$

179.7272

179.8792

0.1271

0.0271

179.3077
$-\mathrm{DE} / \mathrm{DX}=$

$-\mathrm{DE} / \mathrm{DX}=$

$-D E / D X=$

$-\mathrm{DE} / \mathrm{DX}=$

$-\mathrm{DE} / \mathrm{DX}=$

$-\mathrm{DE} / \mathrm{DX}=$

$-D E / D X=$

$-\mathrm{DE} / \mathrm{DX}=$

$-\mathrm{DE} / \mathrm{DX}=$

$-D E / D X=$

$-D E / D X=$

$-\mathrm{DE} / \mathrm{DX}=$

$-D E / D X=$

$-\mathrm{DE} / \mathrm{DX}=$

$-\mathrm{DE} / \mathrm{DX}=$

$-D E / D X=$

$-D E / D X=$

$-\mathrm{DE} / \mathrm{DX}=$

$-D E / D X=$

$-D E / D X=$

$-\mathrm{DE} / \mathrm{DX}=$

$-\mathrm{DE} / \mathrm{DX}=$

$-D E / D X=$

$-\mathrm{DE} / \mathrm{DX}=$

$-\mathrm{DE} / \mathrm{DX}=$

$-\mathrm{DE} / \mathrm{DX}=$

$-\mathrm{DE} / \mathrm{DX}=$

$-\mathrm{DE} / \mathrm{DX}=$

$-\mathrm{DE} / \mathrm{DX}=$

$-\mathrm{DE} / \mathrm{DX}=$

$-\mathrm{DE} / \mathrm{DX}=$

$-\mathrm{DE} / \mathrm{DX}=$

$-\mathrm{DE} / \mathrm{DX}=$

$-\mathrm{DE} / \mathrm{DX}=$

$-D E / D X=$

$-\mathrm{DE} / \mathrm{DX}=$

$-\mathrm{DE} / \mathrm{DX}=$

$-\mathrm{DE} / \mathrm{DX}=$

$-\mathrm{DE} / \mathrm{DX}=$

$-\mathrm{DE} / \mathrm{DX}=$

$-\mathrm{DE} / \mathrm{DX}=$

$-\mathrm{DE} / \mathrm{DX}=$

$-\mathrm{DE} / \mathrm{DX}=$

$-\mathrm{DE} / \mathrm{DX}=$

$-\mathrm{DE} / \mathrm{DX}=$

$-\mathrm{DE} / \mathrm{DX}=$

$-\mathrm{DE} / \mathrm{DX}=$

$-\mathrm{DE} / \mathrm{DX}=$

$-\mathrm{DE} / \mathrm{DX}=$

$-\mathrm{DE} / \mathrm{DX}=$

$-\mathrm{DE} / \mathrm{DX}=$

$-\mathrm{DE} / \mathrm{DX}=$

$-D E / D X=$

$-\mathrm{DE} / \mathrm{DX}=$

$-\mathrm{DE} / \mathrm{DX}=$

$-\mathrm{DE} / \mathrm{DX}=$

$-\mathrm{DE} / \mathrm{DX}=$

$-\mathrm{DE} / \mathrm{DX}=$

$-\mathrm{DE} / \mathrm{DX}=$

$-\mathrm{DE} / \mathrm{DX}=$

$-\mathrm{DE} / \mathrm{DX}=$

$-\mathrm{DE} / \mathrm{DX}=$

$-\mathrm{DE} / \mathrm{DX}=$

$-\mathrm{DE} / \mathrm{DX}=$

$-\mathrm{DE} / \mathrm{DX}=$

$-\mathrm{DE} / \mathrm{DX}=$
0.0
0.0

0.0

0.0

0.0

0.0

0.0

0.0

0.0

0.0

0.0

0.0

0.0

0.0

0.0

0.0

0.0

0.0

0.0

0.0

0.0

0.0

0.0

0.0

0.0

0.0

0.0

0.0

0.0

0.0

0.0

0.0

0.0

0.0

0.0

0.0

0.0

0.0

0.0

0.0

0.0

0.0

0.0

0.0

0.0

0.0

0.0

0.0

0.0

0.0

0.0

0.0

0.0

0.0

0.0

0.0

0.0

0.0

0.0

0.0

0.0

0.0

0.0

0.0

0.0

0.0

0.0 


\begin{tabular}{|c|c|c|}
\hline & D11 & $D(40,2,3,4)$ \\
\hline ! & $\mathrm{D} 12$ & $D(40,2,3,8)$ \\
\hline & D13 & $D(1,2,40,27)$ \\
\hline & D14 & $D(1,2,40,42)$ \\
\hline & D15 & $D(3,2,40,27)$ \\
\hline & D16 & $\mathrm{D}(3,2,40,42)$ \\
\hline & D17 & $D(2,3,4,5)$ \\
\hline & D18 & $\mathrm{D}(2,3,4,10)$ \\
\hline & D19 & $D(8,3,4,5)$ \\
\hline & D2 0 & $D(8,3,4,10)$ \\
\hline ! & D21 & $D(3,4,5,6)$ \\
\hline & D22 & $\mathrm{D}(3,4,5,9)$ \\
\hline ! & D23 & $D(10,4,5,6)$ \\
\hline & D24 & $\mathrm{D}(10,4,5,9)$ \\
\hline & D2 5 & $\mathrm{D}(3,4,10,11)$ \\
\hline ! & D2 6 & $\mathrm{D}(3,4,10,12)$ \\
\hline ! & D27 & $\mathrm{D}(3,4,10,13)$ \\
\hline ! & D2 8 & $\mathrm{D}(5,4,10,11)$ \\
\hline ! & D29 & $D(5,4,10,12)$ \\
\hline ! & D30 & $D(5,4,10,13)$ \\
\hline ! & D31 & $\mathrm{D}(4,5,6,1)$ \\
\hline ! & D32 & $D(4,5,6,41)$ \\
\hline ! & D33 & $\mathrm{D}(9,5,6,1)$ \\
\hline ! & D34 & $D(9,5,6,41)$ \\
\hline ! & D35 & $\mathrm{D}(1,6,41,14)$ \\
\hline ! & D36 & $D(1,6,41,43)$ \\
\hline ! & D37 & $D(5,6,41,14)$ \\
\hline ! & D38 & $D(5,6,41,43)$ \\
\hline ! & D39 & $\mathrm{D}(19,14,15,16)$ \\
\hline ! & D4 0 & $\mathrm{D}(19,14,15,17)$ \\
\hline ! & D4 1 & $\mathrm{D}(19,14,15,18)$ \\
\hline ! & $\mathrm{D} 42$ & $\mathrm{D}(23,14,15,16)$ \\
\hline ! & D4 3 & $\mathrm{D}(23,14,15,17)$ \\
\hline ! & $\mathrm{D} 44$ & $\mathrm{D}(23,14,15,18)$ \\
\hline ! & D45 & $\mathrm{D}(41,14,15,16)$ \\
\hline ! & D4 6 & $\mathrm{D}(41,14,15,17)$ \\
\hline ! & D4 7 & $\mathrm{D}(41,14,15,18)$ \\
\hline ! & $\mathrm{D} 48$ & $\mathrm{D}(15,14,19,20)$ \\
\hline ! & D49 & $\mathrm{D}(15,14,19,21)$ \\
\hline ! & D50 & $\mathrm{D}(15,14,19,22)$ \\
\hline ! & D51 & $\mathrm{D}(23,14,19,20)$ \\
\hline ! & D52 & $\mathrm{D}(23,14,19,21)$ \\
\hline ! & D53 & $\mathrm{D}(23,14,19,22)$ \\
\hline ! & D54 & $\mathrm{D}(41,14,19,20)$ \\
\hline ! & D5 5 & $\mathrm{D}(41,14,19,21)$ \\
\hline ! & D56 & $\mathrm{D}(41,14,19,22)$ \\
\hline ! & D57 & $\mathrm{D}(15,14,23,24)$ \\
\hline ! & D58 & $D(15,14,23,25)$ \\
\hline ! & D59 & $\mathrm{D}(15,14,23,26)$ \\
\hline ! & $\mathrm{D} 60$ & $\mathrm{D}(19,14,23,24)$ \\
\hline ! & D61 & $D(19,14,23,25)$ \\
\hline ! & D62 & $\mathrm{D}(19,14,23,26)$ \\
\hline ! & D63 & $D(41,14,23,24)$ \\
\hline ! & D64 & $\mathrm{D}(41,14,23,25)$ \\
\hline ! & D65 & $D(41,14,23,26)$ \\
\hline ! & D66 & $D(15,14,41,6)$ \\
\hline ! & D67 & $D(15,14,41,43)$ \\
\hline ! & D68 & $\mathrm{D}(19,14,41,6)$ \\
\hline ! & D69 & $\mathrm{D}(19,14,41,43)$ \\
\hline ! & D70 & $\mathrm{D}(23,14,41,6)$ \\
\hline ! & D71 & $D(23,14,41,43)$ \\
\hline ! & D72 & $\mathrm{D}(32,27,28,29)$ \\
\hline ! & D73 & $\mathrm{D}(32,27,28,30)$ \\
\hline ! & D74 & $\mathrm{D}(32,27,28,31)$ \\
\hline ! & D75 & $\mathrm{D}(36,27,28,29)$ \\
\hline ! & D76 & $D(36,27,28,30)$ \\
\hline & D77 & $\mathrm{D}(36,27,28,31)$ \\
\hline
\end{tabular}

\begin{tabular}{|c|c|c|c|}
\hline-179.6851 & - DE/DX & $=$ & 0.0 \\
\hline-0.4045 & $-\mathrm{DE} / \mathrm{DX}$ & $=$ & 0.0 \\
\hline 173.2829 & - DE/DX & $=$ & 0.0 \\
\hline-5.8328 & - DE/DX & $=$ & 0.0 \\
\hline-6.9979 & - DE/DX & $=$ & 0.0 \\
\hline 173.8864 & - DE/DX & $=$ & 0.0 \\
\hline-0.5763 & - DE/DX & $=$ & 0.0 \\
\hline 177.7459 & - DE/DX & $=$ & 0.0 \\
\hline-179.8821 & - DE/DX & $=$ & 0.0 \\
\hline-1.5599 & - DE/DX & $=$ & 0.0 \\
\hline 0.5791 & $-\mathrm{DE} / \mathrm{DX}$ & $=$ & 0.0 \\
\hline 179.9 & - DE/DX & $=$ & 0.0 \\
\hline-177.743 & $-D E / D X$ & $=$ & 0.0 \\
\hline 1.5779 & - DE/DX & $=$ & 0.0 \\
\hline-89.0926 & $-D E / D X$ & $=$ & 0.0 \\
\hline 30.588 & - DE/DX & $=$ & 0.0 \\
\hline 151.225 & - DE/DX & $=$ & 0.0 \\
\hline 89.2339 & - DE/DX & $=$ & 0.0 \\
\hline-151.0855 & - DE/DX & $=$ & 0.0 \\
\hline-30.4485 & - DE/DX & $=$ & 0.0 \\
\hline-0.0327 & - DE/DX & $=$ & 0.0 \\
\hline 179.7002 & - DE/DX & $=$ & 0.0 \\
\hline-179.3289 & - DE/DX & $=$ & 0.0 \\
\hline 0.4039 & - DE/DX & $=$ & 0.0 \\
\hline-173.4745 & - DE/DX & $=$ & 0.0 \\
\hline 5.6641 & - DE/DX & $=$ & 0.0 \\
\hline 6.7862 & - DE/DX & $=$ & 0.0 \\
\hline-174.0752 & - DE/DX & $=$ & 0.0 \\
\hline 59.4514 & - DE/DX & $=$ & 0.0 \\
\hline 179.8552 & - DE/DX & $=$ & 0.0 \\
\hline-58.8873 & -DE/DX & $=$ & 0.0 \\
\hline-60.1772 & - DE/DX & $=$ & 0.0 \\
\hline 60.2266 & -DE/DX & $=$ & 0.0 \\
\hline-178.5159 & - DE/DX & $=$ & 0.0 \\
\hline 176.4136 & - DE/DX & $=$ & 0.0 \\
\hline-63.1825 & - DE/DX & $=$ & 0.0 \\
\hline 58.0749 & $-\mathrm{DE} / \mathrm{DX}$ & $=$ & 0.0 \\
\hline 179.9495 & - DE/DX & $=$ & 0.0 \\
\hline-60.3174 & $-D E / D X$ & $=$ & 0.0 \\
\hline 59.2248 & - DE/DX & $=$ & 0.0 \\
\hline-57.5289 & - DE/DX & $=$ & 0.0 \\
\hline 62.2042 & - DE/DX & $=$ & 0.0 \\
\hline-178.2537 & - DE/DX & $=$ & 0.0 \\
\hline 61.1108 & -DE/DX & $=$ & 0.0 \\
\hline-179.156 & - DE/DX & $=$ & 0.0 \\
\hline-59.6139 & - DE/DX & $=$ & 0.0 \\
\hline 179.7525 & - DE/DX & $=$ & 0.0 \\
\hline-59.0968 & - DE/DX & $=$ & 0.0 \\
\hline 61.2877 & - DE/DX & $=$ & 0.0 \\
\hline 60.1906 & - DE/DX & $=$ & 0.0 \\
\hline-178.6588 & - DE/DX & $=$ & 0.0 \\
\hline-58.2742 & $-D E / D X$ & $=$ & 0.0 \\
\hline-56.7161 & - DE/DX & $=$ & 0.0 \\
\hline 64.4346 & - DE/DX & $=$ & 0.0 \\
\hline-175.1809 & -DE/DX & $=$ & 0.0 \\
\hline 57.5048 & - DE/DX & $=$ & 0.0 \\
\hline-121.6398 & - DE/DX & $=$ & 0.0 \\
\hline 174.9646 & - DE/DX & $=$ & 0.0 \\
\hline-4.18 & -DE/DX & $=$ & 0.0 \\
\hline-67.5571 & - DE/DX & $=$ & 0.0 \\
\hline 113.2984 & - DE/DX & $=$ & 0.0 \\
\hline 178.6336 & - DE/DX & $=$ & 0.0 \\
\hline-60.2171 & -DE/DX & $=$ & 0.0 \\
\hline 58.2502 & - DE/DX & $=$ & 0.0 \\
\hline 59.0711 & $-\mathrm{DE} / \mathrm{DX}$ & $=$ & 0.0 \\
\hline - 179.7796 & - DE/DX & $=$ & 0.0 \\
\hline-61.3123 & - DE/DX & $=$ & 0.0 \\
\hline
\end{tabular}




\begin{tabular}{|c|c|c|}
\hline & D78 & $D(40,27,28,29)$ \\
\hline & D79 & $\mathrm{D}(40,27,28,30)$ \\
\hline & D80 & $D(40,27,28,31)$ \\
\hline & D81 & $D(28,27,32,33)$ \\
\hline & D82 & $D(28,27,32,34)$ \\
\hline & D83 & $\mathrm{D}(28,27,32,35)$ \\
\hline & D84 & $D(36,27,32,33)$ \\
\hline & D85 & $D(36,27,32,34)$ \\
\hline & D86 & $(36,27,32,35)$ \\
\hline & D87 & $D(40,27,32,33)$ \\
\hline & D88 & $D(40,27,32,34)$ \\
\hline & D89 & $D(40,27,32,35)$ \\
\hline & D90 & $D(28,2$ \\
\hline & D91 & $\mathrm{D}(28,27,36,3$ \\
\hline & D9 2 & $D(28,27,36,3$ \\
\hline & D93 & $\mathrm{D}(32,27$, \\
\hline & D94 & $2,27,36,3$ \\
\hline & D95 & $32,27,36,39)$ \\
\hline & D96 & $\mathrm{D}(40,27,36,37)$ \\
\hline & D9 7 &, 27, \\
\hline & D98 & $\mathrm{D}(40,27,36,39)$ \\
\hline & D99 & $\mathrm{D}(28,27,40,2)$ \\
\hline & D100 & $\mathrm{D}(28,27,40,42)$ \\
\hline & D101 & $D(32,27,40,2)$ \\
\hline & D102 & $\mathrm{D}(32,27,40,42)$ \\
\hline & D103 & $\mathrm{D}(36,27,40,2)$ \\
\hline & D104 & $\mathrm{D}(36,27,40,42)$ \\
\hline
\end{tabular}

$\begin{array}{rll}-64.4617 & -\mathrm{DE} / \mathrm{DX}= & 0.0 \\ 56.6876 & -\mathrm{DE} / \mathrm{DX}= & 0.0 \\ 175.1549 & -\mathrm{DE} / \mathrm{DX}= & 0.0 \\ -62.227 & -\mathrm{DE} / \mathrm{DX}= & 0.0 \\ 57.5085 & -\mathrm{DE} / \mathrm{DX}= & 0.0 \\ 178.2335 & -\mathrm{DE} / \mathrm{DX}= & 0.0 \\ 60.2939 & -\mathrm{DE} / \mathrm{DX}= & 0.0 \\ -179.9706 & -\mathrm{DE} / \mathrm{DX}= & 0.0 \\ -59.2457 & -\mathrm{DE} / \mathrm{DX}= & 0.0 \\ 179.1367 & -\mathrm{DE} / \mathrm{DX}= & 0.0 \\ -61.1278 & -\mathrm{DE} / \mathrm{DX}= & 0.0 \\ 59.5972 & -\mathrm{DE} / \mathrm{DX}= & 0.0 \\ 178.5234 & -\mathrm{DE} / \mathrm{DX}= & 0.0 \\ -60.2168 & -\mathrm{DE} / \mathrm{DX}= & 0.0 \\ 60.1858 & -\mathrm{DE} / \mathrm{DX}= & 0.0 \\ 58.8928 & -\mathrm{DE} / \mathrm{DX}= & 0.0 \\ -179.8475 & -\mathrm{DE} / \mathrm{DX}= & 0.0 \\ -59.4449 & -\mathrm{DE} / \mathrm{DX}= & 0.0 \\ -58.0703 & -\mathrm{DE} / \mathrm{DX}= & 0.0 \\ 63.1895 & -\mathrm{DE} / \mathrm{DX}= & 0.0 \\ -176.4079 & -\mathrm{DE} / \mathrm{DX}= & 0.0 \\ 67.7111 & -\mathrm{DE} / \mathrm{DX}= & 0.0 \\ -113.1671 & -\mathrm{DE} / \mathrm{DX}= & 0.0 \\ -174.8101 & -\mathrm{DE} / \mathrm{DX}= & 0.0 \\ 4.3117 & -\mathrm{DE} / \mathrm{DX}= & 0.0 \\ -57.3488 & -\mathrm{DE} / \mathrm{DX}= & 0.0 \\ 121.7729 & -\mathrm{DE} / \mathrm{DX}= & 0.0\end{array}$

GradGradGradGradGradGradGradGradGradGradGradGradGradGradGradGradGradGrad

Input orientation:

\begin{tabular}{|c|c|c|c|c|c|}
\hline \multirow{2}{*}{$\begin{array}{l}\text { Center } \\
\text { Number }\end{array}$} & \multirow{2}{*}{$\begin{array}{l}\text { Atomic } \\
\text { Number }\end{array}$} & \multirow{2}{*}{$\begin{array}{c}\text { Atomic } \\
\text { Type }\end{array}$} & \multicolumn{3}{|c|}{ Coordinates (Angstroms) } \\
\hline & & & $\mathrm{X}$ & $\mathrm{Y}$ & Z \\
\hline 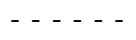 & 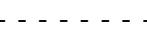 & $-\ldots-\ldots$ & $-\ldots-\ldots$ & $\ldots$ & $\ldots-\ldots$ \\
\hline 1 & 6 & 0 & -0.087431 & -0.663471 & -0.029287 \\
\hline 2 & 6 & 0 & -0.092106 & -0.626378 & 1.372197 \\
\hline 3 & 6 & 0 & 1.134579 & -0.607916 & 2.066454 \\
\hline 4 & 6 & 0 & 2.341100 & -0.625874 & 1.363155 \\
\hline 5 & 6 & 0 & 2.339160 & -0.674392 & -0.032645 \\
\hline 6 & 6 & 0 & 1.120324 & -0.693229 & -0.740633 \\
\hline 7 & 1 & 0 & -1.022556 & -0.675708 & -0.565508 \\
\hline 8 & 1 & 0 & 1.174889 & -0.568263 & 3.144768 \\
\hline 9 & 1 & 0 & 3.290928 & -0.685333 & -0.542507 \\
\hline 10 & 6 & 0 & 3.653072 & -0.554306 & 2.113801 \\
\hline 11 & 1 & 0 & 3.969020 & 0.486621 & 2.263609 \\
\hline 12 & 1 & 0 & 3.574750 & -1.015912 & 3.103809 \\
\hline 13 & 1 & 0 & 4.455598 & -1.062369 & 1.568694 \\
\hline 14 & 6 & 0 & 2.183418 & -0.912813 & -3.122094 \\
\hline 15 & 6 & 0 & 2.937333 & -2.222733 & -2.815034 \\
\hline 16 & 1 & 0 & 3.728198 & -2.365104 & -3.559678 \\
\hline 17 & 1 & 0 & 3.402078 & -2.242829 & -1.828297 \\
\hline 18 & 1 & 0 & 2.252363 & -3.074467 & -2.882008 \\
\hline 19 & 6 & 0 & 1.588129 & -1.024652 & -4.534911 \\
\hline 20 & 1 & 0 & 1.038263 & -0.123457 & -4.811870 \\
\hline 21 & 1 & 0 & 2.411982 & -1.168247 & -5.242561 \\
\hline 22 & 1 & 0 & 0.904702 & -1.872778 & -4.614008 \\
\hline 23 & 6 & 0 & 3.098347 & 0.329016 & -3.081404 \\
\hline 24 & 1 & 0 & 2.517707 & 1.228824 & -3.309673 \\
\hline 25 & 1 & 0 & 3.588944 & 0.480766 & -2.118462 \\
\hline 26 & 1 & 0 & 3.880343 & 0.227148 & -3.842014 \\
\hline 27 & 6 & 0 & -1.616072 & -0.706985 & 3.498378 \\
\hline 28 & 6 & 0 & -1.086307 & 0.554699 & 4.211397 \\
\hline 29 & 1 & 0 & -0.003711 & 0.674611 & 4.143515 \\
\hline 30 & 1 & 0 & -1.552187 & 1.448849 & 3.784369 \\
\hline 31 & 1 & 0 & -1.350967 & 0.507898 & 5.273558 \\
\hline 32 & 6 & 0 & -3.138582 & -0.769550 & 3.700872 \\
\hline
\end{tabular}




\begin{tabular}{|c|c|c|c|c|c|}
\hline 33 & 1 & 0 & -3.337201 & -0.860037 & 4.774411 \\
\hline 34 & 1 & 0 & -3.631268 & 0.129089 & 3.325504 \\
\hline 35 & 1 & 0 & -3.574198 & -1.630230 & 3.188870 \\
\hline 36 & 6 & 0 & -1.005228 & -2.009781 & 4.053442 \\
\hline 37 & 1 & 0 & -1.431143 & -2.874860 & 3.534444 \\
\hline 38 & 1 & 0 & 0.080255 & -2.062857 & 3.958842 \\
\hline 39 & 1 & 0 & -1.252496 & -2.097798 & 5.117087 \\
\hline 40 & 7 & 0 & -1.363572 & -0.603788 & 2.005478 \\
\hline 41 & 7 & 0 & 1.025267 & -0.735869 & -2.157435 \\
\hline 42 & 8 & 0 & -2.396846 & -0.503252 & 1.252750 \\
\hline 43 & 8 & 0 & -0.143490 & -0.631510 & -2.674603 \\
\hline
\end{tabular}

\section{DFT calculations on nitroxide diradical 4a at the UB3LYP/6-31G(d) level with Gaussian 03}
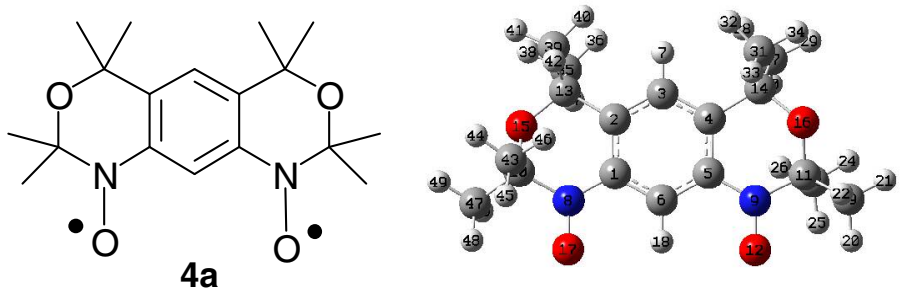

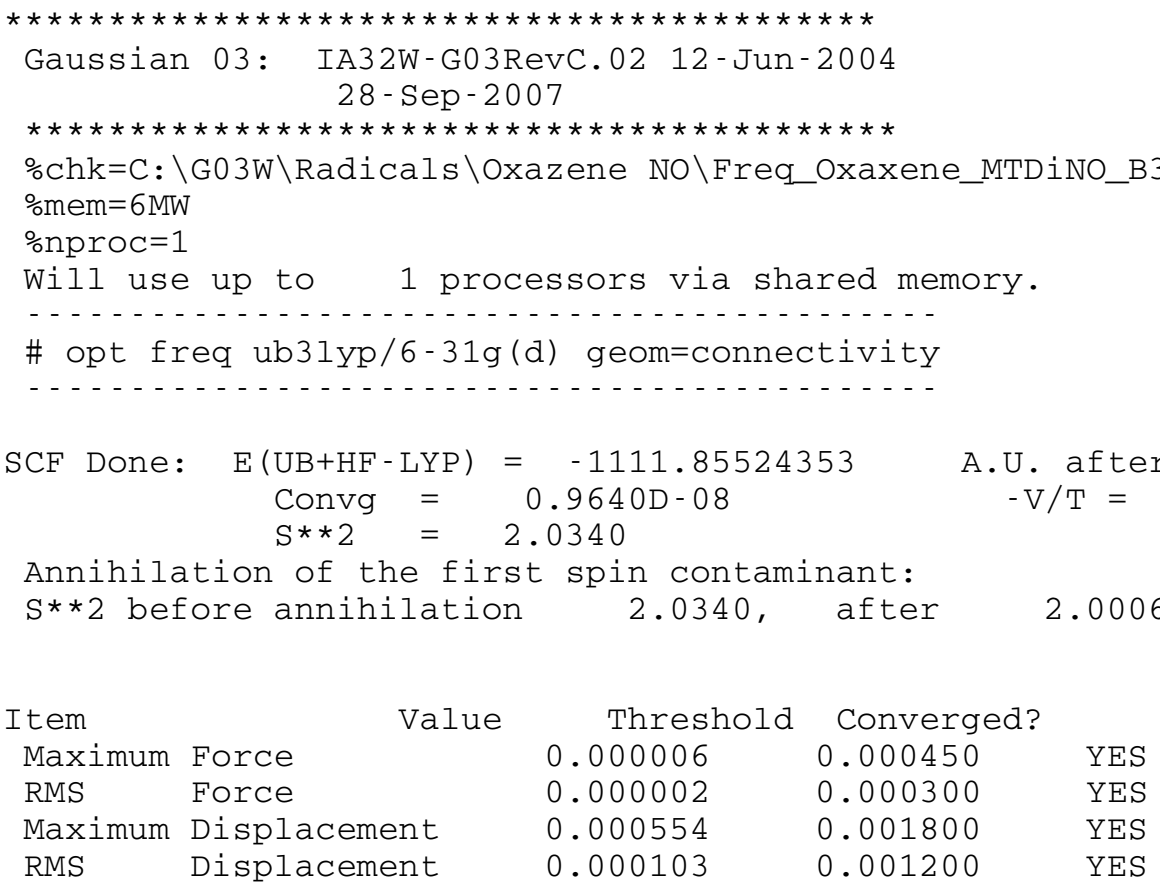

Predicted change in Energy $=-4.120980 \mathrm{D}-09$

optimization completed.

- stationary point found.

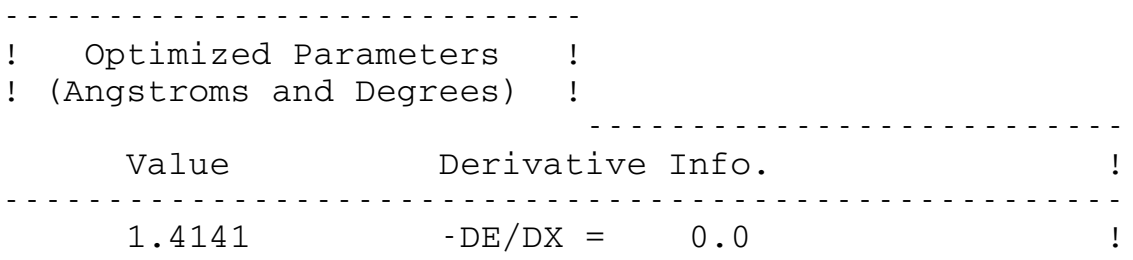




\begin{tabular}{|c|c|c|}
\hline ! & R2 & $R(1,6)$ \\
\hline ! & R3 & $R(1,8)$ \\
\hline ! & R4 & $R(2,3)$ \\
\hline ! & R5 & $R(2,13)$ \\
\hline ! & R6 & $R(3,4)$ \\
\hline ! & R7 & $R(3,7)$ \\
\hline ! & R8 & $R(4,5)$ \\
\hline ! & R9 & $R(4,14)$ \\
\hline ! & R10 & $R(5,6)$ \\
\hline ! & R11 & $R(5,9)$ \\
\hline ! & R12 & $R(6,18)$ \\
\hline ! & R13 & $R(8,10)$ \\
\hline ! & R14 & $R(8,17)$ \\
\hline ! & R15 & $R(9,11)$ \\
\hline ! & R16 & $R(9,12)$ \\
\hline ! & R17 & $R(10,15)$ \\
\hline ! & R18 & $R(10,43)$ \\
\hline ! & R19 & $R(10,47)$ \\
\hline ! & R2 0 & $R(11,16)$ \\
\hline ! & R21 & $R(11,19)$ \\
\hline ! & $\mathrm{R} 22$ & $R(11,23)$ \\
\hline ! & R23 & $R(13,15)$ \\
\hline ! & R24 & $R(13,35)$ \\
\hline ! & R2 5 & $R(13,39)$ \\
\hline ! & R26 & $R(14,16)$ \\
\hline ! & R2 7 & $R(14,27)$ \\
\hline ! & R2 8 & $R(14,31)$ \\
\hline ! & R29 & $R(19,20)$ \\
\hline ! & R30 & $R(19,21)$ \\
\hline ! & R31 & $R(19,22)$ \\
\hline ! & R32 & $R(23,24)$ \\
\hline ! & R33 & $R(23,25)$ \\
\hline ! & R34 & $R(23,26)$ \\
\hline ! & R35 & $R(27,28)$ \\
\hline ! & R36 & $R(27,29)$ \\
\hline ! & R37 & $R(27,30)$ \\
\hline ! & R3 8 & $R(31,32)$ \\
\hline ! & R39 & $R(31,33)$ \\
\hline ! & $\mathrm{R} 40$ & $\mathrm{R}(31,34)$ \\
\hline ! & $\mathrm{R} 41$ & $R(35,36)$ \\
\hline ! & $\mathrm{R} 42$ & $R(35,37)$ \\
\hline ! & R4 3 & $R(35,38)$ \\
\hline ! & $\mathrm{R} 44$ & $R(39,40)$ \\
\hline ! & R4 5 & $R(39,41)$ \\
\hline ! & $\mathrm{R} 46$ & $R(39,42)$ \\
\hline ! & R4 7 & $R(43,44)$ \\
\hline ! & $\mathrm{R} 48$ & $R(43,45)$ \\
\hline ! & R49 & $R(43,46)$ \\
\hline ! & R50 & $R(47,48)$ \\
\hline ! & R51 & $R(47,49)$ \\
\hline ! & R52 & $R(47,50)$ \\
\hline ! & $\mathrm{A} 1$ & $A(2,1,6)$ \\
\hline ! & A2 & $A(2,1,8)$ \\
\hline ! & A3 & $A(6,1,8)$ \\
\hline ! & A4 & $A(1,2,3)$ \\
\hline ! & A 5 & $A(1,2,13)$ \\
\hline ! & A 6 & $A(3,2,13)$ \\
\hline ! & A 7 & $A(2,3,4)$ \\
\hline ! & A 8 & $A(2,3,7)$ \\
\hline ! & A9 & $A(4,3,7)$ \\
\hline ! & A10 & $A(3,4,5)$ \\
\hline ! & A11 & $\mathrm{A}(3,4,14)$ \\
\hline ! & A12 & $A(5,4,14)$ \\
\hline ! & A13 & $A(4,5,6)$ \\
\hline ! & A14 & $A(4,5,9)$ \\
\hline ! & A15 & $A(6,5,9)$ \\
\hline ! & A16 & $A(1,6,5)$ \\
\hline
\end{tabular}

\begin{tabular}{|c|c|c|c|}
\hline 1.3979 & $-\mathrm{DE} / \mathrm{DX}$ & $=$ & 0.0 \\
\hline 1.3998 & $-\mathrm{DE} / \mathrm{DX}$ & $=$ & 0.0 \\
\hline 1.3968 & - DE/DX & $=$ & 0.0 \\
\hline 1.522 & $-\mathrm{DE} / \mathrm{DX}$ & $=$ & 0.0 \\
\hline 1.3968 & -DE/DX & $=$ & 0.0 \\
\hline 1.0862 & $-\mathrm{DE} / \mathrm{DX}$ & $=$ & 0.0 \\
\hline 1.4141 & -DE/DX & $=$ & 0.0 \\
\hline 1.522 & $-\mathrm{DE} / \mathrm{DX}$ & $=$ & 0.0 \\
\hline 1.3979 & -DE/DX & $=$ & 0.0 \\
\hline 1.3998 & $-\mathrm{DE} / \mathrm{DX}$ & $=$ & 0.0 \\
\hline 1.0806 & -DE/DX & $=$ & 0.0 \\
\hline 1.4964 & $-\mathrm{DE} / \mathrm{DX}$ & $=$ & 0.0 \\
\hline 1.279 & $-\mathrm{DE} / \mathrm{DX}$ & $=$ & 0.0 \\
\hline 1.4964 & - DE/DX & $=$ & 0.0 \\
\hline 1.279 & $-\mathrm{DE} / \mathrm{DX}$ & $=$ & 0.0 \\
\hline 1.4146 & -DE/DX & $=$ & 0.0 \\
\hline 1.5373 & $-\mathrm{DE} / \mathrm{DX}$ & $=$ & 0.0 \\
\hline 1.5264 & - DE/DX & $=$ & 0.0 \\
\hline 1.4146 & $-\mathrm{DE} / \mathrm{DX}$ & $=$ & 0.0 \\
\hline 1.5264 & - DE/DX & $=$ & 0.0 \\
\hline 1.5373 & $-\mathrm{DE} / \mathrm{DX}$ & $=$ & 0.0 \\
\hline 1.4453 & -DE/DX & $=$ & 0.0 \\
\hline 1.5401 & $-\mathrm{DE} / \mathrm{DX}$ & $=$ & 0.0 \\
\hline 1.5415 & $-\mathrm{DE} / \mathrm{DX}$ & $=$ & 0.0 \\
\hline 1.4453 & $-\mathrm{DE} / \mathrm{DX}$ & $=$ & 0.0 \\
\hline 1.5415 & $-\mathrm{DE} / \mathrm{DX}$ & $=$ & 0.0 \\
\hline 1.5401 & - DE/DX & $=$ & 0.0 \\
\hline 1.0902 & $-\mathrm{DE} / \mathrm{DX}$ & $=$ & 0.0 \\
\hline 1.0936 & - DE/DX & $=$ & 0.0 \\
\hline 1.0929 & $-\mathrm{DE} / \mathrm{DX}$ & $=$ & 0.0 \\
\hline 1.0941 & - DE/DX & $=$ & 0.0 \\
\hline 1.094 & $-\mathrm{DE} / \mathrm{DX}$ & $=$ & 0.0 \\
\hline 1.0931 & $-\mathrm{DE} / \mathrm{DX}$ & $=$ & 0.0 \\
\hline 1.0953 & $-\mathrm{DE} / \mathrm{DX}$ & $=$ & 0.0 \\
\hline 1.0948 & $-\mathrm{DE} / \mathrm{DX}$ & $=$ & 0.0 \\
\hline 1.0922 & $-\mathrm{DE} / \mathrm{DX}$ & $=$ & 0.0 \\
\hline 1.0943 & $-\mathrm{DE} / \mathrm{DX}$ & $=$ & 0.0 \\
\hline 1.0934 & $-\mathrm{DE} / \mathrm{DX}$ & $=$ & 0.0 \\
\hline 1.0949 & $-\mathrm{DE} / \mathrm{DX}$ & $=$ & 0.0 \\
\hline 1.0943 & - DE/DX & $=$ & 0.0 \\
\hline 1.0934 & $-\mathrm{DE} / \mathrm{DX}$ & $=$ & 0.0 \\
\hline 1.0949 & - DE/DX & $=$ & 0.0 \\
\hline 1.0953 & $-\mathrm{DE} / \mathrm{DX}$ & $=$ & 0.0 \\
\hline 1.0948 & $-\mathrm{DE} / \mathrm{DX}$ & $=$ & 0.0 \\
\hline 1.0922 & $-\mathrm{DE} / \mathrm{DX}$ & $=$ & 0.0 \\
\hline 1.0941 & $-\mathrm{DE} / \mathrm{DX}$ & $=$ & 0.0 \\
\hline 1.0939 & $-\mathrm{DE} / \mathrm{DX}$ & $=$ & 0.0 \\
\hline 1.0931 & $-\mathrm{DE} / \mathrm{DX}$ & $=$ & 0.0 \\
\hline 1.0902 & $-\mathrm{DE} / \mathrm{DX}$ & $=$ & 0.0 \\
\hline 1.0936 & $-\mathrm{DE} / \mathrm{DX}$ & $=$ & 0.0 \\
\hline 1.0929 & $-\mathrm{DE} / \mathrm{DX}$ & $=$ & 0.0 \\
\hline 1.0099 & $-\mathrm{DE} / \mathrm{DX}$ & $=$ & 0.0 \\
\hline 9.972 & $-\mathrm{DE} / \mathrm{DX}$ & $=$ & 0.0 \\
\hline 9.0139 & $-\mathrm{DE} / \mathrm{DX}$ & $=$ & 0.0 \\
\hline 7.5756 & - DE/DX & $=$ & 0.0 \\
\hline 1.1151 & $-\mathrm{DE} / \mathrm{DX}$ & $=$ & 0.0 \\
\hline 1.2589 & - DE/DX & $=$ & 0.0 \\
\hline 3.1597 & $-\mathrm{DE} / \mathrm{DX}$ & $=$ & 0.0 \\
\hline 8.4202 & $-\mathrm{DE} / \mathrm{DX}$ & $=$ & 0.0 \\
\hline 8.4201 & $-\mathrm{DE} / \mathrm{DX}$ & $=$ & 0.0 \\
\hline 7.5756 & $-\mathrm{DE} / \mathrm{DX}$ & $=$ & 0.0 \\
\hline 1.2588 & $-\mathrm{DE} / \mathrm{DX}$ & $=$ & 0.0 \\
\hline 1.1152 & $-\mathrm{DE} / \mathrm{DX}$ & $=$ & 0.0 \\
\hline 1.0098 & - DE/DX & $=$ & 0.0 \\
\hline 9.9722 & $-\mathrm{DE} / \mathrm{DX}$ & $=$ & 0.0 \\
\hline 9.0137 & $-\mathrm{DE} / \mathrm{DX}$ & $=$ & 0.0 \\
\hline 9.5876 & $-\mathrm{DE} / \mathrm{DX}$ & $=$ & 0.0 \\
\hline
\end{tabular}




\begin{tabular}{|c|c|c|}
\hline & A17 & $A(1,6,18)$ \\
\hline & A18 & $A(5,6,18)$ \\
\hline & A19 & $A(1,8,10)$ \\
\hline & $\mathrm{A} 20$ & $A(1,8,17)$ \\
\hline & A 21 & $A(10,8,17)$ \\
\hline & A 22 & $A(5,9,11)$ \\
\hline & A23 & $A(5,9,12)$ \\
\hline & A 24 & $A(11,9,12)$ \\
\hline & A2 5 & $A(8,10,15)$ \\
\hline & A2 6 & $A(8,10,43)$ \\
\hline & A2 7 & $A(8,10,47)$ \\
\hline & A2 8 & $A(15,10,43)$ \\
\hline & A29 & $A(15,10,47)$ \\
\hline & A30 & $A(43,10,47)$ \\
\hline & A31 & $A(9,11,16)$ \\
\hline & A32 & $A(9,11,19)$ \\
\hline & A33 & $A(9,11,23)$ \\
\hline & A34 & $A(16,11,19)$ \\
\hline & A35 & $A(16,11,23)$ \\
\hline & A3 6 & $A(19,11,23)$ \\
\hline & A37 & $A(2,13,15)$ \\
\hline & A3 8 & $A(2,13,35)$ \\
\hline & A39 & $A(2,13,39)$ \\
\hline & A 40 & $A(15,13,35)$ \\
\hline & A 41 & $A(15,13,39)$ \\
\hline & A 42 & $A(35,13,39)$ \\
\hline & A 43 & $A(4,14,16)$ \\
\hline & A 44 & $A(4,14,27)$ \\
\hline & A4 5 & $A(4,14,31)$ \\
\hline & A 46 & $A(16,14,27)$ \\
\hline & A 47 & $A(16,14,31)$ \\
\hline & A 48 & $A(27,14,31)$ \\
\hline & A 49 & $A(10,15,13)$ \\
\hline & A 50 & $A(11,16,14)$ \\
\hline & A 51 & $A(11,19,20)$ \\
\hline & A 52 & $A(11,19,21)$ \\
\hline & A53 & $A(11,19,22)$ \\
\hline & A 54 & $A(20,19,21)$ \\
\hline & A 55 & $A(20,19,22)$ \\
\hline & A 56 & $A(21,19,22)$ \\
\hline & A 57 & $A(11,23,24)$ \\
\hline & A 58 & $A(11,23,25)$ \\
\hline & A59 & $A(11,23,26)$ \\
\hline & A 60 & $A(24,23,25)$ \\
\hline & A61 & $A(24,23,26)$ \\
\hline & A 62 & $A(25,23,26)$ \\
\hline & A63 & $A(14,27,28)$ \\
\hline & A 64 & $A(14,27,29)$ \\
\hline & A 65 & $A(14,27,30)$ \\
\hline & A 66 & $A(28,27,29)$ \\
\hline & A 67 & $A(28,27,30)$ \\
\hline & A68 & $A(29,27,30)$ \\
\hline & A69 & $A(14,31,32)$ \\
\hline & A70 & $A(14,31,33)$ \\
\hline & A71 & $A(14,31,34)$ \\
\hline & A72 & $A(32,31,33)$ \\
\hline & A73 & $A(32,31,34)$ \\
\hline & A 74 & $A(33,31,34)$ \\
\hline & A75 & $A(13,35,36)$ \\
\hline & A 76 & $A(13,35,37)$ \\
\hline & A 77 & $A(13,35,38)$ \\
\hline & A 78 & $A(36,35,37)$ \\
\hline & A79 & $A(36,35,38)$ \\
\hline & A 80 & $A(37,35,38)$ \\
\hline & A81 & $A(13,39,40)$ \\
\hline & A 82 & $A(13,39,41)$ \\
\hline & A83 & $A(13,39,42)$ \\
\hline
\end{tabular}

120.2062

120.2062

119.1342

121.1201

118.2972

119.1343

121.1201

118.2972

109.1165

107.8879

108.9441

114.1742

105.117

111.4908

109.1165

108.9437

107.8876

105.1164

114.1759

111.4901

111.0969

110.1798

112.6354

102.8563

110.0406

109.5908

111.0968

112.6359

110.1793

110.042

102.8556

109.5899

122.118

122.1193

110.6554

108.7195

109.7515

109.7477

109.1404

108.7988

109.7843

109.2112

111.7446

109.1508

108.9729

107.9255

110.7529

109.2049

112.1626

108.2375

107.7919

108.5873

111.1818

110.1439

109.4655

108.769

108.6414

108.5842

111.1818

110.144

109.4655

108.7689

108.6414

108.5842

110.7529

109.205

112.1621
$-\mathrm{DE} / \mathrm{DX}=$

$-\mathrm{DE} / \mathrm{DX}=$

$-D E / D X=$

$-D E / D X=$

$-\mathrm{DE} / \mathrm{DX}=$

$-\mathrm{DE} / \mathrm{DX}=$

$-\mathrm{DE} / \mathrm{DX}=$

$-\mathrm{DE} / \mathrm{DX}=$

$-\mathrm{DE} / \mathrm{DX}=$

$-D E / D X=$

$-\mathrm{DE} / \mathrm{DX}=$

$-\mathrm{DE} / \mathrm{DX}=$

$-D E / D X=$

$-\mathrm{DE} / \mathrm{DX}=$

$-\mathrm{DE} / \mathrm{DX}=$

$-D E / D X=$

$-D E / D X=$

$-\mathrm{DE} / \mathrm{DX}=$

$-D E / D X=$

$-D E / D X=$

$-\mathrm{DE} / \mathrm{DX}=$

$-\mathrm{DE} / \mathrm{DX}=$

$-D E / D X=$

$-\mathrm{DE} / \mathrm{DX}=$

$-\mathrm{DE} / \mathrm{DX}=$

$-D E / D X=$

$-\mathrm{DE} / \mathrm{DX}=$

$-\mathrm{DE} / \mathrm{DX}=$

$-\mathrm{DE} / \mathrm{DX}=$

$-\mathrm{DE} / \mathrm{DX}=$

$-\mathrm{DE} / \mathrm{DX}=$

$-\mathrm{DE} / \mathrm{DX}=$

$-\mathrm{DE} / \mathrm{DX}=$

$-\mathrm{DE} / \mathrm{DX}=$

$-\mathrm{DE} / \mathrm{DX}=$

$-\mathrm{DE} / \mathrm{DX}=$

$-\mathrm{DE} / \mathrm{DX}=$

$-D E / D X=$

$-\mathrm{DE} / \mathrm{DX}=$

$-\mathrm{DE} / \mathrm{DX}=$

$-\mathrm{DE} / \mathrm{DX}=$

$-\mathrm{DE} / \mathrm{DX}=$

$-D E / D X=$

$-\mathrm{DE} / \mathrm{DX}=$

$-D E / D X=$

$-\mathrm{DE} / \mathrm{DX}=$

$-\mathrm{DE} / \mathrm{DX}=$

$-\mathrm{DE} / \mathrm{DX}=$

$-\mathrm{DE} / \mathrm{DX}=$

$-\mathrm{DE} / \mathrm{DX}=$

$-\mathrm{DE} / \mathrm{DX}=$

$-\mathrm{DE} / \mathrm{DX}=$

$-\mathrm{DE} / \mathrm{DX}=$

$-\mathrm{DE} / \mathrm{DX}=$

$-\mathrm{DE} / \mathrm{DX}=$

$-D E / D X=$

$-\mathrm{DE} / \mathrm{DX}=$

$-\mathrm{DE} / \mathrm{DX}=$

$-\mathrm{DE} / \mathrm{DX}=$

$-\mathrm{DE} / \mathrm{DX}=$

$-\mathrm{DE} / \mathrm{DX}=$

$-\mathrm{DE} / \mathrm{DX}=$

$-\mathrm{DE} / \mathrm{DX}=$

$-\mathrm{DE} / \mathrm{DX}=$

$-\mathrm{DE} / \mathrm{DX}=$

$-\mathrm{DE} / \mathrm{DX}=$
0.0

0.0

0.0

0.0

0.0

0.0

0.0

0.0

0.0

0.0

0.0

0.0

0.0

0.0

0.0

0.0

0.0

0.0

0.0

0.0

0.0

0.0

0.0

0.0

0.0

0.0

0.0

0.0

0.0

0.0

0.0

0.0

0.0

0.0

0.0

0.0

0.0

0.0

0.0

0.0

0.0

0.0

0.0

0.0

0.0

0.0

0.0

0.0

0.0

0.0

0.0

0.0

0.0

0.0

0.0

0.0

0.0

0.0

0.0

0.0

0.0

0.0

0.0

0.0

0.0

0.0 


\begin{tabular}{|c|c|c|}
\hline & A 84 & $A(40,39,41)$ \\
\hline & A85 & $A(40,39,42)$ \\
\hline & A 86 & $A(41,39,42)$ \\
\hline & A87 & $A(10,43,44)$ \\
\hline & A88 & $A(10,43,45)$ \\
\hline & A 89 & $A(10,43,46)$ \\
\hline & A9 0 & $A(44,43,45)$ \\
\hline & A91 & $A(44,43,46)$ \\
\hline & A92 & $A(45,43,46)$ \\
\hline & A93 & $A(10,47,48)$ \\
\hline & A94 & $A(10,47,49)$ \\
\hline & A95 & $A(10,47,50)$ \\
\hline & A9 6 & $A(48,47,49)$ \\
\hline & A9 7 & $A(48,47,50)$ \\
\hline & A9 8 & $A(49,47,50)$ \\
\hline & D1 & $D(6,1,2,3)$ \\
\hline & D2 & $D(6,1,2,13)$ \\
\hline & D3 & $D(8,1,2,3)$ \\
\hline & D4 & $D(8,1,2,13)$ \\
\hline & D5 & $\mathrm{D}(2,1,6,5)$ \\
\hline & D6 & $D(2,1,6,18)$ \\
\hline & D7 & $D(8,1,6,5)$ \\
\hline & D8 & $D(8,1,6,18)$ \\
\hline & D9 & $\mathrm{D}(2,1,8,10)$ \\
\hline & D10 & $\mathrm{D}(2,1,8,17)$ \\
\hline & D11 & $\mathrm{D}(6,1,8,10)$ \\
\hline & D12 & $D(6,1,8,17)$ \\
\hline & D13 & $D(1,2,3,4)$ \\
\hline & D14 & $D(1,2,3,7)$ \\
\hline & D15 & $D(13,2,3,4)$ \\
\hline & D16 & $\mathrm{D}(13,2,3,7)$ \\
\hline & D17 & $\mathrm{D}(1,2,13,15)$ \\
\hline & D18 & $D(1,2,13,35)$ \\
\hline & D19 & $D(1,2,13,39)$ \\
\hline & D2 0 & $D(3,2,13,15)$ \\
\hline & D21 & $D(3,2,13,35)$ \\
\hline & $\mathrm{D} 22$ & $D(3,2,13,39)$ \\
\hline & D23 & $\mathrm{D}(2,3,4,5)$ \\
\hline & D24 & $D(2,3,4,14)$ \\
\hline & D2 5 & $D(7,3,4,5)$ \\
\hline & D26 & $D(7,3,4,14)$ \\
\hline & D27 & $D(3,4,5,6)$ \\
\hline & D2 8 & $D(3,4,5,9)$ \\
\hline & D29 & $\mathrm{D}(14,4,5,6)$ \\
\hline & D30 & $\mathrm{D}(14,4,5,9)$ \\
\hline & D31 & $\mathrm{D}(3,4,14,16)$ \\
\hline & D32 & $\mathrm{D}(3,4,14,27)$ \\
\hline & D33 & $\mathrm{D}(3,4,14,31)$ \\
\hline & D34 & $D(5,4,14,16)$ \\
\hline & D35 & $\mathrm{D}(5,4,14,27)$ \\
\hline & D36 & $D(5,4,14,31)$ \\
\hline & D37 & $\mathrm{D}(4,5,6,1)$ \\
\hline & D38 & $D(4,5,6,18)$ \\
\hline & D39 & $D(9,5,6,1)$ \\
\hline & D4 0 & $D(9,5,6,18)$ \\
\hline & D4 1 & $\mathrm{D}(4,5,9,11)$ \\
\hline & $\mathrm{D} 42$ & $\mathrm{D}(4,5,9,12)$ \\
\hline & D4 3 & $D(6,5,9,11)$ \\
\hline & D4 4 & $\mathrm{D}(6,5,9,12)$ \\
\hline & D4 5 & $D(1,8,10,15)$ \\
\hline & D4 6 & $\mathrm{D}(1,8,10,43)$ \\
\hline & D4 7 & $\mathrm{D}(1,8,10,47)$ \\
\hline & D4 8 & $\mathrm{D}(17,8,10,15$ \\
\hline & D49 & $D(17,8,10,43$ \\
\hline & D50 & $\mathrm{D}(17,8,10,47$ \\
\hline & D51 & $\mathrm{D}(5,9,11,16)$ \\
\hline & D52 & $\mathrm{D}(5,9,11,19)$ \\
\hline
\end{tabular}

\begin{tabular}{|c|c|c|c|}
\hline 108.2376 & - DE/DX & $=$ & 0.0 \\
\hline 107.7921 & - DE/DX & $=$ & 0.0 \\
\hline 108.5873 & - DE/DX & $=$ & 0.0 \\
\hline 109.7842 & - DE/DX & $=$ & 0.0 \\
\hline 109.2114 & - DE/DX & $=$ & 0.0 \\
\hline 111.7444 & - DE/DX & $=$ & 0.0 \\
\hline 109.1509 & - DE/DX & $=$ & 0.0 \\
\hline 108.9727 & - DE/DX & $=$ & 0.0 \\
\hline 107.9257 & - DE/DX & $=$ & 0.0 \\
\hline 110.6554 & - DE/DX & $=$ & 0.0 \\
\hline 108.7195 & - DE/DX & $=$ & 0.0 \\
\hline 109.7515 & -DE/DX & $=$ & 0.0 \\
\hline 109.7477 & - DE/DX & $=$ & 0.0 \\
\hline 109.1404 & - DE/DX & $=$ & 0.0 \\
\hline 108.7987 & - DE/DX & $=$ & 0.0 \\
\hline-2.6644 & - DE/DX & $=$ & 0.0 \\
\hline 174.7841 & - DE/DX & $=$ & 0.0 \\
\hline 176.5777 & - DE/DX & $=$ & 0.0 \\
\hline-5.9738 & - DE/DX & $=$ & 0.0 \\
\hline 1.3716 & - DE/DX & $=$ & 0.0 \\
\hline-178.6286 & - DE/DX & $=$ & 0.0 \\
\hline-177.8777 & - DE/DX & $=$ & 0.0 \\
\hline 2.1222 & - DE/DX & $=$ & 0.0 \\
\hline-13.2867 & -DE/DX & $=$ & 0.0 \\
\hline-179.3204 & - DE/DX & $=$ & 0.0 \\
\hline 165.9705 & - DE/DX & $=$ & 0.0 \\
\hline-0.0632 & $-\mathrm{DE} / \mathrm{DX}$ & $=$ & 0.0 \\
\hline 1.3048 & - DE/DX & $=$ & 0.0 \\
\hline-178.6954 & - DE/DX & $=$ & 0.0 \\
\hline-176.1398 & - DE/DX & $=$ & 0.0 \\
\hline 3.8601 & - DE/DX & $=$ & 0.0 \\
\hline-2.185 & - DE/DX & $=$ & 0.0 \\
\hline-115.5061 & - DE/DX & $=$ & 0.0 \\
\hline 121.7902 & - DE/DX & $=$ & 0.0 \\
\hline 175.1691 & - DE/DX & $=$ & 0.0 \\
\hline 61.8481 & - DE/DX & $=$ & 0.0 \\
\hline-60.8557 & $-\mathrm{DE} / \mathrm{DX}$ & $=$ & 0.0 \\
\hline 1.3039 & - DE/DX & $=$ & 0.0 \\
\hline-176.1397 & - DE/DX & $=$ & 0.0 \\
\hline-178.6959 & - DE/DX & $=$ & 0.0 \\
\hline 3.8605 & $-\mathrm{DE} / \mathrm{DX}$ & $=$ & 0.0 \\
\hline-2.6641 & $-\mathrm{DE} / \mathrm{DX}$ & $=$ & 0.0 \\
\hline 176.5793 & - DE/DX & $=$ & 0.0 \\
\hline 174.7834 & - DE/DX & $=$ & 0.0 \\
\hline-5.9732 & - DE/DX & $=$ & 0.0 \\
\hline 175.1696 & $-\mathrm{DE} / \mathrm{DX}$ & $=$ & 0.0 \\
\hline-60.853 & - DE/DX & $=$ & 0.0 \\
\hline 61.8496 & $-\mathrm{DE} / \mathrm{DX}$ & $=$ & 0.0 \\
\hline-2.1836 & - DE/DX & $=$ & 0.0 \\
\hline 121.7938 & - DE/DX & $=$ & 0.0 \\
\hline-115.5035 & - DE/DX & $=$ & 0.0 \\
\hline 1.3719 & $-\mathrm{DE} / \mathrm{DX}$ & $=$ & 0.0 \\
\hline-178.6279 & $-\mathrm{DE} / \mathrm{DX}$ & $=$ & 0.0 \\
\hline-177.8786 & - DE/DX & $=$ & 0.0 \\
\hline 2.1215 & - DE/DX & $=$ & 0.0 \\
\hline-13.288 & - DE/DX & $=$ & 0.0 \\
\hline-179.3217 & $-\mathrm{DE} / \mathrm{DX}$ & $=$ & 0.0 \\
\hline 165.9705 & - DE/DX & $=$ & 0.0 \\
\hline-0.0633 & - DE/DX & $=$ & 0.0 \\
\hline 38.822 & - DE/DX & $=$ & 0.0 \\
\hline-85.74 & $-\mathrm{DE} / \mathrm{DX}$ & $=$ & 0.0 \\
\hline 153.0761 & - DE/DX & $=$ & 0.0 \\
\hline-154.7496 & $-\mathrm{DE} / \mathrm{DX}$ & $=$ & 0.0 \\
\hline 80.6885 & - DE/DX & $=$ & 0.0 \\
\hline-40.4955 & $-\mathrm{DE} / \mathrm{DX}$ & $=$ & 0.0 \\
\hline 38.8215 & - DE/DX & $=$ & 0.0 \\
\hline 153.0748 & - DE/DX & $=$ & 0.0 \\
\hline
\end{tabular}




\begin{tabular}{|c|c|c|}
\hline & D53 & $\mathrm{D}(5,9,11,23)$ \\
\hline & D54 & $\mathrm{D}(12,9,11,16)$ \\
\hline & D55 & $\mathrm{D}(12,9,11,19)$ \\
\hline & 56 & $\mathrm{D}(12,9,11,23)$ \\
\hline & D57 & $\mathrm{D}(8,10,15,13)$ \\
\hline & 58 & $D(43,10,15,13)$ \\
\hline & 59 & $\mathrm{D}(47,10,15,13)$ \\
\hline & 50 & $D(8,10,43,44)$ \\
\hline & 61 & $D(8,10,43,45)$ \\
\hline & 62 & $D(8,10,43,46)$ \\
\hline & & $\mathrm{D}(15,10,43,44)$ \\
\hline & & $D(15,10,43,45)$ \\
\hline & 65 & $D(15,10,43,46)$ \\
\hline & & $\mathrm{D}(47,10,43,44)$ \\
\hline & D67 & $\mathrm{D}(47,10,43,45)$ \\
\hline & D68 & $\mathrm{D}(47,10,43,46)$ \\
\hline & 69 & $\mathrm{D}(8,10,47,48)$ \\
\hline & 70 & $\mathrm{D}(8,10,47,49)$ \\
\hline ! & D71 & $\mathrm{D}(8,10,47,50)$ \\
\hline & D72 & $D(15,10,47,48)$ \\
\hline & 73 & $\mathrm{D}(15,10,47,49)$ \\
\hline & D74 & $D(15,10,47,50)$ \\
\hline ! & D75 & $\mathrm{D}(43,10,47,48)$ \\
\hline & D76 & $\mathrm{D}(43,10,47,49)$ \\
\hline & D77 & $\mathrm{D}(43,10,47,50)$ \\
\hline & D78 & $\mathrm{D}(9,11,16,14)$ \\
\hline ! & D79 & $\mathrm{D}(19,11,16,14)$ \\
\hline & D8 80 & $D(23,11,16,14)$ \\
\hline & D81 & $\mathrm{D}(9,11,19,20)$ \\
\hline ! & D82 & $\mathrm{D}(9,11,19,21)$ \\
\hline & D83 & $\mathrm{D}(9,11,19,22)$ \\
\hline & D84 & $\mathrm{D}(16,11,19,20)$ \\
\hline ! & D85 & $\mathrm{D}(16,11,19,21)$ \\
\hline ! & D86 & $\mathrm{D}(16,11,19,22)$ \\
\hline ! & D87 & $\mathrm{D}(23,11,19,20)$ \\
\hline ! & D88 & $\mathrm{D}(23,11,19,21)$ \\
\hline & D89 & $\mathrm{D}(23,11,19,22)$ \\
\hline ! & D90 & $D(9,11,23,24)$ \\
\hline ! & D91 & $D(9,11,23,25)$ \\
\hline ! & D92 & $D(9,11,23,26)$ \\
\hline ! & D93 & $\mathrm{D}(16,11,23,24)$ \\
\hline ! & D94 & $D(16,11,23,25)$ \\
\hline ! & D95 & $D(16,11,23,26)$ \\
\hline ! & D96 & $D(19,11,23,24)$ \\
\hline ! & D9 7 & $11,23,25)$ \\
\hline ! & D98 & $11,23,26)$ \\
\hline ! & D99 & $\mathrm{D}(2,13,15,10)$ \\
\hline ! & D100 & $\mathrm{D}(35,13,15,10)$ \\
\hline$!$ & D101 & $13,15,10)$ \\
\hline ! & D102 & $3,35,36)$ \\
\hline ! & D103 & $D(2,13,35,37)$ \\
\hline ! & D104 & $\mathrm{D}(2,13,35,38)$ \\
\hline ! & D105 & $13,35,36)$ \\
\hline$!$ & D106 & $13,35,37)$ \\
\hline ! & D107 & $13,35,38)$ \\
\hline$!$ & D108 & $(3,35,36)$ \\
\hline ! & D109 & $13,35,37)$ \\
\hline ! & D110 & $13,35,38)$ \\
\hline ! & D111 & $\mathrm{D}(2,13,39,40)$ \\
\hline ! & D112 & $3,39,41)$ \\
\hline ! & D113 & $D(2,13,39,42)$ \\
\hline ! & D114 & $D(15,13,39,40)$ \\
\hline & D115 & $D(15,13,39,41)$ \\
\hline ! & D116 & $3,39,42)$ \\
\hline ! & D117 & $D(35,13,39,40)$ \\
\hline ! & D118 & $D(35,13,39,41)$ \\
\hline & D119 & $D(35,13,39,42)$ \\
\hline
\end{tabular}

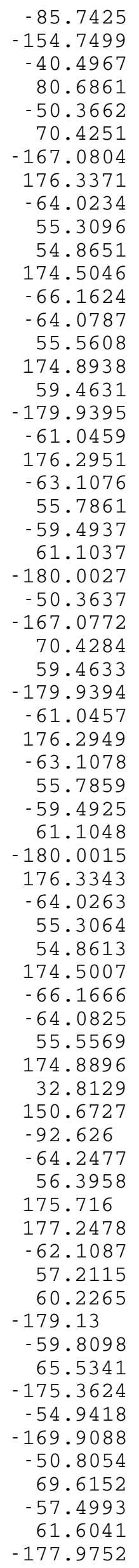

$-85.7425$

$-40.4967$

50.3662

176.3371

55.3096

54.8651

174.5046

$-64.0787$

59.4631

$-179.9395$

$-61.0459$

63.1076

$-59.4937$

61.1037

$-180.0027$

$-167.0772$

70.4284

$-179.9394$

$-61.0457$

176.2949

55.7859

$-59.4925$

80.0015

176.3343

64.0263

54.8613

174.5007

6.1666

55.5569

74.8896

32.8129

150.6727

$-64.2477$

56.3958

175.716

177.2478

57.2115

179.13

59.8098

65.5341

$-54.9418$

169.9088

69.6152

$-57.4993$

$-177.9752$

\begin{tabular}{|c|c|c|}
\hline - DE/DX & $=$ & 0.0 \\
\hline - DE/DX & $=$ & 0.0 \\
\hline$-\mathrm{DE} / \mathrm{DX}$ & $=$ & 0.0 \\
\hline$-\mathrm{DE} / \mathrm{DX}$ & $=$ & 0.0 \\
\hline$-\mathrm{DE} / \mathrm{DX}$ & $=$ & 0.0 \\
\hline - DE/DX & $=$ & 0.0 \\
\hline - DE/DX & $=$ & 0.0 \\
\hline$-\mathrm{DE} / \mathrm{DX}$ & $=$ & 0.0 \\
\hline - DE/DX & $=$ & 0.0 \\
\hline - DE/DX & $=$ & 0.0 \\
\hline - DE/DX & $=$ & 0.0 \\
\hline$-\mathrm{DE} / \mathrm{DX}$ & $=$ & 0.0 \\
\hline - DE/DX & $=$ & 0.0 \\
\hline - DE/DX & $=$ & 0.0 \\
\hline - DE/DX & $=$ & 0.0 \\
\hline$-\mathrm{DE} / \mathrm{DX}$ & $=$ & 0.0 \\
\hline - DE/DX & $=$ & 0.0 \\
\hline - DE/DX & $=$ & 0.0 \\
\hline$-\mathrm{DE} / \mathrm{DX}$ & $=$ & 0.0 \\
\hline - DE/DX & $=$ & 0.0 \\
\hline - DE/DX & $=$ & 0.0 \\
\hline -DE/DX & $=$ & 0.0 \\
\hline$-\mathrm{DE} / \mathrm{DX}$ & $=$ & 0.0 \\
\hline$-\mathrm{DE} / \mathrm{DX}$ & $=$ & 0.0 \\
\hline - DE/DX & $=$ & 0.0 \\
\hline -DE/DX & $=$ & 0.0 \\
\hline$-\mathrm{DE} / \mathrm{DX}$ & $=$ & 0.0 \\
\hline - DE/DX & $=$ & 0.0 \\
\hline$-\mathrm{DE} / \mathrm{DX}$ & $=$ & 0.0 \\
\hline$-\mathrm{DE} / \mathrm{DX}$ & $=$ & 0.0 \\
\hline - DE/DX & $=$ & 0.0 \\
\hline - DE/DX & $=$ & 0.0 \\
\hline - DE/DX & $=$ & 0.0 \\
\hline$-\mathrm{DE} / \mathrm{DX}$ & $=$ & 0.0 \\
\hline - DE/DX & $=$ & 0.0 \\
\hline - DE/DX & $=$ & 0.0 \\
\hline -DE/DX & $=$ & 0.0 \\
\hline$-\mathrm{DE} / \mathrm{DX}$ & $=$ & 0.0 \\
\hline - DE/DX & $=$ & 0.0 \\
\hline - DE/DX & $=$ & 0.0 \\
\hline - DE/DX & $=$ & 0.0 \\
\hline$-\mathrm{DE} / \mathrm{DX}$ & $=$ & 0.0 \\
\hline - DE/DX & $=$ & 0.0 \\
\hline - DE/DX & $=$ & 0.0 \\
\hline - DE/DX & $=$ & 0.0 \\
\hline$-\mathrm{DE} / \mathrm{DX}$ & $=$ & 0.0 \\
\hline - DE/DX & $=$ & 0.0 \\
\hline - DE/DX & $=$ & 0.0 \\
\hline$-D E / D X$ & $=$ & 0.0 \\
\hline - DE/DX & $=$ & 0.0 \\
\hline$-\mathrm{DE} / \mathrm{DX}$ & $=$ & 0.0 \\
\hline - DE/DX & $=$ & 0.0 \\
\hline - DE/DX & $=$ & 0.0 \\
\hline - DE/DX & $=$ & 0.0 \\
\hline - DE/DX & $=$ & 0.0 \\
\hline - DE/DX & $=$ & 0.0 \\
\hline - DE/DX & $=$ & 0.0 \\
\hline - DE/DX & $=$ & 0.0 \\
\hline - DE/DX & $=$ & 0.0 \\
\hline$-\mathrm{DE} / \mathrm{DX}$ & $=$ & 0.0 \\
\hline - DE/DX & $=$ & 0.0 \\
\hline - DE/DX & $=$ & 0.0 \\
\hline - DE/DX & $=$ & 0.0 \\
\hline - DE/DX & $=$ & 0.0 \\
\hline - DE/DX & $=$ & 0.0 \\
\hline - DE/DX & $=$ & 0.0 \\
\hline$-D E / D X$ & $=$ & 0 \\
\hline
\end{tabular}

$-\mathrm{DE} / \mathrm{DX}$

0.0

0.0

0.0

.0

0.0

0.0

0.0

0.0

0.0

0.0

.0

0.0

0.0

0.0

.0

0.0

0.0

0.0

0.0

0.0

.0

0.0

0.0

0.0

0.0

0.0

0.0

0.0

0.0

0.0

0.0

0.0

0.0

0.0

0.0

0.0

0.0

0.0

0.0

0.0

0.0

0.0

0.0

0.0

0.0

0.0 
$-\mathrm{DE} / \mathrm{DX}=$

$-\mathrm{DE} / \mathrm{DX}=$

$-\mathrm{DE} / \mathrm{DX}=$

$-\mathrm{DE} / \mathrm{DX}=$

$-\mathrm{DE} / \mathrm{DX}=$

$-\mathrm{DE} / \mathrm{DX}=$

$-\mathrm{DE} / \mathrm{DX}=$

$-D E / D X=$

$-\mathrm{DE} / \mathrm{DX}=$

$-\mathrm{DE} / \mathrm{DX}=$

$-\mathrm{DE} / \mathrm{DX}=$

$-\mathrm{DE} / \mathrm{DX}=$

$-\mathrm{DE} / \mathrm{DX}=$

$-\mathrm{DE} / \mathrm{DX}=$

$-\mathrm{DE} / \mathrm{DX}=$

$-D E / D X=$

$-\mathrm{DE} / \mathrm{DX}=$

$-\mathrm{DE} / \mathrm{DX}=$

$-\mathrm{DE} / \mathrm{DX}=$

$-\mathrm{DE} / \mathrm{DX}=$

$-\mathrm{DE} / \mathrm{DX}=$
0.0
0.0
0.0
0.0
0.0
0.0
0.0
0.0
0.0
0.0
0.0
0.0
0.0
0.0
0.0
0.0
0.0
0.0
0.0
0.0
0.0

\section{Repeat geometry optimization for 4a with "tight" convergence constraints}

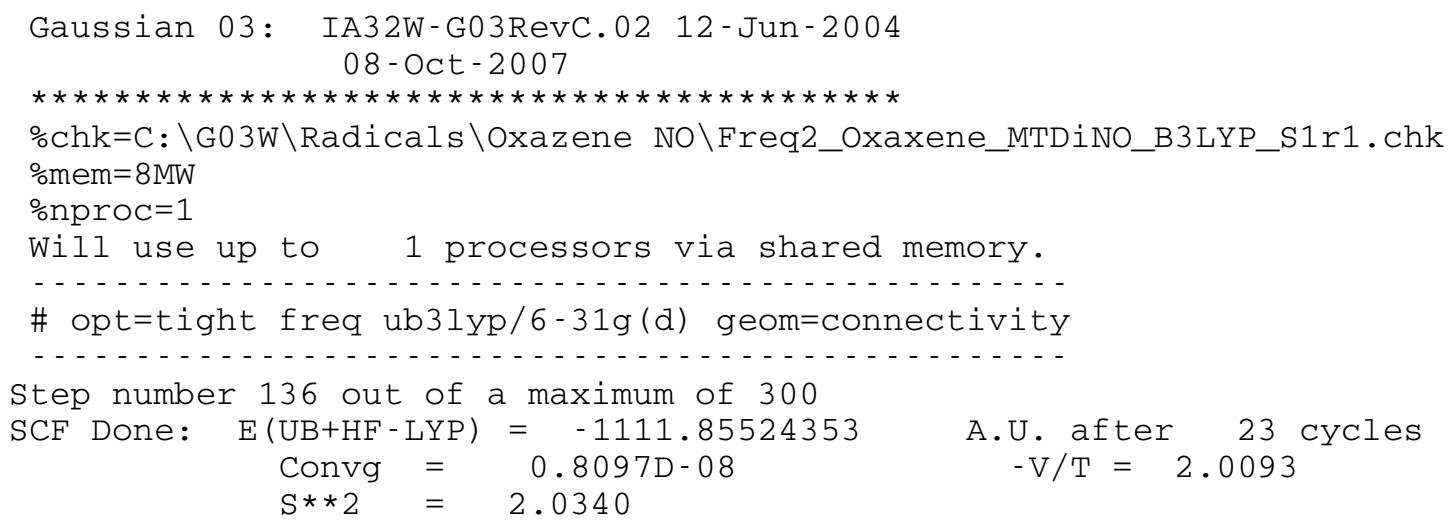

\begin{tabular}{|c|c|c|c|c|c|}
\hline \multirow{2}{*}{$\begin{array}{l}\text { Center } \\
\text { Number }\end{array}$} & \multirow{2}{*}{$\begin{array}{l}\text { Atomic } \\
\text { Number }\end{array}$} & \multirow{2}{*}{$\begin{array}{c}\text { Atomic } \\
\text { Type }\end{array}$} & \multicolumn{3}{|c|}{ Coordinates (Angstroms) } \\
\hline & & & $\mathrm{X}$ & $\mathrm{Y}$ & Z \\
\hline 1 & 6 & 0 & -0.000059 & 0.000118 & -0.000004 \\
\hline 2 & 6 & 0 & -0.000055 & -0.000040 & 1.414126 \\
\hline 3 & 6 & 0 & 1.238069 & -0.000099 & 2.060714 \\
\hline 4 & 6 & 0 & 2.456445 & 0.026621 & 1.378166 \\
\hline 5 & 6 & 0 & 2.414465 & 0.083417 & -0.034202 \\
\hline 6 & 6 & 0 & 1.196754 & 0.055937 & -0.720186 \\
\hline 7 & 1 & 0 & 1.254203 & -0.021954 & 3.146599 \\
\hline 8 & 7 & 0 & -1.210488 & -0.072256 & -0.699288 \\
\hline 9 & 7 & 0 & 3.603619 & 0.184587 & -0.765672 \\
\hline
\end{tabular}




\begin{tabular}{|c|c|c|c|c|c|}
\hline 10 & 6 & 0 & -2.456891 & -0.447946 & 0.038743 \\
\hline 11 & 6 & 0 & 4.871757 & 0.530594 & -0.050501 \\
\hline 12 & 8 & 0 & 3.590477 & 0.250615 & -2.042851 \\
\hline 13 & 6 & 0 & -1.301815 & 0.057968 & 2.200652 \\
\hline 14 & 6 & 0 & 3.780954 & -0.062081 & 2.122724 \\
\hline 15 & 8 & 0 & -2.440103 & 0.160089 & 1.315901 \\
\hline 16 & 8 & 0 & 4.892341 & -0.128274 & 1.201130 \\
\hline 17 & 8 & 0 & -1.235384 & -0.086551 & -1.977916 \\
\hline 18 & 1 & 0 & 1.180701 & 0.077700 & -1.800478 \\
\hline 19 & 6 & 0 & 6.051857 & -0.049864 & -0.825331 \\
\hline 20 & 1 & 0 & 6.081998 & 0.352229 & -1.838241 \\
\hline 21 & 1 & 0 & 6.976269 & 0.204303 & -0.299221 \\
\hline 22 & 1 & 0 & 5.962236 & -1.138005 & -0.874244 \\
\hline 23 & 6 & 0 & 4.958232 & 2.062630 & 0.042918 \\
\hline 24 & 1 & 0 & 5.843235 & 2.349191 & 0.618881 \\
\hline 25 & 1 & 0 & 5.035055 & 2.480923 & -0.964974 \\
\hline 26 & 1 & 0 & 4.071396 & 2.490089 & 0.517863 \\
\hline 27 & 6 & 0 & 3.984129 & 1.101895 & 3.112740 \\
\hline 28 & 1 & 0 & 3.247801 & 1.055849 & 3.922254 \\
\hline 29 & 1 & 0 & 4.983424 & 1.029120 & 3.553984 \\
\hline 30 & 1 & 0 & 3.887425 & 2.076135 & 2.628695 \\
\hline 31 & 6 & 0 & 3.879038 & -1.402544 & 2.874614 \\
\hline 32 & 1 & 0 & 3.114522 & -1.475515 & 3.654153 \\
\hline 33 & 1 & 0 & 3.751514 & -2.235397 & 2.177718 \\
\hline 34 & 1 & 0 & 4.865243 & -1.487051 & 3.342620 \\
\hline 35 & 6 & 0 & -1.376790 & 1.367306 & 3.008008 \\
\hline 36 & 1 & 0 & -0.589414 & 1.409594 & 3.766787 \\
\hline 37 & 1 & 0 & -1.269553 & 2.227382 & 2.341419 \\
\hline 38 & 1 & 0 & -2.348615 & 1.432452 & 3.508092 \\
\hline 39 & 6 & 0 & -1.476100 & -1.144716 & 3.149029 \\
\hline 40 & 1 & 0 & -0.715927 & -1.130638 & 3.937413 \\
\hline 41 & 1 & 0 & -2.461741 & -1.090166 & 3.622439 \\
\hline 42 & 1 & 0 & -1.394519 & -2.098795 & 2.623789 \\
\hline 43 & 6 & 0 & -2.540884 & -1.982578 & 0.073082 \\
\hline 44 & 1 & 0 & -3.408659 & -2.292903 & 0.662785 \\
\hline 45 & 1 & 0 & -2.647337 & -2.360163 & -0.948103 \\
\hline 46 & 1 & 0 & -1.640577 & -2.427872 & 0.504277 \\
\hline 47 & 6 & 0 & -3.659369 & 0.162023 & -0.676730 \\
\hline 48 & 1 & 0 & -3.720022 & -0.199466 & -1.703483 \\
\hline 49 & 1 & 0 & -4.567725 & -0.113555 & -0.133706 \\
\hline 50 & 1 & 0 & -3.570758 & 1.251313 & -0.684980 \\
\hline
\end{tabular}

